AN EXPLORATION OF THE EXPERIENCE OF FEAR AND

ITS IMPACT ON PERFORMANCE IN NCAA DIVERS

\author{
A Dissertation \\ presented to
}

the Faculty of the Graduate School

at the University of Missouri-Columbia

In Partial Fulfillment

of the Requirements for the Degree

Doctor of Philosophy

by

JOANNA FOSS, M.A.

Dr. Matthew Martens, Dissertation Supervisor

July 2019 
The undersigned, appointed by the dean of the Graduate School, have examined the dissertation entitled

\section{AN EXPLORATION OF THE EXPERIENCE OF FEAR AND}

ITS IMPACT ON PERFORMANCE IN NCAA DIVERS

presented by Joanna Foss, M.A.,

A candidate for the degree of

Doctor of Philosophy,

And hereby certify that, in their opinion, it is worthy of acceptance.

Matthew Martens, Ph.D.

Professor Directing Dissertation

Niels Beck, Ph.D.

Committee Member

Brandon Orr, Ph.D.

Committee Member

Christopher Slaten, Ph.D.

Committee Member 
This dissertation is dedicated to all those who have helped me on this journey.

To my sport psychology mentors: Thank you to all those who have helped me navigate my professional path through the field of sport psychology. I am so grateful to have access to incredible professionals and people who are so committed to their craft. Thank you for being the inspiration for this dissertation.

To Mom and Dad: Thank you for your unwavering support throughout my many years of sport and school. Thank you for the countless hours of driving, watching competitions, and pushing me to pursue my goals of being a collegiate volleyball player. I never thought volleyball would lead me to the field of sport psychology, and it would not have been possible without your willingness to let me forge my path.

To Gram: Thank you for your support and your positivity. Thank you for being a refuge from the stress of school and always providing me space to sit on the porch and enjoy a morning of drinking coffee and listening to the waves (physically or metaphorically). To Anita: Thank you for being my other half. Thank you for being the person I can be myself with and for always understanding where I am coming from. Thank you for talking me through the many ups and downs of graduate school and for always calling me out when I use too much psychobabble.

To Beth, Melissa, and Nikki: I am so appreciative for your support throughout the internship and dissertation process. It is incredible to be connected to such passionate and successful women who are going to be fantastic at what you do. Thank for your edits on essays, your support in helping me navigate all the ins and outs of these processes, and overall your incredible friendship. 


\section{ACKNOWLEDGEMENTS}

Dr. Matthew Martens: I cannot begin to thank you enough for your role not only in this dissertation but in my ability to succeed in graduate school in general. Your unwavering support and guidance in helping me balance the numerous demands allowed me to have the experience that I did. Your calm and collected manner of telling me that things would work out when I had no sense of how I could make everything fit in my day never failed to appease my concerns. You made sure I never felt like I was sacrificing the experience that I wanted as I determined how to navigate this professional path. For that, and for actually allowing me to do a qualitative dissertation, I will always be grateful.

Dr. Brandon Orr: Thank you for your investment in my professional journey. Thank you for consistently going above and beyond what is called for to ensure the best quality experience in whatever it is that you are committing to. Thank you for signing up to be my auditor before you even had a sense of what that meant, as your perspective was vital in the successful analysis of this data. I am so thankful for all that you have helped me not only within this dissertation but also in academics and in my consulting. Though, I promise to continue arguing with you about the benefits of CBT in addition to ACT. To my research team, Tim and Lucy: Thank you so much for your level of commitment and dedication to this project. Quite simply, there is no way this project would have been possible without you. Thank you for sticking with this longer than any

of us anticipated. Thank you for conducting my interviews, for sharing your perspectives, and for continuously challenging me and each other to bring our best to our (many) meetings. Your perspectives were vital in this process, and I cannot thank you enough for your impact on me as a person and as a professional. 


\section{TABLE OF CONTENTS}

Acknowledgements ..................................................................................................................................ii

List of Tables.............................................................................................................................vi

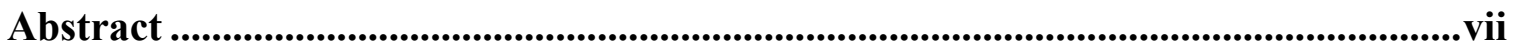

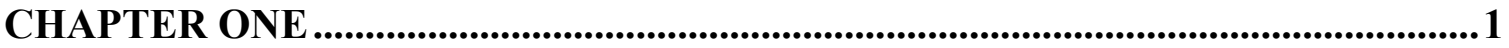

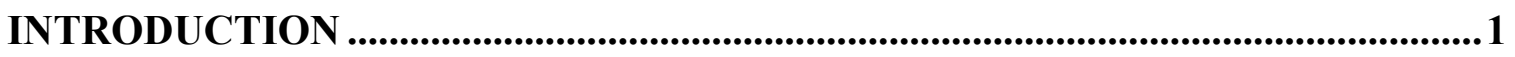

Impact of Fear of Performance ................................................................................2

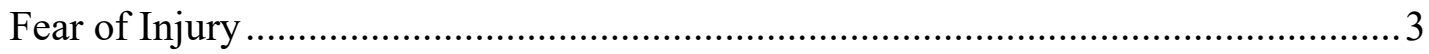

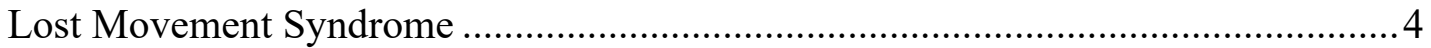

Characteristics of Fear Development ...............................................................................6

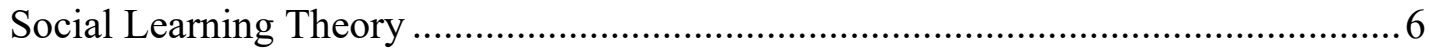

Existing Intervention Research .........................................................................................

CHAPTER TWO ....................................................................................................................9

LITERATURE REVIEW .................................................................................................9

Sport Background and Characteristics .......................................................................9

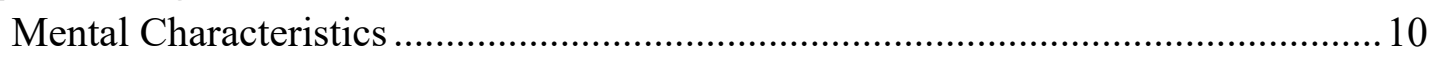

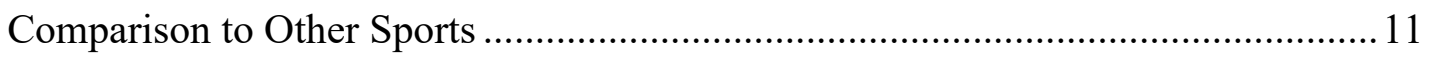

Fear in Sport ..................................................................................................................11

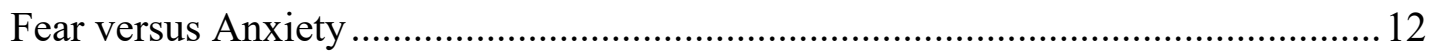

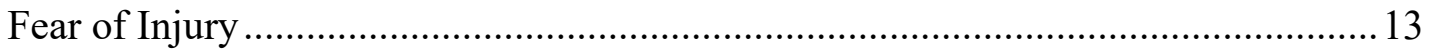

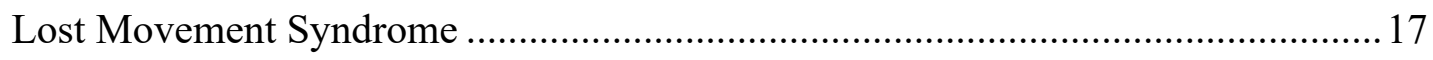

Impact of Fear on Performance ............................................................................ 19

Development of Fear ..................................................................................................21

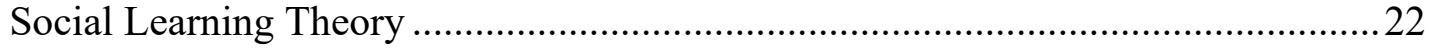

Existing Interventions ...................................................................................................23

Reliance on Theories from Psychology ……………….....................................25

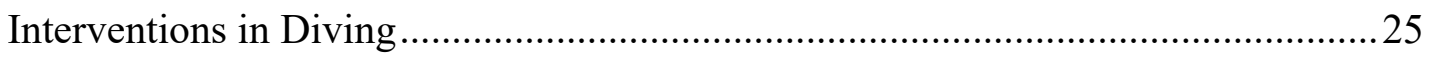

Conclusions .......................................................................................................................27

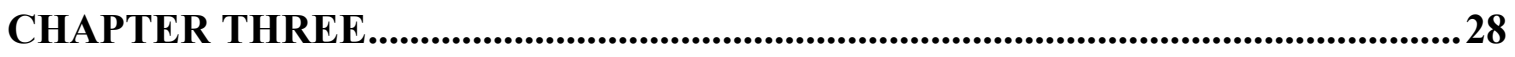

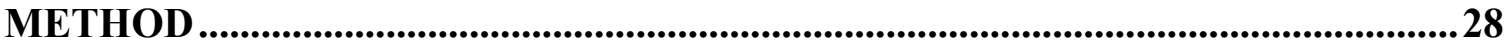

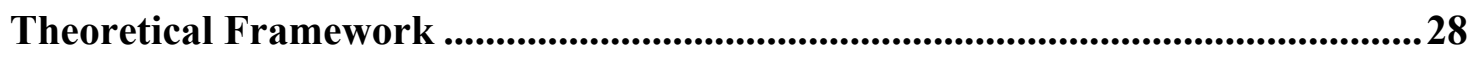

Participants ..........................................................................................................................29

Data Analysis Team ...................................................................................................................30 


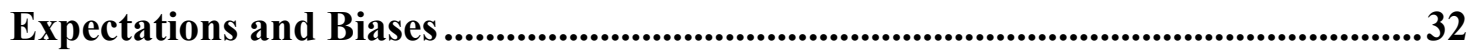

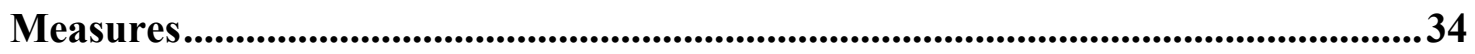

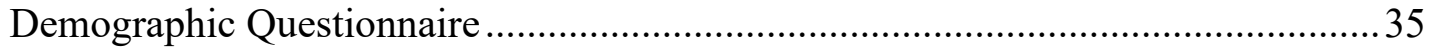

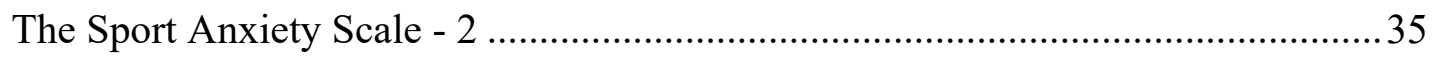

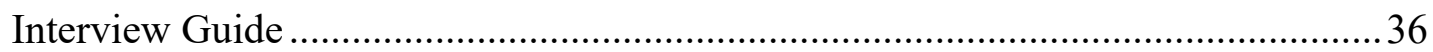

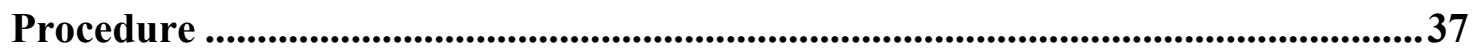

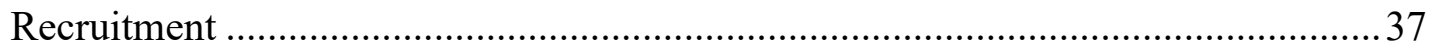

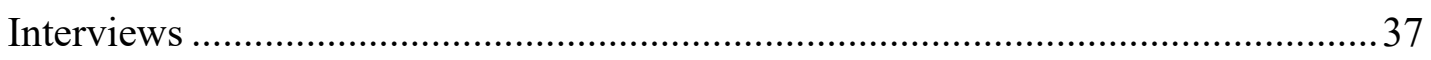

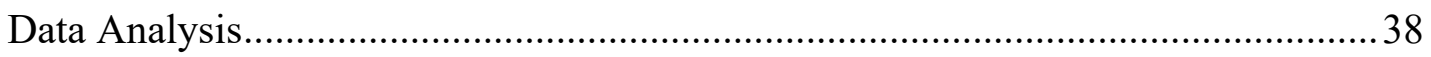

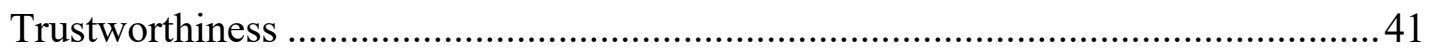

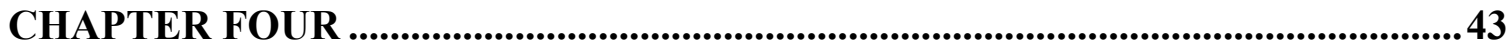

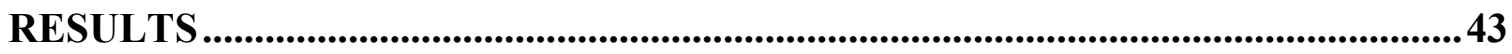

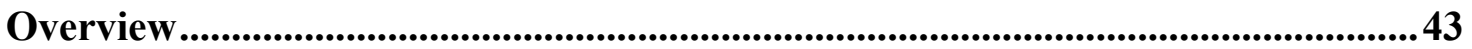

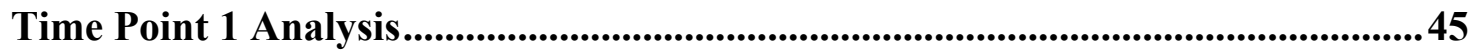

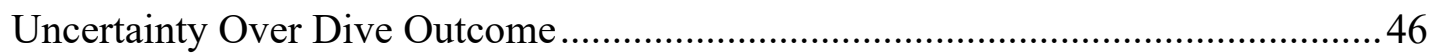

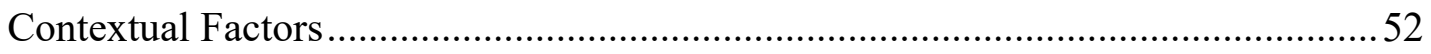

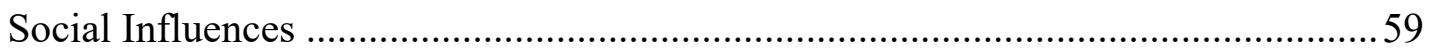

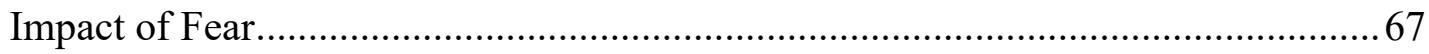

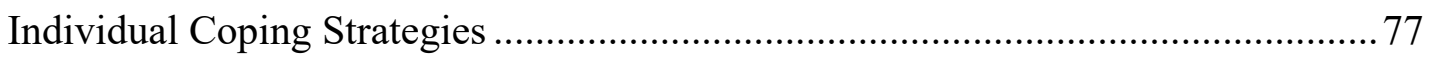

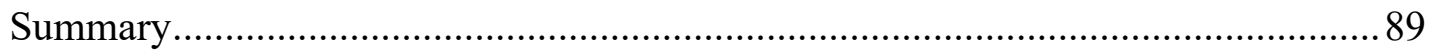

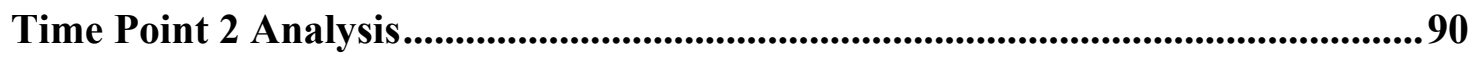

External Protective Factors.................................................................................... 91

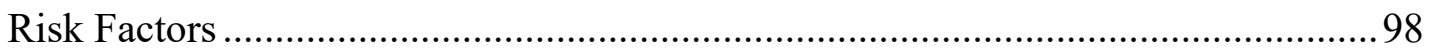

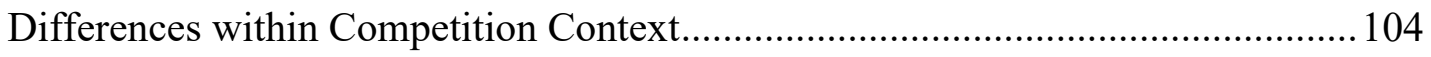

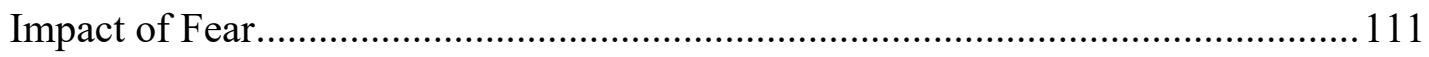

Individual Attitude and Strategies Towards Coping ...........................................120

Growth and Personal Development..................................................................130

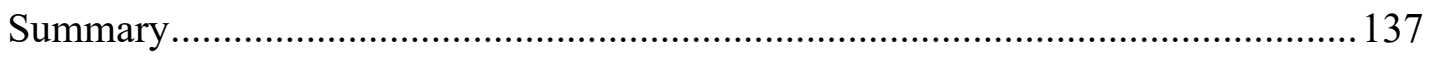

Integration of Time Points .......................................................................................138

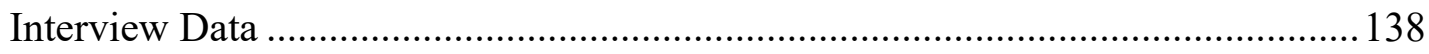

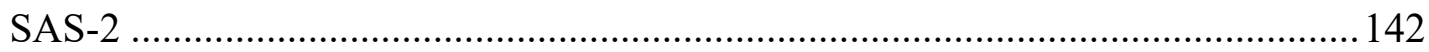

CHAPTER FIVE ................................................................................................................143

DISCUSSION_...................................................................................................................143

Conclusions .....................................................................................................................145

Limitations and Future Directions...........................................................................152

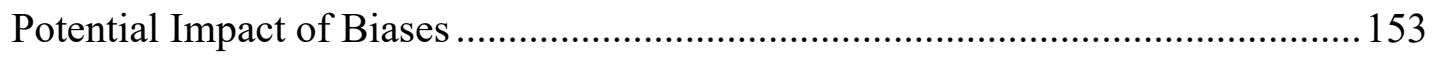




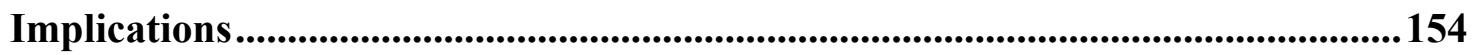

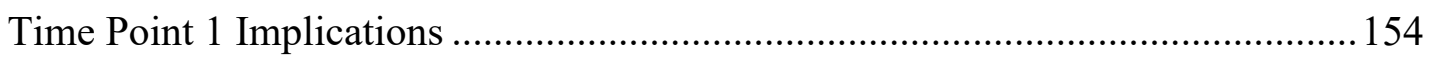

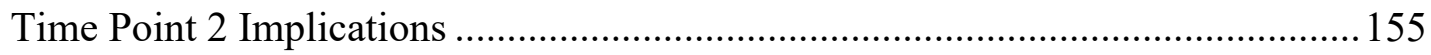

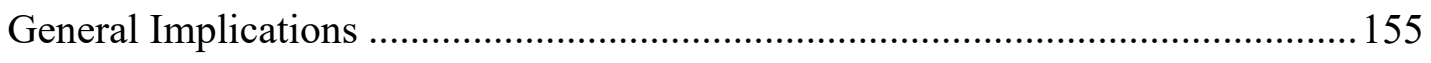

REFERENCES .......................................................................................................................... 157

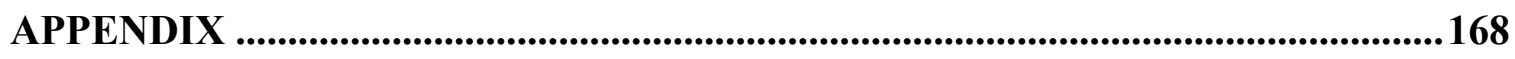

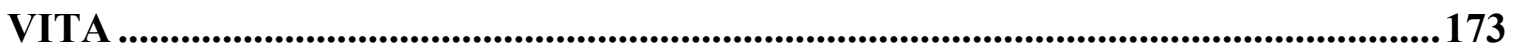




\section{LIST OF TABLES}

Table 4-1 Participant Demographic Information and Sport Anxiety Scale - 2 Results ...44

Table 4-2 Time Point 1 Domains, Categories, and Frequencies ................................... 45

Table 4-3 Time Point 2 Domains, Categories, and Frequencies ..................................90 


\title{
AN EXPLORATION OF THE EXPERIENCE OF FEAR AND \\ ITS IMPACT ON PERFORMANCE IN NCAA DIVERS
}

\author{
Joanna Foss
}

Dr. Matthew Martens, Dissertation Supervisor

\begin{abstract}
Fear is a basic human emotion that can have numerous impacts on athletes seeking to achieve performance excellence. The level of physical risk within sport can also influence athletes' experiences of fear. Within springboard and platform diving, divers can commonly face fear of injury and performance anxiety (Highlen \& Bennet, 1983; McGregor \& Abrahamson, 2000; Post, Simpson, Young, \& Parker, 2014), which can be either detrimental or beneficial to performance (Buckley, 2016; Eysenck, Derakshan, Santos, \& Calvo, 2007; Post et al., 2014). Understanding the experience of fear in its full context is important to successfully manage fear within sport. Utilizing Consensual Qualitative Research methodology (Hill, 2012), the current study examined the experience of fear in 10 collegiate divers through semi-structured interviews at two time points. Findings indicated that fear was an inherent part of the sport of diving, and an underlying cause of fear was consistent uncertainty over the dive's outcome. Experience of fear varied across time points based on factors including divers' social influences, dive-specific factors, and setting. Divers viewed fear as predominantly negatively impacting performance; however, benefits were also addressed. Generally, strategies for coping with fear were seen as unique to the individual, though participants highlighted the importance of accepting fear as part of the sport and committing to executing dives. This study offers practical implications to sport psychology practitioners, coaches, and divers seeking to successfully work with fear in diving.
\end{abstract}




\section{CHAPTER ONE}

\section{INTRODUCTION}

Elite divers face a number of challenges on the road to achieving peak

performance. Divers in the NCAA often train and compete on three different apparatuses: 1-meter springboard, 3-meter springboard, and 10-meter platform. Athletes are typically required to complete six dives per event, one from each of five different dive categories and a sixth from a category of their choice, and they can be completed in one of four different positions. A panel of judges score dives on a scale of 0-10 and multiply the total by the dive's degree of difficulty in order to attain an overall score (NCAA, 2015). Thus, at any given time, collegiate divers may be training and competing 15-18 different competitive dives across the various apparatuses, though some divers may compete the same dive at different competitive heights or on multiple apparatus.

Beyond the variety of different motor patterns trained by divers, the level of risk involved in the sport can also be a barrier that athletes must overcome to achieve performance excellence. Lack of appropriate technical execution can result in serious injury or even death. Research has demonstrated several difficult psychological experiences divers face including fear of injury and anxiety (Highlen \& Bennet, 1983; McGregor \& Abrahamson, 2000, Post, Simpson, Young, \& Parker, 2014). Some consider mental challenges to be the largest obstacles faced by divers (Huber, 2016). Stressors can include combining factors of near nakedness in front of spectators during competition, low margins for error in successfully executing dives, the individual nature of the performance, and the ongoing threat of becoming disoriented or injured while diving (Huber, 2016). In an examination of imagery use in divers, Post et al. (2014) found that 
divers may experience fear or anxiety on several different occasions including when performing an unfamiliar dive, when completing a dive on which they were previously injured, and prior to or during competitions.

\section{Impact of Fear on Performance}

While often viewed as detrimental to performance, the experience of fear in and of itself cannot be classified as positive or negative. Fear is a basic human emotion that serves a protective function in humans (Ekman, 1992). Fear signals the perception of danger within the environment, resulting in behaviors meant to eliminate or avoid the perceived threat. The fear response, often considered the fight/flight/freeze response, is natural and necessary in many cases as it helps people respond to threats in a way that encourages safety (Olsson \& Phelps, 2007). Many physiological symptoms could arise in response to fear including hyperventilation, increased heart rate, increased muscle tension, sweating, and increased alertness. While sometimes unpleasant, these physiological responses could be used to improve athlete performance in the right settings. For example, Hanin's IZOF model (2000) suggests that each athlete has an individual zone of optimal functioning in which a certain level of arousal contributes to optimal performance. An athlete who is either below or above this optimal level may underperform. Thus, fear could benefit athletes who are under aroused by increasing their physiological responses.

Several other factors may influence the impact of fear on an individual's performance including intensity of expression, level of risk of the event, or individual personality factors (Buckley, 2016). For example, in comparison with normative samples, divers showed higher levels of thrill or adventure seeking personality characteristics 
(Hinton-Bayre \& Hanrahan, 1999). Thus, divers' responses or reactions to fear may differ from a general population given personality characteristics leading them to persist within the sport of diving. Fear could also impact performance indirectly through affecting an athlete's attentional focus. Buckley (2016) notes that "perceived danger generates intense focus and awareness" (p. 1), which could be beneficial in some performance contexts. However, others have noted that increasing anxiety may decrease overall attentional control. Rather, athletes may direct attention towards threat-related stimuli as opposed to task related stimuli (Eysenck, Derakshan, Santos, \& Calvo, 2007). Smith (2010) noted that fear of failure can increase a chance that athletes would choke during performance, since they were likely directing attention towards the negative consequences of mistakes rather than tasks needed to achieve performance excellence.

Beyond performance in a competition setting, fear could be a barrier in skill development or sport retention. Almost all participants in Post et al.'s (2014) study disclosed that fear could prevent them from physically practicing specific dives. Given that deliberate practice is considered an imperative aspect of developing expertise in a domain (Ericsson, Krampe, \& Tesch-Romer, 1993), inability to overcome fear could have lasting impacts on an athlete's skill development in the sport.

Fear of injury. Research has clearly shown that the injury process has a psychological impact on athletes. Negative impacts on self-concept, self-esteem, life satisfaction, depressive symptoms, and anxiety symptoms have all been demonstrated within the literature (Brewer, 1994; Leddy, Lambert, \& Ogles, 1994). Athletes can also experience strong feelings of loss, frustration, and anger after experiencing an athletic injury (Tracey, 2003), which is understandable since many athletes identify strongly with 
the athletic role (Brewer, Van Raalte, \& Linder, 1993). Athletes highly value their ability to compete, to be physically active, and to be a part of a team. Unfortunately, injury often prevents athletes from participating with their sport in their usual manner. Additionally, athletes may doubt their ability to re-engage in sport activities (Tripp, Stanish, Ebel-Lam, Brewer, \& Birchard, 2007).

Beyond the initial impact of injury and the removal from sport participation, the other negative psychological and emotional reactions can occur during the rehabilitation process and reintroduction to various sport activities. Kinesiophobia, or fear of reinjury, has been defined as "an irrational and debilitating fear of physical movement resulting from a feeling of vulnerability to painful injury or reinjury" (Kori, Miller, \& Todd, 1990, p. 37). This fear can contribute to an athlete's reluctance to return to sport even if cleared for full participation because they may no longer trust their body to remain unharmed during participation. Additionally, they may try to compensate for their fear by altering technique, which could impact the likelihood of reinjury or experiencing a different injury. Tripp et al. (2007) that higher levels of kinesiophobia were associated with lower levels of sport participation post injury. Within competitive gymnasts, fear of physical injury was a common worry for participants which could also lead athletes to leave the sport of gynmastics (Duda, 1995; Duda \& Gano-Overway, 1996; Klint \& Weiss, 1986). Thus, it seems that fear of pain associated with injury may be one factor associated with fear of injury; however, athletes may also worry about the consequences to other aspects of their life in response to injury including identity as an athlete, social support, sport participation, and status on the team.

Lost movement syndrome. While fear of injury may lead to hesitation or 
tentativeness in skills, fear can also impede athletes from executing a previously learned skill. This phenomenon has been referred to as Lost Movement Syndrome (LMS; Day, Thatcher, Greenlees, \& Woods, 2006), a performance phobia (Silva, 1994), or mental block (Pattinson \& Cotterill, 2017). Characteristics of LMS have been noted in several different acrobatic sports, including trampolinists, gymnasts, and divers (Bennett, Hays, Lindsay, Olusoga, \& Maynard, 2015; Bennett, Rotherham, Hays, Olusoga, \& Maynard, 2016; Collins, Morriss, \& Trower, 1999; Day et al., 2006; Pattinson \& Cotterill, 2017). Themes across studies of LMS indicate that one characteristic of this syndrome is an "irrational fear and anxiety specific to the skill they were previously capable of executing without concern" (Bennett et al., 2015, p. 2). Day et. al (2006) stated that this could manifest itself in a number of different physical ways including involuntary or unwanted twists or body positions, limbs locking, and/or a general loss of awareness of one's body. All of these factors could hinder skill execution and lead to increasing fear as athletes feel out of control of their performance. Furthermore, LMS may worsen with time. Bennet et al. (2016) found that athletes experiencing LMS demonstrated higher levels of rumination and perfectionism than controls. These ruminative thinking patterns could be one reason why it is difficult for athletes to regain their lost move. Although LMS has been examined in such populations, the specific cause of this performance concern remains somewhat unclear.

In one of the few studies on this phenomenon in diving specifically, Pattinson and Cotterill (2017) conducted a qualitative analysis of mental blocks (e.g., LMS) in diving with a sample of three retired divers. The study identified barriers in overcoming mental blocks and also facilitators of overcoming them. Identified barriers included emotions 
like fear or frustration. All three participants identified fear as the root cause of their mental block. Additional barriers were a sense of loss of control (e.g., smacking) or even "the more abstract concept of an unknown outcome" (Pattinson \& Cotterill, 2017, pp. 67), poor coaching, and physical sensations such as muscle spasms, nausea, fatigue, dizziness, or pain. Facilitators included doing more lead-ups or dive progressions prior to the dive, teammate support, beneficial coaching behaviors such as trust, expert knowledge, and emotional support, and use of psychological skills such as visualization, modeling, self-talk, and adapting their training environment to their needs.

Overall, it is clear that there are numerous ways in which fear can impact performance in the sport of diving. Given that similar precipitating events may lead to different emotional responses within athletes, understanding what factors may draw an individual to a sport like diving in addition to a theoretical understanding of how fear responses might develop can serve to generate a more nuanced understanding of this phenomenon.

\section{Characteristics of Fear Development}

Much of the research on high-risk sport athletes to date has focused on the personality characteristics of people who choose to engage in such activities. For example, research has noted that these athletes may be inherent risk takers (Woodman et al., 2013). Furthermore, they may have personality characteristics that tend towards lower conscientiousness, higher extraversion, and higher neuroticism (Castanier et al., 2013). However, there may be differences in athletes' attitudes towards taking risk within higher risk sports. For example, many may seek to minimize safety risks while others may purposefully engage in risky behaviors within the sport context (Llewellyn \& Sanchez, 
2008; Slanger \& Rudestam, 1997). Some athletes may take precautions within their sport to reduce potential danger and to feel more in control. However, level of precaution does not always prevent injury. Thus, cautious athletes may become frustrated after injury when other athletes or teammates who were not as cautious or prepared remain healthy (Woodman et al., 2013).

Social learning theory. In understanding the development of fear or impact of fear on performance, considering how the fear response was learned can provide useful information for sport and performance psychology practitioners. Divers could experience fear as a direct result of their own personal experiences with a dive, such as smacking on the water or hitting the diving board. However, people can develop a fear response through observation or instruction from others even if an individual has not directly learned to fear a stimulus through their own experience (Olsson \& Phelps, 2007). Social Learning Theory (Bandura, 1963; 1977) provides a framework for understanding how such learning occurs. Social Learning Theory posits that learning is a cognitive event that incorporates social contextual variables as well as behaviors. Individuals can learn from a number of sources including observing the behavior, observing behavioral consequences, direct instruction, and reinforcement. An individual's cognitions, environment, and behaviors are all seen to influence each other in social learning theory. In the context of diving, this means a diver may learn to fear a specific dive or event from watching another person hit the board/platform, from coaches providing instruction (ex. "keep your down or you will hit the board"), from teammates, or from numerous other social sources within their environment.

\section{Existing Intervention Research}


Despite the fact that fear is a common presence in the sport of diving (Post et al., 2014), there has been limited research examining how divers manage the need to successfully execute complex motor patterns while also dealing with other mental stresses during practices and competition. Researchers have discussed some strategies that divers use such as imagery (Post et al., 2014), self-talk, and rationalization (Highlen \& Bennett, 1983). Most interventions conducted with divers have focused on understanding or using mental skills like modeling or imagery (Feltz et al., 1979; Grouios, 1992; Post et al., 2014). An exception to this was a case study conducted by Schwanhausser (2009), who detailed the positive effects of a mindfulness and acceptance-based approach with an adolescent springboard diver. In general, information on how divers specifically can successfully cope with fear within their sport is limited within the literature.

Prior to developing interventions to work with divers, an understanding of the psycho-emotional experience of divers is needed. Research in other contexts offers a broad understanding of how athletes might experience fear or how it may impact performance; however, a more nuanced understanding would provide a better base from which sport psychology professionals could build interventions with this population. Given the dearth of literature specific to the sport of diving in general, and on the unique aspect of fear specifically, it is clear that this sport merits further attention and investigation within the research. Thus, the purpose of this study is to increase understanding of divers' experiences of fear and its impact on their performance, examine strategies used to cope with fear, and discuss recommendations for sport psychology professionals seeking to work with this unique population. 


\section{CHAPTER TWO}

\section{LITERATURE REVIEW}

The sport of diving presents a unique series of challenges for sport psychology practitioners. However, there has been minimal examination of this sport on its own within the sport psychology literature. In seeking to better understand the experience and needs of divers to achieve performance excellence, researchers and practitioners need an understanding of the demands of the sport. Thus, this literature review first describes the nature of the sport to provide a context for understanding concerns. Then, the experience of fear and anxiety will be more specifically examined, as this phenomenon seems unique within the sport of diving. Both how a fear response develops and how it may impact performance will be discussed. Finally, there will be an examination of existing interventions for managing fear and anxiety within divers.

\section{Sport Background and Characteristics}

NCAA divers can compete on three different apparatuses: 1-meter springboard, 3meter springboard, and platform. Platform dives can be competed at three different heights: five-meter, seven-meter, or ten-meter. Athletes are typically required to complete six dives per event, one from each of five different dive categories and a sixth from a category of their choice, and they can be completed in one of four different positions. A panel of judges score dives on a scale of 0-10 and multiply the total by the dive's degree of difficulty in order to attain an overall score (NCAA, 2015). Thus, at any given time, collegiate divers may be training and competing 15-18 different competitive dives across the various apparatuses, though some divers may compete the same dive at different competitive heights. 
There are several different ways a diver may leave the board, which is based on the category of dive that one is competing. For example, for a forward approach, an athlete will start partway down the board, stride forward, and hurdle on the end of the board to gain height and power. From there, an athlete will either spin forwards if completing a forward dive or spin backwards towards the board if completing a reverse dive. Diving coaches note that the forward approach can be very difficult to master (Huber, 2016). For inward or back dives, athletes stand on the end of the board with their back facing the water. Then, they complete a backward press to leave the board and either spin backwards for back dives or spin in towards the board for inward dives. Divers can incorporate twists into any of these dive categories.

Mental characteristics. Jeffrey Huber, a diving coach with over 37 years of experience at the highest competitive levels, noted that mental challenges can be considered the largest obstacles that divers must face (Huber, 2016). Huber shared that, in his experience, the diver who wins was the individual who could best handle the stress of competition. Furthermore, Huber discussed how combining factors of near nakedness in front of spectators, little room for error in dives, individual accountability to performance, and the threat of becoming disoriented or injured during a dive make diving an incredibly mentally challenging sport. In an examination of imagery use in divers, Post et al. (2014) found that divers may experience fear or anxiety on several different occasions, including when performing an unfamiliar dive, completing a dive on which they were previously injured, and prior to or during competitions. Research has demonstrated several difficult psychological experiences divers experience including fear 
of injury and anxiety (Highlen \& Bennet, 1983; McGregor \& Abrahamson, 2000, Post, Simpson, Young, \& Parker, 2014).

Comparison to other sports. Beyond the variety of different motor patterns trained by divers, the level of risk involved in the sport can also be a barrier that athletes must overcome to achieve performance excellence. Any athlete must face the possibility that he or she will experience an injury at some point in their career. The risk for different types of injury varies from sport to sport; however, the possibility of injury is inherent in

all sports. For example, research has indicated higher risk of acute for wrestling, football, women's soccer, and other contact sports, while overuse injuries were more common in rowing, softball, volleyball, cross country, track, and other low-contact sports (Hootman, Dick, \& Agel, 2007). Divers also face the possibility of acute or overuse injuries, though the nature of the apparatus used adds an additional element of risk to the sport. Thus, it seems natural that divers would experience a sense of fear or anxiety related within their sport.

\section{Fear in Sport}

Throughout the sport psychology literature, the concepts of fear and anxiety have been used somewhat interchangeably. Anxiety has been discussed as the most studied emotion in sport and is believed to have the most influence on performance (Cox, 2012). It is beyond the scope of this chapter to review the entirety of that research line. However, a brief review of how anxiety develops and impacts sport performance can provide a conceptual framework for understanding fear, as there may be similarities in the experience of these emotions (though with likely differing intensity of emotional expressions). 
Fear versus anxiety. Fear is a basic emotion that serves a protective function in humans (Ekman, 1992). Fear signals the perception of danger within the environment, resulting in behaviors meant to eliminate or avoid the perceived threat. The fear response, often considered the fight/flight/freeze response, is natural and ingrained in humans as it generates response to threats that encourage safety (Olsson \& Phelps, 2007). Anxiety, on the other hand, may arise when "facing uncertain, existential threat" (Lazarus, 2000, p. 234). Thus, an emotion could be considered fear when in response to a specific object (e.g. the height of the tower) or experience (ex. hitting the board/tower on reverse dives), while anxiety is related to a more general worry. For example, athletes may experience anxiety about failing or about losing, but they may have difficulty articulating why or how that emotion is arising.

Fear of failure. One area in which it may be difficult to differentiate between experiencing fear or anxiety is the concept of fear of failure (FF), which is commonly discussed within the sport psychology literature. Fear of failure has been defined as the “dispositional tendency to experience apprehension and anxiety in evaluative situations because individuals have learned that failure is associated with aversive consequences" (Conroy \& Elliot, 2004, p. 273) or, more simply, the motivation to avoid failure (Sagar \& Lavallee, 2010). Research has shown associations between fear of failure and scores of trait anxiety and trait performance anxiety (Conroy, 2001; Conroy, Willow, \& Metzler, 2002), which may demonstrate that FF is aptly described as connected to an experience of anxiety rather than the above definition of fear. However, researchers have noted that socialization experiences impact the development of FF (Sagar \& Lavallee, 2010). Based on individual experiences growing up, it is possible that athletes have very real 
consequences to fear if they do fail. For example, they may fear that their parents will not be supportive or that they will be loved less if they fail. In a professional sport context, athletes may fear failure since it could result in loss of income and livelihood. Attending to specific situational variables is needed to identify the emotion underlying the athlete's experience and to determine appropriate intervention strategies.

Fear of injury. The possibility of becoming injured during the course of sport participation is one with which all athletes must contend. Injury risk varies based on the sport requirements, type of contact, and apparatus used during the course of regular participation. For example, analysis of data from the NCAA Injury Surveillance Program found that the injury rate for athletes was 7.7 per 1,000 athlete exposures in men's soccer, 4.3 per 1,000 athlete exposures in women's volleyball, and 8.1 per 1,000 athlete exposures in football from the 2004/05-2008/09 seasons (Datalys Center, 2014). Other studies have found that the rate of injury in intercollegiate athletics was about one injury every two games and one injury every five practices for a team of fifty participants. Most of the reported injuries did not result in a substantial time loss (Hootman, Dick, \& Agel, 2007).

It is difficult to determine the injury rate in divers specifically, as little research has examined either large populations of divers or tracked athletes over a period of time (Kerr, Baugh, Hibberd, Snook, Hayden, \& Dompier, 2015). Day, Stolz, Meghan, Smith, and McKenzie (2008) provides an exception to the small sample sizes, as these researchers examined data from an estimated 111,341 patients under the age of 20 who came to emergency departments due to diving-related injuries. This sample likely included both recreational and competitive divers, as specific information about the level 
of ability of the patient was not attained. Researchers reviewed incident narratives to determine whether or not the injury met inclusion criteria for a diving-related injury rather than another accident (ex. exiting the pool after completing a dive). The researchers found that injuries to the head, neck, and face were most common injury type. The most common cause of injury in this sample was collision with the diving board and/or platform. While this provides important insight into the potential risks of diving, this may not be representative of the most typical injury type for divers, since this only examined injuries of a severity that resulted in trips to the emergency room. Furthermore, the sample likely included many recreational divers who would not have the same training or physical demands as would a competitive diver. In a separate investigation, Kerr et al. (2015) found that the most common injury for male divers was shoulder injuries (32.0\%) and for female divers was trunk injuries (37.8\%). Results also indicated that contact with the water accounted for a somewhat large proportion of injuries men's and women's diving (32.0\% and $16.2 \%$, respectively).

Another area of concern for researchers is that of concussions. Zillmer (2003) noted that the repeated impact with the water and the deceleration may increase the chances of divers experiencing a concussion, particularly given the high volume of dives completed over the course of their lifetime. Zillmer (2003) sought to examine this through testing six collegiate divers. Athletes completed a battery of neurocognitive tests at baseline and after completing 50 practice dives to determine if any neurological changes occurred over the course of practice. Results found no detectable deficits in functioning, noting that the standard technique likely protected divers' heads from concussive forces. The researcher suggested that wrist, shoulder, and back injuries would 
likely be more susceptible to injury due to impact or improper alignment during entry. However, a limitation of this study is that it did not examine platform diving where athletes may impact the water at over 30 miles per hour. Furthermore, the researcher did not address how concussions may occur if improper technique is used or if the diver contacted the water in an undesirable position, such as smacking the water in a flatter position. Within Kerr et al.'s (2015) study, athletic trainers reported three cases of concussions in divers, two of which occurred via contact with the water and one from contact with the diving board.

While injuries may not always result in a substantial time loss, they can still affect the daily functioning of the athlete. Athletes may experience restricted playing time, decreased time with their team while the undergo rehabilitation, or difficulty completing normal activities due to injury limitations. Research has clearly demonstrated that there is a psychological impact when athletes experience an injury including lower self-concept, self-esteem, decreased life satisfaction, increased depressive symptoms, increased anxiety symptoms, and feelings of loss or anger (Brewer, 1994; Leddy, Lambert, \& Ogles, 1994; Tracey, 2003).

Part of these negative psycho-emotional consequences seems to stem from the loss of an important role within their life, either temporarily or permanently, depending on injury severity. The degree to which athletes identify with this role, termed athletic identity by Brewer, Van Raalte, and Linder (1993), can significantly affect an athlete's reaction to being injured. Athletes who highly value their ability to compete, to be physically active, and to be a part of a team in particular may be more at risk for negative consequences, since injury often prevents athletes from participating in their usual 
manner. Instead of participating in practice, athletes may be spending significant amounts of time in the training room and away from their team.

After coping with negative reactions to the injury itself and to the frustrations of the recovery process, re-introduction to sport can be another significant barrier for athletes. Research has indicated that athletes may experience intense fear or anxiety about re-injuring themselves during re-introduction to activity, which can be an additional psychological and emotional struggle In the rehabilitation process. This phenomenon, termed kinesiophobia, has been defined as "an irrational and debilitating fear of physical movement resulting from a feeling of vulnerability to painful injury or reinjury" (Kori, Miller, \& Todd, 1990, p. 37).

Kinesiophobia can contribute to an athlete's reluctance to return to sport even if cleared for full participation by the athletic training staff. Athletes may no longer trust their body to remain unharmed during participation. Higher levels of kinesiophobia have been associated with lower levels of sport participation post injury and could result in athletes leaving the sport (Duda, 1995; Duda \& Gano-Overway, 1996; Klint \& Weiss, 1986; Tripp et al., 2007). Furthermore, this fear can impact an athlete's performance even if they choose to stay in their sport. Athletes returning from injury have been shown to hesitate in their movements and not give their best effort during practices or competitions (Ardern, Taylor, Feller, \& Webster, 2012; Evans, Hardy, \& Fleming, 2000). Fear of pain associated with injury may be one factor associated with fear of injury; however, athletes may also worry about the consequences to other aspects of their life in response to injury, including identity as an athlete, social support, sport participation, and status on the team. Overall, fear of reinjury has been considered the most salient concern for athletes 
returning to sport post injury (Podlog, Dimmock, \& Miller, 2011; Wadey, Podlog, Hall, Hamson-Utley, Hicks-Little, \& Hammer, 2014).

Lost movement syndrome. As noted above, evidence of fear of injury has been found across sports, though its specific manifestations may vary based on the context of the sport. However, fear may also have a unique impact on athletes in acrobatic sports outside of specific concern over injury. Research has described a phenomenon in acrobatic sports, referred to referred to as Lost Movement Syndrome (LMS; Day, Thatcher, Greenlees, \& Woods, 2006), a performance phobia (Silva, 1994), or mental block (Pattinson \& Cotterill, 2017), in which athletes become unable to execute previously learned skills. Characteristics of LMS have been described in several different acrobatic sports, including trampolinists, gymnasts, and divers (Bennett, Hays, Lindsay, Olusoga, \& Maynard, 2015; Bennett, Rotherham, Hays, Olusoga, \& Maynard, 2016, Collins, Morriss, \& Trower, 1999; Day et al., 2006; Pattinson \& Cotterill, 2017). Themes across studies of LMS indicate that one characteristic of this syndrome is an "irrational fear and anxiety specific to the skill they were previously capable of executing without concern" (Bennett et al., 2015, p. 2). Day et. al (2006) noted that this can manifest itself different mental hysical ways that could impact performance including a loss of body awareness, locking of limbs, involuntary twists or rotations, or unwanted body positions. All of these factors could hinder skill execution and lead to increasing fear as athletes feel out of control of their performance.

Pattinson and Cotterill (2017) conducted a qualitative analysis of mental blocks (e.g., LMS) in divers with a sample of three retired divers. The study identified barriers in overcoming mental blocks and also facilitators of overcoming them. Identified barriers 
included emotions like fear or frustration. All three participants identified fear as the root cause of their mental block within analysis. Additional barriers were a sense of loss of control (e.g., smacking) or even "the more abstract concept of an unknown outcome" (Pattinson \& Cotterill, 2017, pp. 6-7), poor coaching, and physical sensations such as muscle spasms, nausea, fatigue, dizziness, or pain. Facilitators in overcoming mental blocks included doing more lead-ups or dive progressions prior to the dive, teammate support, beneficial coaching behaviors such as trust, expert knowledge, and emotional support, and use of psychological skills such as visualization, modeling, self-talk, and adapting their training environment to their needs.

Some research has compared LMS to that of the yips in baseball or cricket. The yips has been described as a condition where athletes experience involuntary freezing, tremors, jerks, or spasms in the course of executing a previously learned or automatic motor pattern (Bawden \& Maynard, 2001). Similar to LMS, athletes experiencing the yips have described feelings of loss of control over their performance and increasing fear or anxiety related to skill execution (Bawden et al., 2001). Bennett et al. (2015) interviewed a total of 16 athletes, 8 who were experiencing LMS and 8 who were experiencing the yips. Researchers found that the experience of both were similar for athletes, including feelings of loss of control (cognitive, emotional, and physical) in addition to intense anxiety. The main difference between the two experiences seemed to be related to sport specific movement execution concerns. Furthermore, Bennet et al. (2016) found that athletes experiencing LMS or the yips both demonstrated higher levels of rumination and perfectionism than controls. These ruminative thinking patterns could be one reason why it is difficult for athletes to regain their lost move or overcome the 
yips. Bennet et al. (2013) concluded that these concerns have been historically treated as movement disorders, though the anxiety underpinning the physical movement concern may mean that the experiences should be treated like anxiety-related disorders. Given the small sample sizes for comparison, though, such recommendations should be made with caution. Overall, although LMS has been examined in such populations, the cause of this performance concern remains somewhat unclear.

Impact of fear on performance. Beyond the specific occurrences of fear of injury and LMS, fear may impact general performance in a number of ways. The impact of fear on individual performance may vary based on factors such as intensity of the emotion, level of risk of the event, or individual personality factors (Buckley, 2016). For example, a diver would likely be more scared to do a front dive with three- and one-half flips off the 10-meter platform than they would be if executing the dive from the threemeter springboard. Although the way in which the dive is executed does not vary significantly between those two levels once in the air, the increased height may decrease athlete's comfort or confidence in successfully completing the dive.

Emotions of both fear and anxiety can manifest in physiological symptoms. These symptoms could impact an athlete's performance given that physiological arousal level influences muscle tension, heart rate, ventilation, and concentration. However, this does not mean that the impact on performance is necessarily bad. Although potentially unpleasant, these physiological responses could be used to improve athlete performance in the right settings. For example, Hanin's IZOF model (2000) suggests that each athlete has an individual zone of optimal functioning in which a certain level of arousal contributes to optimal performance. An athlete either below or above this optimal level 
may underperform. Thus, fear could benefit athletes who are under aroused by increasing their physiological readiness. However, athletes already at or above their ideal arousal level could be negatively impacted by increased anxiety or fear.

Fear could also impact performance indirectly through affecting an athlete's attentional focus. Buckley (2016) notes that "perceived danger generates intense focus and awareness" (p. 1), which could be beneficial in some performance contexts. However, others have noted that increasing anxiety may decrease overall attentional control. Rather, athletes may direct attention towards threat-related stimuli as opposed to task related stimuli (Eysenck, Derakshan, Santos, \& Calvo, 2007). Smith (2010) noted that fear of failure can increase a chance that athletes would choke during performance, since they are likely directing attention towards the negative consequences of mistakes rather than tasks needed to achieve performance excellence.

Beyond performance in a competition setting, fear can be a barrier in skill development or sport retention. Almost all participants in Post et al.'s (2014) study disclosed that fear could prevent them from practicing specific dives. Given that deliberate practice has been considered an imperative aspect of developing expertise in a domain (Ericsson, Krampe, \& Tesch-Romer, 1993), inability to overcome fear could have lasting impacts on an athlete's skill development in the sport. Overall, research demonstrates that there are numerous ways in which fear could impact performance in the sport of diving. Given that similar precipitating events may lead to different emotional responses within athletes (ex. fear vs. thrill vs. calm), understanding what factors may draw an individual to a sport like diving in addition to a theoretical 
understanding of how fear responses might develop can serve to generate a more nuanced understanding of this phenomenon.

\section{Development of Fear}

Research describes two main dimensions of behaviors likely to be found in highrisk sport athletes: risk-taking behavior and precautionary behaviors. Some individuals seem to be inherent risk takers and deliberately engaged in behaviors that increase the risk level within their sport beyond baseline levels (Llewellyn \& Sanchez, 2008; Slanger \& Rudestam, 1997; Woodman et al., 2013). Athletes could also find satisfaction from controlling risk inherent within their sport by using precautionary behaviors to maintain safety (Pain \& Pain, 2005; Woodman et al. 2013). Some of the risk taking and precautionary behaviors may be better understood through the context of personality characteristics, an area in which most research on high-risk sport athletes has focused.

Research on high-risk athletes has focused on sports such as skydiving, rock climbing, and white water kayaking. Within these populations, athletes may tend to demonstrate personality characteristics lower in conscientiousness, higher in extraversion, and higher neuroticism when compared to normative samples (Castanier et al., 2013). In a series of three studies, Barlow et al. (2015) noted that the sensation seeking of high-risk sport athletes could be related to difficulty identifying and experiencing their own emotions. Researchers concluded that alexithymia was linked to increased likelihood of experiencing accidents or close calls, as the desire to experience intense emotions could lead individuals to increase their risk taking behaviors within the sport. However, reasons for engaging in complex behaviors such as risk-taking should 
not be simplified to simply sensation-seeking, as the reality of behavior choice is likely much more complex (Barlow, Woodman, \& Hardy, 2013).

As noted above, most of the examinations of personality characteristics has occurred in high risk athletes such as sky divers or wrestlers. Hinton-Bayre and Hanrahan (1999) conducted the only published study that could be located examining personality characteristics specifically in divers. In a comparison of divers to non-divers, divers reported higher levels of thrill, adventure seeking, sensation seeking, and disinhibition. However, any interpretations from this data should be made with caution given the limited sample size $(n=18)$. While personality characteristics may set the stage for how athletes interpret fear or pursue higher risk situations, learning also plays a strong role in how athletes respond to fearful stimuli.

Social learning theory. Learning can still occur even if an individual has not experienced a stimulus directly. Social Learning Theory (Bandura, 1963; 1977) provides a framework for understanding how such learning occurs. Social Learning Theory posits that learning is a cognitive event that incorporates social contextual variables as well as behaviors. Individuals can learn from a number of sources including observing the behavior, observing behavioral consequences, direct instruction, and reinforcement. An individual's cognitions, environment, and behaviors all influence each other in social learning theory. Thus, people could develop a fear response through observation or instruction from others even if they have not experienced the fearful event themselves (Olsson \& Phelps, 2007).

In the sport setting, researchers have often examined social learning theory in the context of understanding aggression in sport (Cox, 2012). Aggression in sports like ice 
hockey has been discussed as likely due, at least in part, to socialization processes

(Weinstein, Smith, \& Wiesenthal, 1995; Sheldon \& Aimar, 2001). Other research has suggested that individuals tend to conform their behaviors to the norms of their team (Stephens, 2001; Tucker and Parks, 2001). Stephens (2001) showed that likelihood to aggress was predicted by a player's perceptions of team norms. However, critics of this application to the phenomenon of aggression argued that pulling theories from mainstream psychology does not attend to the unique context of aggression in sport, as violence without intention to injure the opponent may be sanctioned as part of the sport (Grange \& Kerr, 2010.) However, this critique of the application of social learning theory seemed to be unique to the aggression phenomenon rather than to applications to the sport environment as a whole. Grange et al. (2010) argued that social learning theory may not apply due to differences in how aggression is defined in mainstream versus sport contexts. As the definition of fear does not vary significantly from sport to non-sport contexts, the critique may not apply to the experience of learning fear through socialization processes in sport. Specific examples of how fear may be socially learned in diving include learning to fear a specific dive or event from watching another person hit the board/platform, from coaches providing instruction (ex. "keep your down or you will hit the board"), from teammates sharing how scared they are of a specific event, or from numerous other social sources. Given that there are numerous ways in which fear can be learned and also can impact performance, sport psychologists seeking to work with this population need an understanding of how to best intervene in these settings.

\section{Existing Interventions}

Historically, many interventions in sport psychology fall into the category of 
"psychological skills training" (PST) interventions. Psychological skill training programs often consist of providing education and descriptions of specific techniques designed to enhance performance. Vealey (1988) described the basic premises of the PST model as understanding that athletes are basically mentally healthy, though may need skills or strategies to cope with competition demands. PST models tend to be systematic and require consistent practice on the part of athletes to achieve goals of increasing enjoyment or enhancing performance (Weinberg \& Gould, 2007).

The specific content of these PST programs seems to vary based on practitioner preferences and sport demands. For example, Thelwell, Greenless, and Weston (2005) conducted a PST intervention with soccer players that consisted of relaxation, imagery, and self-talk, while an intervention designed for adolescent swimmers consisted of goal setting, visualization, relaxation, concentration, and thought stopping (Sheard \& Golby, 2006). However, there tends to be little explanation or consistency as to why certain skills were included in programs compared to others. Some researchers have called into question the applicability of various psychological skills training models, noting that recommended programs are often too generic to be adaptable to different sports. Thus, an understanding of the unique needs of each sport is needed prior to the development of such programs (Birrer \& Morgan, 2010).

Beyond potential difficulty in applying general PST interventions to new populations, use of PST models may limit a practitioner's ability to understand athlete concerns at a deeper level. Originally grounded in Cognitive-Behavioral Therapy (CBT) strategies, PST has been reduced to a mostly skills-based approach. Although PST has been reflective of aspects of cognitive-behavioral therapy, practitioners have noted that it 
lacks the ability to either describe or explain behavior (Tod, Anderson, \& Marchant, 2009). Thus, it seems that PST in and of itself is not sufficient to provide a deeper understanding as to how athletes achieve performance excellence or develop psychopathology.

Reliance on theories from psychology. In general, the field of sport psychology has typically relied on second-wave cognitive behavioral approaches to work through psychological concerns. However, as noted above, CBT as it is typically used in sport psychology may be limited in scope compared to its use within general psychology practice. Although many sport psychology practices are rooted in CBT, there is currently a shift in the field towards third-wave therapy techniques and mindfulness-based approaches such as Acceptance and Commitment Therapy (ACT; Hayes, Strosahl, \& Wilson, 2012). Given that these theories were developed to explain psychopathology rather than performance excellence, it is unclear if the current applications of these theories are scientifically valid. Thus, there have been calls in the literature to develop theoretical orientations specific to achieving performance excellence (see for example Aoyagi \& Poczwardowski, 2012; Foss, Minaker, Doerr, \& Aoyagi, 2017).

While still mostly being referred to as mindfulness and acceptance-based approaches within athletic contexts, specific models such as the mindfulness-acceptance-commitment (MAC) protocol have been developed specifically for performance enhancement (Gardner \& Moore, 2004; 2007).

Interventions in diving. Overall, interventions specific to the sport of diving have been somewhat neglected within the sport psychology literature. Most interventions have been related to PST strategies such as imagery (Post et al., 2014), modeling (Feltz et 
al., 1979; Grouios, 1992) self-talk, or rationalization (Highlen \& Bennett, 1983). Feltz et al. (1979) examined the impact of different types of modeling on back dive performance and on self-efficacy. It is of note, however, that the participants had no prior experience with diving prior to inclusion in the study. Thus, it is unclear how these results would compare to more experienced divers. Grouios (1992) examined the impact of mental practice (e.g., imagery) on diving performance. Grouios examined 30 female adolescent divers within his sample and found that mental practice had a positive impact on performance.

As an exception to the typical PST interventions, Schwanhausser (2009) examined the impact of the Mindfulness-Acceptance-Commitment approach on performance with an adolescent springboard diver. The intervention consisted of nine individual sessions including providing psychoeducation, teaching mindfulness skills, identifying values and shifting to values-driven behavior rather than emotion-driven behavior, and learning to accept emotional experiences rather than seeking to change them. Results of this intervention included increases in acceptance behaviors, mindful attention, and competitive scores. The diver within the study improved his performance on both one-meter and three-meter springboard dives, and he described that the "concept of being able to perform optimally despite his emotions was an integral piece of his ability to maintain focus" (Schwanhausser, 2009, p. 391). Thus, there seems to be preliminary evidence supporting the use of MAC protocols with divers; however, the dearth of literature on this context provides little grounding in which intervention protocols could be based. Thus, further understanding is needed related to the diving context in addition to specific interventions that may be beneficial for this populations. 


\section{Conclusions}

Prior to developing interventions to work with divers, an understanding of the unique psycho-emotional experience of divers is needed. Research in other contexts offers a broad understanding of how athletes might experience fear or how it may impact performance; however, a more nuanced understanding of the fear experience and its psychological and physical impact on divers would provide a better base from which sport psychology professionals could build interventions with this population. Given the dearth of literature specific to the sport of diving in general, and on the unique aspect of fear specifically, it is clear that this sport merits further attention and investigation within the research. Thus, the purpose of this study was three fold including to increase an understanding of factors that influence divers' experiences of fear within their sport, identify how fear impacts performance within divers, and to examine strategies that divers use to successfully manage fear within their sport. Overall, this study sought to provide practical recommendations for divers, coaches, and sport psychology professionals seeking to adaptively work with fear in the sport of diving. 


\section{CHAPTER THREE}

\section{METHOD}

\section{Theoretical Framework}

Consensual qualitative research methodology (CQR) was used as a framework for understanding divers' experiences of fear and anxiety within their sport. Hill (2012) described nine key components that characterize CQR research: using inductive rather than deductive analytic procedures, asking open-ended questions, reliance on words over numbers to understand participants' experiences, understanding the context from which participants are making statements, using small sample sizes, utilizing a team approach to data analysis, reaching consensus, emphasis on ethics, trustworthiness, and attention to culture, and continuously returning to the data to check for trustworthiness. In addition to qualitative interviews, participants were also given one quantitative measure examining anxiety in sport to serve as a triangulation point for comparison with the content of the qualitative interviews.

From an epistemological standpoint, CQR has been described as "predominantly constructivist, with some post positivist elements" (Hill, Knox, Thompson, Williams, Hess, \& Ladany, 2005, p. 197). Thus, CQR researchers believe that there are multiple versions of the truth, which vary based on an individual's construction of their own reality. Researchers attempt to identify individual experiences as well as common themes across people's experiences, which is another form of constructed reality. With regards to post-positivist elements, CQR seeks to minimize, as much as possible, the impact of the researcher biases on results and also uses consistent interview protocols to standardize the data collection process. In general, CQR attempts to represent the participant's reality as 
closely as possible, while also attending to different ways in which the researcher is impacting the interpretation of results.

The theoretical framework used in this study, as discussed by Crotty (1988), was in alignment with the epistemological standpoints of CQR. As discussed previously, Social Learning Theory (Bandura 1963; 1977) provided a context for understanding how individuals learn through their own socialization experiences. Thus, the primary investigator did not expect there to be one true reality or standard experience of fear across participants in this study. Rather, it was hypothesized that the participant's reality would vary based on their socialization experiences, as these experiences provide a unique lens through which individuals make sense of their world.

\section{Participants}

Participants included ten current NCAA Division I collegiate divers aged 18-22 $(\mathrm{M}=19.9, \mathrm{SD}=1.37)$ at a large Midwestern university. This in alignment with the recommended sample size of eight to fifteen participants in CQR (Hill, 2012). Participants were evenly split across gender with five men and five women included in the sample. The athletes represented all four collegiate classes. Related to other demographic variables, nine participants self-identified as heterosexual/straight and one participant identified as gay. Eight participants self-identified as White, one as Asian American/Asian, and one as Hispanic/Latinx. Related to religious/spiritual preference, six participants identified as Christian, one as Catholic, one as Lutheran, one as Agnostic, and one indicated no preference. Divers ranged in their years of diving experience from six to fifteen years $(M=8.9, \mathrm{SD}=3.31)$. Divers had experience succeeding on a national stage including NCAA All-American/All-American Honorable mentions, Conference 
meet finalists, USA Nationals finalists, and several high school state champions. All participants had previous exposure to sport and performance psychology principles for varying lengths of time including approximately one month at the first time point for incoming freshman to approximately 2.5 years for incoming seniors. Types of experiences ranged from attending group sessions with the team to a combination of group and individual work with the primary investigator. By the second time point, all participants had at least five months of experience in group sessions with the team learning performance enhancement strategies. See Table 4-1 for participant demographic information in addition to result from the Sport Anxiety Scale-2.

\section{Data Analysis Team}

A team approach was used to analyze the data, including three individuals who served as primary data analyzers and a fourth member who served as an external auditor for the analysis. The primary investigator is a fifth-year doctoral student in counseling psychology. She self-identifies as a White, agnostic, straight, cis female. The primary investigator played four years of collegiate volleyball, and her primary sport psychology work prior to coming to her current institution was in team sports. Through the time of data analysis, the primary investigator was immersed with the diving team for approximately three years as a mental performance coach. This role included attending practices, traveling with the team to competitions, and meeting with divers both on an individual and group basis. Her lack of initial familiarity with the sport, and her subsequent efforts to better serve this population, motivated her interest in better understanding the experience of how divers cope with fear.

In addition to the primary investigator, two other advanced doctoral students with 
experience in sport and performance psychology served as primary members of the data analysis team. One student self-identified as a White, straight, Christian, cis male. He had 12 years of professional experience, including 12 years as an athletic trainer (sports medicine) and 3 years as a sport psychology coach. As an athletic trainer, he often applied various sport psychology skills and techniques while working with injured athletes. The large majority (greater than $80 \%$ ) of his professional experience was with individuals and teams competing at the collegiate and professional levels of sport. As a high school athlete, this investigator competed in the sport of swimming. This exposed him to the sport of diving and provided him with a basic understanding of the sport; however, he did not consider himself an expert or well-versed in the finer details of the sport of diving.

The third member of the primary analysis team self-identified as a White, straight, agnostic, cis female. She had six years of professional experience, including two years as a gymnastics coach and four years as a mental performance coach. Within the role of gymnastics coach, she reinforced mental performance skills and techniques initially taught outside of training sessions. All experiences were with populations at the youth or collegiate level, primarily with female athletes. This investigator was also an athlete herself, competing in gymnastics from the age of three through college. This considerable experience within gymnastics gave her some understanding of the techniques and fears associated with diving, but she did not consider herself an expert within the sport of diving.

The final member of the data analysis team, the external auditor, was a White Christian male who had 17 years of experience in coaching and sport psychology having 
served in capacities as a defensive assistant coaching, including coordinator duties for football. He also had 4 years of experience of Director of Strength and Conditioning in that time. He had a decade of service to Division I teams, professional organizations, and military combat arms units in performance enhancement work through sport psychology. Through that time, he had been immersed with sport psychology delivery while embedded with teams performing duties commensurate to embedding with a team: attending practices, delivering team and individual sessions for performance enhancement, and travelling with teams to competitions including conference and championship venues. Currently, he was the director of operational and performance psychology for a Special Warfare unit within AirForce Special Operations affording him the opportunity to immerse and embed within an elite military unit for the purposes of improving psychological skills related to performance enhancement tactics and strategies for Special Warfare operators. Academically he had served as a graduate faculty with doctoral status for 5 years having published 3 peer reviewed articles, 6 book chapters, and served as chair or committee member for 7 doctoral studies and more than 15 master thesis'. This project was his $4^{\text {th }}$ doctoral study in which he had served in capacity as auditor.

Expectations and biases. Throughout the process of interviews and data analysis, members of the primary data analysis team identified potential biases in the data and revisited how these biases could impact the analysis. Expectations for the data fell into several different areas: expectation that every diver would have experienced fear related to their sport at both time points, expected differences in the cause of fear between the two time points, gendered differences in how fear was experienced and coped with, and 
an expectation that the coach would be a primary social influence in divers' experiences of fear.

As noted above, all members of the team expected that divers would experience fear in their sport. To mitigate this bias, participants were directly asked if they experienced fear in their sport within the interview guide. Additionally, the interview guide provided language and options for questions in the case that divers denied experiencing fear in their sport.

Related to differences between the two time points, team members discussed an expectation that there may be more fear of injury apparent in the first time point due to that fact the divers were likely learning new dives at that point in season. Thus, it was expected that this fear may be more primary than other fears, such as competition fears, at that time point. Related to the second time point, researchers discussed an expectation that divers would feel more comfortable with their dive list at that point in time, and there may be a shift to experiencing more outcome-based fear compared to earlier in the season.

Researchers also noted biases related to the influence of gender on fear expression and coping mechanisms. Researchers identified expectations that women may more readily discuss experiences of fear while men may demonstrate more minimization of fear. Additionally, researchers shared how they anticipated that women may rely more on social support to cope with fear, when men may use more individual coping strategies. Additionally, a source of bias that researchers were aware of when analyzing the second time point was the impact of results from the first time point's analysis on expectations for the second time point. This included expectations that divers would 
discuss uncertainty over their dive, concern over injury, increased fear based on specific dive types and apparatuses, and that the coach would continue to be a large influence. Researchers also expected to see more maladaptive impacts of fear than benefits of fear connected to dive outcome and well-being. In order to manage this bias, researchers were intentional about continuously returning to the data, checking with each other that domains and categories made sense based solely on the existing data set, and using frequency tables to check biases based on how often data points were emerging. For example, researchers initially had a category for "apparatus" in time point two, which may have been in part due to bias based on the first time point's results. However, this category was variant when analyzed for frequency. As a result, researchers revised the category to be more inclusive and representative of the second time point's data. There were resulting similarities in analyses between time point 1 and time point 2 , particularly the impact of fear domain, even with various checks on the data. The research team felt these similarities were due to expressed consistencies in experience of fear across time points and each time point's analysis accurately reflected that data in that time point.

\section{Measures}

Consistent with CQR principles, the interview guide utilized open-ended questions and relied on words in order to best understand the participant's experience (Hill, 2012). To add additional depth to the data, participants were also given a quantitative measure on anxiety. The purpose behind these measures was to compare participants at different season time points on both subjective and objective measures to add an additional level of trustworthiness to the subjective reports and understanding of participants' experiences. 
Demographic questionnaire. All participants were given a demographic questionnaire including information on age, gender, sexual orientation, religion, academic major, amount of exposure to sport and performance psychology, years of diving experience, and level of accomplishment in the sport. The demographic questionnaire is included in the Appendix.

The sport anxiety scale - 2. The Sport Anxiety Scale - 2 (SAS-2; Smith, Smoll, Cumming, \& Grossbard, 2006) is a 15-item self-report questionnaire which measures anxiety either prior to or during sport competition. It consists of three subscales (somatic anxiety, worry, and concentration disruption) with five questions addressing each subscale. Questions are responded to on a 4-point Likert scale ranging from not at all to very much. Total scores on the scale range from 15 to 60 . The SAS-2 is a revision of the original Sport Anxiety Scale (Smith, Smoll, \& Schultz, 1990). Internal consistency for the SAS-2 was found to be moderate to high. Using cronbach's alpha, internal consistency with college aged students for subscales was found to be $.89(95 \% \mathrm{CI}=.87$ $.90), .91(95 \% \mathrm{CI}=.90-.92)$ and $.84(95 \% \mathrm{CI}=.82-.86)$ for somatic, worry, and concentration disruption subscales, respectively. Total cronbach's alpha for the entire was $.91(95 \% \mathrm{CI}=.90-.92)$. With regards to convergent validity, the SAS-2 was correlated at .90 with the original SAS, indicating that the revised scale was likely measuring the same construct as the original scale (Smith et al., 2006).

Within the SAS-2 results, overall scores could range from 15-60, which higher scores being associated with higher levels of anxiety. Similarly, scores on each subscale could range from 5-20, with higher scores indicating higher levels of anxiety. Normative data for this scale was conducted with a sample of 593 college-aged student athletes. 
Participants were enrolled in an introductory psychology class and currently involved in organized athletes (e.g., intramural sports, club sports, intercollegiate sports) and/or had participated in varsity sports in high school within the past three to nine months. The normative sample had a mean age of $18.36(\mathrm{SD}=3.17)$ and was $59 \%$ Caucasian, $33 \%$ Asian American, and 8\% African American or "other." Average scoreson the Somatic Anxiety Scale was $9.78(S D=3.61)$, on Worry was $12.12(S D=3.85)$, and on Concentration Disruption was $6.93(S D=2.37)$. Average total score for college-aged athletes was $28.83(S D=8.05$; Smith et al., 2006).

Interview guide. A semi-structured interview guide was developed based on the existing literature and on the investigators' experiences with the setting (Hill et al., 1997; Hill et al., 2005). The interview guide was designed to allow for flexibility within the interview to understand relevant information without limiting participant disclosure or interviewer questioning (Patton, 2002). Questions were structured as open-ended probes to facilitate exploration without setting limits on response type (Hill, 2012). Grounded in Social Learning Theory (Bandura 1963; 1977), participants were first asked to describe general perceptions of fear and anxiety in diving. After some comfort and rapport was been developed in the interview, the second section of questioning sought to understand specific examples of how fear had affected the participant in the sport of diving and various influences on the participants' experience of fear. Additionally, the impact of fear on divers' performance in addition to strategies participants have used to manage experiences of fear were explored. Within the second time point, similar questions were asked but were focused on exploring experiences that occurred in the time between the 
first and second interview. See the Appendix for the complete interview guide for the first and second time point.

\section{Procedure}

Recruitment. After obtaining IRB approval, participants were recruited through the primary investigators existing relationships in the athletic department. The primary investigator first discussed the study and its requirements with the head coach of a diving team, with whom she had an existing relationship. After obtaining permission from the diving team head coach, the investigator met with the divers as a group to explain the purpose of the study and the time requirements. She provided space to discuss questions or concerns related to the study. Additionally, athletes were encouraged to reach out to the investigator individually if they had concerns or questions that they were not comfortable speaking about in a group setting. Given the existing relationship with the team, the investigator emphasized that participation was not mandatory nor would nonparticipation impact the researcher's view of the individual. Additionally, team members were informed that individuals who did or did not participate would not be revealed to others such as the head coach or other teammates. Athletes who agreed to be in the study then scheduled individual meetings with members of the primary investigator's research team for the purpose of data collection.

Interviews. Two pilot interviews were conducted, one by each member of the research team who would be interviewing participants. Each pilot interviewee was a current diving coach and former competitive diver. Slight modifications to the interview protocol were be made based on feedback from the participant and from interviewer reactions to the experience, though the format and questions were primarily maintained. 
Interviews were conducted at two time-points to assess the experience of fear and anxiety across a competitive season. The first collection time point occurred in late August to early September, which was early in the training cycle. The second data collection time point occurred in late January, which was closer to important competitions such as the conference meet and the NCAA qualification meet.

Given the primary researcher's existing relationship with the team, interviews were conducted by the other two main members of the research team. The primary investigator did not want participants to feel pressured to reveal specific information disclosed within other settings in the context of their relationship with the primary investigators. Interviewers remained consistent for participants between the first and second time points. At the beginning of each interview, interviewers discussed informed consent and answered any questions from the participants about the research. Participants then completed the demographic questionnaire and SAS-2. After measures were complete, interviewers then proceeded with the semi-structured interview. Interview length for the first time point ranged from 35 minutes to two hours and 20 minutes. Interview length for the second time point was often shorter, ranging from 23 minutes to 61 minutes. Given that divers could be speaking about difficult experiences related to fear, researchers provided contact information for and encourage participants to seek appropriate resources (e.g., mental performance coach/athletic department psychologist) if they were in need of support after the interview.

Data analysis. All interviews were transcribed from audio recordings using the TranscribeMe transcription service, and the primary investigator reviewed all transcriptions for accuracy. As discussed in Hill (2012), there were three main steps in 
the data analysis process: developing a domain list, elucidating core ideas, and conducting cross-analysis of the data. Researchers analyzed the data from the two time points separately.

Domain list. Domains are considered broad topics or themes that seem to encompass the data, which served to break interview data into different segments (Hill et al., 2005). To develop a domain list, members of the data analysis team individually reviewed one transcript and identified naturally emerging themes. Members then met to discuss domains and to reach consensus on a domain list that best represents the data from that interview. Researchers then tested the domain list by applying it to other transcripts and seeing if the data fit the domain list. This process continued until the domain list stabilized. After the domain list was complete, researchers then assigned interview data blocks into domains (Hill, 2012). For both time points, all three members of the research team coded transcripts until the domain list stabilized, which occurred after incorporating data from five cases. After this, two members of the data analysis team (primary investigator and one other member) reviewed each and reached consensus on assigning interview data into domains for the remaining five cases.

Core ideas. Core ideas are summary statements that serve to clarify interview data and "capture the essence of what was said" by participants (Hill et al., 2005, p. 200). After the data was coded into specific domains, researchers individually reviewed interview data blocks within each domain to narrow data down to the core ideas. Hill et al. (2005) noted that core ideas should not contain assumptions or interpretations from the researchers, rather they should be as close to the initial interview segment as possible while increasing clarity, conciseness, and allowing for comparison across cases. After 
coding individually, the research team reached consensus on the content of each core idea. After consensus was reached on each case, domains and core ideas were sent to the auditor for review. After feedback was received, the research team met to discuss the incorporation of auditor feedback. Consensus was reached on how to incorporate feedback from the auditor into the coding.

Cross-analysis. Once feedback from the auditor on the domains and core ideas was incorporated, researchers conducted a cross-analysis of the data. Until this point of the analysis, the research team were examining cases individually. The cross-analysis is where researchers looked for similarities across cases and determined how core ideas within domains cluster into categories (Hill et al., 1997). Within each domain, researchers reviewed core ideas and created categories that encapsulated most, if not all, of the data blocks. Researchers then reached consensus on which categories should be included and the name of categories. This process was repeated for each domain that was identified previously. The research team then assessed the representativeness of categories to the whole sample by determining how frequently the categories occur within the sample. If a category was found to only apply to one or two cases, researchers attempted to see if the core ideas could be encapsulated into other categories. Following this, categorical information was returned to the external auditor for review and feedback (Hill et al., 1997).

Auditing. The purpose of the auditor was to serve as a check for the research team to provide a different perspective within the data analysis. After data blocks were coded into core ideas, the auditor read through the raw data and determined if the data was in the correct domain, if all the important material from the data was coded, and if the core 
ideas accurately and concisely reflected the raw data. In response to the first time point, the auditor recommended significant alternations in the structure of the domain list. Research team members met with the auditor to discuss this feedback, and the research team agreed upon the need for restructuring. In response to this feedback, research team members reached consensus on a revised domain list and on recoding data points into the new domains. Related to the second time point, the auditor generally agreed with the domain list structure and provided feedback around wording of domains and inclusion of specific data points in one domain compared to another.

The auditor also conducted an analysis after the cross analysis to determine if the core ideas fit under the categories specified by the research team. The auditor also served as a check to determine that the category label accurately captures the essence of all core ideas within that category (Hill et al., 1997). The external auditor generally agreed with the categorical labels in the first time point and felt that they encompassed the data. Related to the second time point, the auditor generally agreed with categorical labels and provided feedback around potential collapsing of categories together based on frequency of categories. The auditor also recommended maintaining several variant categories due to their unique nature.

Trustworthiness. Creswell (2014) described several methods that can be used to enhance trustworthiness including triangulating different sources of information, use of member checking procedures, providing rich descriptions of the findings, clarifying researcher biases, presenting discrepant information, using peer debriefing procedures, and using an external auditor. The data analysis method of CQR addresses several aspects of establishing trustworthiness including the use of peer debriefing and the use of 
an external auditor. Through researching consensus for all data analysis, researchers seek to minimize the impact of biases on the data (Hill et al., 1997).

Other procedures used to enhance trustworthiness of findings include member checking procedures, reporting researcher expectations and potential biases, and triangulation of data from a quantitative measure. Member checking procedures were utilized after analyses have been conducted. Member checking procedures help validate the accuracy of findings through taking the final thematic report back to participants and determining if participants feel that the findings are an accurate representation of their experience (Creswell, 2014). Within this study, no participants suggested alterations were needed when they received the thematic report from the primary investigator. Reporting researcher expectations and biases was an additional measure of trustworthiness, which allows readers to evaluate results with the potential expectations and biases in mind (Hill, Thompson, \& Williams, 1997). Hill et al. (2005) noted that the inclusion an honest evaluation of how biases may have impacted data analysis within the discussion section can further serve to establish trustworthiness. Finally, the study included a quantitative scale to help triangulate interview information. While this scale was not analyzed at a quantitative level, it was compared to the qualitative data to add richness to the analysis. 


\section{CHAPTER FOUR}

\section{RESULTS}

\section{Overview}

The purpose of this study was to better understand the experience of fear in diving, how this fear has impacted performance, and coping mechanisms athletes use to manage their cognitive, emotional, physiological, and behavioral experiences in response. The intention behind examining two time points, one occurring in the beginning of season and one close to important competition experiences, was to capture potential changes in the experience of fear over the course of the season and to understand the factors that may influence divers' fear over time. Within this section, results from each time point are treated as unique and specific to that point in time.

Within the first time point, which occurred in late August to early September, athletes described a number of reasons they may experience fear including concern over the meaning of not performing well, generally being unable to know how a dive will turn out, and inherent risk as an integral component of the sport. Several reasons were identified that influenced athletes' experience of fear ranging from specific dive factors to performance setting to social influences in their environment such as coaches or teammates. Athletes identified various types of ways in which fear could impact their performance and suggested that the ways in which they cope with fear are individually unique and diverse.

Within the second time point, which occurred in late January to early February of the same academic year, participants identified a number of protective factors that positively impacted their experience of fear and risk factors that negatively influenced 
their sense of fear. Athletes described ways in which their experience of fear and coping needs differed within a competition setting compared to a practice setting and how their experience can change based on the level of competition. Athletes also discussed again the ways in which fear positively and negatively impacted performance and the ways in which they coped with fear. Finally, athletes described how they grew and developed related to their mentality towards fear, their ability to cope with fear, and their general level of fear over time.

Results were not only examined independently but also examined through integrating results across time points. Themes of the need for acceptance of fear, impacts of fear, and categories of coping strategies remained consistent across time points. Other experiences changed somewhat from the first to second time point including more fear related to specific dives at the first time point, more attention paid to competition-related concerns at the second time point, and acknowledgement of growth over time related to their experience of fear at the second time point. Results from the SAS-2 varied across participants over time including two whose scores increased, two whose overall score remained the same, and six participants whose scores decreased from the first to second time point. See Table 4-1 for participant demographic information and overall results from the SAS-2.

Table 4-1

Participant Demographic Information and Sport Anxiety Scale - 2 Results

\begin{tabular}{|c|c|c|c|c|c|c|c|c|c|c|c|}
\hline \multirow{2}{*}{$\begin{array}{c}\text { Participant } \\
\text { (pseudonym) }\end{array}$} & \multirow{2}{*}{$\begin{array}{l}\text { Gender } \\
\text { Identity }\end{array}$} & \multirow{2}{*}{$\begin{array}{c}\text { Religious/ } \\
\text { Spiritual } \\
\text { Orientation }\end{array}$} & \multirow{2}{*}{$\begin{array}{c}\text { Year of } \\
\text { Diving } \\
\text { Experience }\end{array}$} & \multicolumn{2}{|c|}{ Somatic } & \multicolumn{2}{|c|}{ Worry } & \multicolumn{2}{|c|}{$\begin{array}{c}\text { Concen. } \\
\text { Disruption }\end{array}$} & \multicolumn{2}{|c|}{ Total } \\
\hline & & & & T1 & $\mathbf{T} 2$ & T1 & $\mathbf{T 2}$ & T1 & $\mathbf{T} 2$ & T1 & $\mathbf{T} 2$ \\
\hline Adam & Man & Catholic & 6 & 12 & 13 & 12 & 12 & 5 & 5 & 29 & 30 \\
\hline Anna & Woman & Christian & 8 & 8 & 10 & 16 & 12 & 6 & 6 & 30 & 28 \\
\hline Emily & Woman & Christian & 5 & 15 & 11 & 19 & 17 & 10 & 7 & 44 & 35 \\
\hline John & Man & $\begin{array}{l}\text { Catholic/ } \\
\text { Christian }\end{array}$ & 15 & 18 & 10 & 11 & 10 & 7 & 5 & 38 & 25 \\
\hline Julie & Woman & Christian & 10 & 13 & 7 & 18 & 11 & 10 & 8 & 41 & 26 \\
\hline
\end{tabular}


Table 4-1 (continued)

\begin{tabular}{|c|c|c|c|c|c|c|c|c|c|c|c|}
\hline Kevin & Man & Agnostic & 10 & 9 & 9 & 9 & 9 & 5 & 5 & 23 & 23 \\
\hline Katie & Woman & Christian & 13 & 9 & 8 & 14 & 10 & 5 & 6 & 28 & 24 \\
\hline Megan & Woman & Christian & 6 & 6 & 8 & 12 & 10 & 9 & 9 & 27 & 27 \\
\hline Mike & Man & $\begin{array}{c}\text { No } \\
\text { preference }\end{array}$ & 6 & 9 & 13 & 17 & 17 & 10 & 10 & 35 & 40 \\
\hline Nick & Man & Lutheran & 10 & 11 & 9 & 16 & 13 & 10 & 8 & 37 & 30 \\
\hline
\end{tabular}

\section{Time Point 1 Analysis}

Data analysis of time point one yielded five domains: (a) Uncertainty over Dive Outcome; (b) Contextual Factors; (c) Social Influences; (d) Impact of Fear; and (e) Individual Coping Strategies, with a total of 22 categories across the five domains. Following the recommendation presented in Hill et al. (2005), categories were classified as general if they included all or all but one respondent, typical if they appeared in more than half the respondents, and variant if they appeared in $50 \%$ or below of cases.

Considering there were ten participants in this study, a category was considered general if discussed by nine or ten respondents, typical if mentioned by six to eight respondents, and variant if occurring in two to five respondents. Overall, eleven categories were general, nine were typical, and two were variant. See Table 4-2 for a presentation of the data. Analysis of the SAS-2 results are included within the Impact of Fear domain, as participants spoke to experiences consistent with subscales as impacting performance.

Table 4-2

Time Point 1 Domains, Categories, and Frequencies

\begin{tabular}{|c|c|c|}
\hline Domain & Category & Frequency \\
\hline \multirow{3}{*}{$\begin{array}{l}\text { Uncertainty over Dive } \\
\text { Outcome }\end{array}$} & Inherent Risk & General (10) \\
\hline & Fear of Failure & Typical (8) \\
\hline & Fear of the Unknown & Typical (6) \\
\hline \multirow{5}{*}{ Contextual Factors } & Previous Personal Experiences & General (10) \\
\hline & Setting & General (10) \\
\hline & Apparatus & General (9) \\
\hline & New versus Learned Dive & Typical (8) \\
\hline & Dive Type & Typical (6) \\
\hline
\end{tabular}


Table 4-2 (continued)

\begin{tabular}{|l|l|l|}
\hline \multirow{4}{*}{ Social Influences } & Vicarious Experiences & General (10) \\
\cline { 2 - 3 } & Diving Coach & General (9) \\
\cline { 2 - 3 } & Teammates & Typical (6) \\
\cline { 2 - 3 } & Team Atmosphere & Variant (5) \\
\cline { 2 - 3 } Impact of Fear & Mental Performance Coach & Variant (5) \\
\hline & Cognitive & General (10) \\
\cline { 2 - 3 } & Benefits of Fear & General (10) \\
\cline { 2 - 3 } & Maladaptive Impact on Performance & General (9) \\
\cline { 2 - 3 } & Physiological Symptoms & Typical (6) \\
\hline \multirow{4}{*}{ Individual Coping Strategies } & Acceptance and Commitment & General (10) \\
\cline { 2 - 3 } & Use of Psychological Skills & General (10) \\
\cline { 2 - 3 } & Process Orientation & Typical (6) \\
\cline { 2 - 3 } & Using Social Resources & Typical (6) \\
\cline { 2 - 3 } & Avoidance & Typical (6) \\
\hline $\begin{array}{l}\text { Note: } N=10 . \text { Categories are classified as general in occurring in nine to ten cases, typical if occurring } \\
\text { in six to eight cases, and variant if in two to five cases. }\end{array}$ \\
\hline
\end{tabular}

\section{Uncertainty over Dive Outcome}

All participants spoke to the idea that a main source of fear in diving was that they could never be exactly sure about the end result of their dive. Nick described this phenomenon:

Every time you step up there you're kind of like - not a gamble but there's a little thought in the back of your head just kind of like, is this going to go well? I've done it a million times, but this is the millionth and one. I've done it a million times good. That doesn't mean I can't do one bad.

Thus, for even well-learned dives, participants did not feel that they could count on the outcome of any particular dive due to the nature of their sport. The Uncertainty over Dive Outcome domain refers to this experience and to the factors contributing to participants' uncertainty. The term "outcome" referenced both competition-based experiences of judged scores as well as more general views of a dive outcome in practice (e.g., manner of entering the water, execution of particular dive techniques, coach's perception of dive, 
etc.). This uncertainty was viewed as ever present and contributing to a sense of fear, though the specific valence of fear varied. Three categories emerged as central to participants' experience of uncertainty: (a) inherent risk, (b) fear of failure, and (c) fear of the unknown.

Inherent risk. Participants highlighted the inherent risk of their sport as a main source of fear. They described concern related to both more serious injuries, up to and including potential death, and more minor experiences of pain related to smacking on the water. Smacking occurs when parts of the diver's body hits the water for a more horizontal than vertical entry, which can cause pain ranging from minor stinging of the impacted body part to more serious injury such as bruising or concussions. Kevin described believing that many people fear pain in diving: "It's unpleasant. If I have the choice of being in pain and not being in pain, I would always choose not being in pain. Sometimes it's the fact that it could be a long-lasting pain is scary." John, who had an existing shoulder injury, shared fear of more serious injury when competing on platform:

Because the pain - that's one of the things that's - that's where the doubt can come in and suck. Because let's say that I just ripped my shoulder out of the socket. I've still got a whole tower competition to go. How do I find that joking group when I'm in sheering pain and I'm like, “How the $\mathrm{f}^{* * *}$ am I supposed to dive?" Suddenly, you have this dark cloud again. It's like, man, I don't want to die. I don't want to be permanently injured.

Even in previously well-learned dives, Anna noted that "you occasionally do something weird or lose your spot," which can lead to smacking. Participants did not feel as though they could take their physical well-being for granted, as they recognized that there was 
always the possibility of experiencing pain or injury when executing dives. Nick described:

Every time you go up there, there's a risk of doing something bad. There's a risk of hurting yourself. No matter where you're at, there's always a risk of injuring yourself, messing up, and potentially ending your life. I mean, that doesn't happen often but there's always that right.

This consistent potential for injury was connected to the inherent risk that athletes described as integral to the nature of their sport due to the challenge of executing all components of a dive in a correct manner. Emily discussed how, in her experience, hurdles are very challenging:

No matter what you do, whether it's a simple hurdle, it's not really even simple. Hurdles are harder that actuals dives, I feel, because everything -- it feels like you always have, I mean, to be super precise. And if you don't do it right, then you whole dive is going to be messed up which is pretty much true in some sense because if you're a little off to the side on the diving board, it will fling you off to the side and it will make dives harder. So I'm always nervous.

As even seemingly simple skills could go poorly, participants also described experiences of fear specifically related to not being able to depend on how a dive would go. In another manifestation of uncertainty, participants discussed concern over the outcome of their performance and how they would be evaluated by others.

Fear of failure. Participants described feeling pressured to perform well in competitions and worry over disappointing people in their lives with poor performances including coaches, teammates, and parents. Several participants noted pressure increased 
over time, as they did not feel an expectation from coach to perform well or contribute points to the team as freshman. Mike shared how Coach “doesn't expect anything from us" as freshman and "you're just figuring out how to do college and be a D1 athlete." This sense of pressure and resulting fear of failure increased as they became older and more experienced because at that point, as Mike described feeling, "I have to start contributing points to the [Conference Meet] and stuff and it's just kind of a big pressure that I don't know how to handle yet."

Katie discussed how this fear of failure was connected to concern over letting others, like teammates, down, but also her coach. She shared that "I know it's not true but it's like 'He loves them more because they dove better." Julie elaborated on this idea further, noting how comparison to others was an inherent part of the sport and easy to do given that many people compete the same dives:

I also think it's more of a fear of being compared to other people. I know [Coach] doesn't put us-- rank us in his eyes. But I think it's just hard to-- It's like you have all your teammates, we're all doing the same dives and you're essentially-- I mean, you are being compared just because that's how diving is. Right. So I think that's like the fear, I don't mind too much everyone watching, because it's like if you mess up, it happens, so it's more just like, kind of almost where do you stack up against everyone, which I don't think anyone really wants to think about but, I mean, everyone does.

This concern over how one compares to divers from other schools was also described. Anna, who reported specializing in tower events, discussed how self-comparison to other 
divers and concern over letting others down negatively impacted her performance in the NCAA Zone meet:

I was putting a lot of pressure on myself to make NCAAs and that was, I think, the worst tower meet of my life [laughter], because I put way too much pressure on myself. I was so anxious about how everybody else was doing. I had a really good diver in front of me and when you're up on tower, I had a hard time not watching her and you hear her rip because - I don't know - she just has a super loud rip. She's very good and I hear the crowd go crazy and that made me super anxious because we had the same order as well. So I was doing the same dive right after her and I knew I couldn't do it as well as her. I just haven't-- I don't know. I'm just not quite as good as her so that gave me anxiety too, like, 'Mine's not going to be as good. I need to do mine as well as hers,' type of thing, so I was very much comparing myself to her and that got me really anxious.

She further shared how, given she was a tower specialist, she worried over "letting my coach down because I should [qualify], or letting my team down because they were all doing really well” if she did not qualify for NCAAs that year. In general, participants clearly described concern related to the negative impacts of failure such as disappointing others. Another source of fear, which was less clearly defined but also seemed present across participants, was specifically fearing the unknown aspects of diving.

Fear of the unknown. In describing their source of fear, participants specifically feared injury or experienced anxiety over not performing well. However, participants also experienced a more general sense of fear connected to the unknown aspects of diving. 
Kevin noted that "sometimes I'm afraid, but I don't know why" and further elaborated on the idea that he was aware something could go wrong when diving off tower:

The fact that I have to leap off of 10-meter and sometimes don't even know how it's going to end up, which is silly to think for me because I normally know how I'm going to land or not necessarily know but it's a very rare occasion that something goes wrong for me. But I think the fact that something could go wrong still was the fact that scared me. [...] It was just the uncertainty knowing that it could happen is what made me uncomfortable.

Nick agreed with this, noting that the "fear that I have is usually just the unknown" and that he fears the unknown because "I don't know what's going to happen."

Several participants described fear of the unknown in connection to trying a new dive for the first time, since they had not executed that exact motor pattern from the particular height before. Katie shared that, when learning a new dive on tower, she worried over what may happen when trying the new dive "because it's not muscle memory yet. It's not ingrained. So it was just all these what-ifs." To help with this lack of certainty, she "had to do a million buildups" so she could "know exactly what this was going to feel like before I can even go up to 10 meter to do it." Emily expressed similar sentiments, noting how even adding "a half more rotation" to a dive could lead to negative thoughts worrying over what if specific events occurred. She summarized "it's a fun concept in diving, I feel [laughter]. You're always kind of - it's the unknown."

Overall, participants described a number of factors connected to their general sense of uncertainty over the dive outcome including inherent components of diving such as the potential for injury, uncertainty over how new dives will feel, a sense that 
something could always go wrong even in well-learned dives, and fear of failure.

Although the presence of uncertainty was consistent across participants, participants also described a number of contextual factors that influenced their sense of fear and its impact on their performance. These factors are described in the following domain.

\section{Contextual Factors}

As described above, a level of uncertainty and fear of injury was seen consistently across participants. In examining this uncertainty deeper, participants described a number of contextual factors related to the dive scenario that influenced the level and type of fear experienced by athletes including a divers' own history of attempting the dive, factors connected to the dive itself, and the setting in which the dive was executed. Five categories emerged when examining various contextual factors: (a) previous personal experiences, (b) setting, (c) apparatus, (d) new versus learned dive, and (e) dive type.

Previous personal experiences. All participants described how previous experiences of smacking or hurting themselves on a dive significantly influenced their experience of fear on that dive in the future. A number of participants described smacking when attempting a new dive, which increased their sense of fear when continuing to learn the dive or when attempting the dive in the future. For example, Anna described getting lost and smacking in a lead-up for a new dive from the 10 meter platform:

I think one of my biggest fears right now is learning a new back twister on 10 meter because I got lost in the lead-up and smacked and now I'm very scared of ever doing that dive because I'm scared that I'm going to get lost again. I had absolutely no idea where I was when-- I didn't know when I was going to hit the 
water. I didn't know how I was going to hit the water [laughter]. It was terrifying and that was only off three meter. I'm absolutely afraid to do that off 10 meter. This experience of fear could also influence dives after they had been well-learned. Nick described experiencing anticipatory physical sensations when attempting a back dive with two and one half flips from the five meter platform because he had previously smacked on that dive. He shared that this was because "you've done it bad once, it can happen any time now." Julie elaborated on this point when discussing fear that arises whenever she was attempting a reverse dive with two and one half flips in the pike position:

I really have no reason to be afraid of it because I know I can make it. I'm never close to the diving board. But I struggled with it in the past. And it was a really scary dive for me. So I think it's just part of my brain is like, "You're scared of this dive." Yeah, I guess I've gotten better than if I was just-- because it used to be really hard for me to make in the past. It's like, "I'm fine now. I think that little piece of me is still remembering--

Thus, participants who previously experienced fear related to a dive were more likely to experience fear on that dive in the future. In addition to participants' own experiences with the dive, the setting in which divers were executing the dive also impacted fear.

Setting. The type and intensity of fear varied across participants based on the setting in which they were completing the dive. Setting in this context referred to the environment in which athletes were performing the dive (e.g., practice, competition, level of competition). In general, participants described experiencing more fear of injury when in practice settings and more comfort with dives but increased fear of failure when in competition settings. Katie provided a representative overview of this: 
Competitions are very different than practice. [...] Okay, more in practice, like the anxiety and fear is more of like the unknown. Like the injuries and stuff, but by the time I get to the competition, I'm like, I'm so well prepared. I know what I'm going to do. I feel like I know how to do these dives, but then the competition fear is more like the performance fear.

In competition settings, participants discussed experiencing a sense of fear of failure and a desire to perform well and to contribute to their team. Two participants noted the experience of doing a dive for the first time in a competition as a potential exception to experiencing primarily fear of failure in competition, as John said the "feeling of doing it the very first time ever comes right back" when first competing a dive. Nick also described an experience of trying a dive for the first time in competition shortly after learning it, and he described feeling a high level of fear prior to executing it. In describing a type of fear unique to competition, three participants identified balking in a meet as a specific source of fear since they did not want to receive a two-point deduction from their dive score.

Several participants described differences in intensity of fear from practice to competition. Kevin shared that he was "more nervous than I am afraid" at competitions, which felt like a "step down from fear." He reported that "intensity is the main thing" that separated his experience of fear from practice to competition. Megan expressed similar thoughts, noting that she tended "not be really scared" of dives in competition, and rather she felt "like I get nervous in competition" that she "is not going to do well, not because I'm scared of the actual diving." 
The experience of fear in competition settings also varied based on the level of competition, with more fear or anxiety connected to conference meets, the NCAA qualification meet (e.g., NCAA Zone Meet), NCAA championships, or USA Diving national competitions. Participants reported less fear connected to dual meet settings comparatively. Nick reported that he can "control myself at smaller meets - anything up to nationals I can usually get around it" but tended to doubt and question himself more at nationals. Julie said how the atmosphere of the meet itself changed and could influence her performance at different settings:

If it's just a dual meet, everyone's just kind of relaxed and hanging out and having a good time that, I don't know, you know what I mean? It makes me less nervous versus at the zone meet, everyone's really intense and no one's talking to each other, and I feel like, oh, this meet's really serious. I need to do well. That will raise my fear of how I perform and where I'll end up. Participants' experiences of fear varied based on the demands of the setting they are performing the dive in. An additional contextual factor impacting fear was the type of apparatus on which athletes were performing the dive.

Apparatus. Height and type of apparatus played a large role in participants' experiences of fear. To provide context, all participants within the sample trained on all three apparatuses at one point in their career (e.g., one-meter springboard, three-meter springboard, and platform). Thus, all had experience learning new dives and executing dives at each level. In general, the higher the apparatus was, the more fear the participants reported experiencing when diving. They described low levels of fear connected to performing on the one-meter springboard, slightly more fear connected to the three-meter 
springboard, and the most fear related to diving from the 10 meter platform. There were several variables participants described in contributing to this increased fear including increased pain if one smacked and increased potential for serious injury from higher heights. Adam clarified that, in his perspective, it was not necessarily the height itself that led to more fear but "being afraid of falling off the height okay" because "if you mess up it's going to hurt a lot worse than 3-meter or 1-meter." Outside of height, Emily also described the stability of the surface as an intersecting variable with height:

Yeah. I have more anxiety on platform than I do on springboard in a height sense. But more anxiety on springboard than platform when I'm doing a dive. If that makes sense? [...] Because pretty much on the platform, you're in control of everything. Because it's a hard concrete thing. Whereas springboard, if you're off the side a little bit or you're too far to the end, then you've kind of messed up. Kevin, who experienced a hand injury due to training on platform, spoke to how the increased height of platform meant that athletes were not able to train their dives as much or become as comfortable with them due to the strain on one's body:

It's also a lot easier on springboard to get a lot more reps in just because of the physicality of platform, because you can't do a whole lot of it or else this happens [referring to hand injury], and you break a bone, so. And it's just like, platform you can't do as many repetitions. But when I'm on springboard and I do a dive that I'm uncertain with, the more that I do it, the less uncertain I become, and the less afraid I become of it.

Height and type of apparatus were factors in influencing the level of emotion experienced; however, as Kevin noted, the number of repetitions that a diver has in doing 
a dive also played a significant role in their experience of fear. Emily also alluded to the next category that emerged from the data, as she reported that "learning new dives is terrifying, especially on 10 meter."

New versus learned dive. Most participants reported experiencing more fear when attempting new dives or dives with which they had fewer repetitions. They reported experiencing less fear when executing more well-learned dives. Julie shared that learning new dives on tower in particular was scary, to the point where she was "shaking and kind of nauseous" because she was "so afraid of the dive." Even for a diver who considered tower her specialty, Anna noted that she "learned an entirely new list" since coming to college and "it was super scary to learn every single one."

Two participants reported that it was particularly challenging for them to attempt new dives if the dive did not feel like other dives they had done before. In learning a twisting dive from the 10 meter platform, Katie shared that "most dives kind of translate" from how it feels on one meter to three meter; however one dive "was something I'd really never done before" on any level, so it took her several years to overcome fear and attempt the dive. Megan also described fear related to learning a new dive that "hasn't felt like any other dive," noting that she was "so scared to do it" and took several months for her to execute the dive.

In an intersecting contextual variable, one participant described differences in his willingness to learn new dives on springboard compared to platform due to the level of fear he experienced. Kevin was learning a back dive with three and one half flips from the 10 meter platform, but he ultimately never attempted the dive due to his level of fear: 
The noticeable fear things when I'm on springboard are when I'm learning a dive. Just because I've never done it before. So it goes back to the uncertainty thing. But I think it's a lot easier for me to see benefits of doing something I'm uncertain with on springboard compared to platform for me. I can see the benefits of a reverse $3 \frac{1}{2}$, and how the DD (degree of difficulty) and can help me out in the long run for diving, and my placement and execution in a meet. Whereas on platform, I knew, yes, if I did a back $3 \frac{1}{2}$, it could have helped me out in the long run, but the fact that I'd have to go up there every single time and be afraid of it again, and again, and again. I didn't want to go through that, so I didn't do it. The emotional toll that fear could have on an athlete was often intense when learning a new dive. Another variable that could influence level of fear when learning a new dive, or an athlete's sense of fear in general, was the specific type of dive being attempted. Participants described differing experiences of fear based on the dive group being attempted as described in the following category.

Dive type. The final contextual factor that was found to influence fear was the specific category of dive that divers were executing. Participants noted they experienced more fear when attempting dives from specific categories, though the individual category identified varied across participants including back dives, gainer dives, inward dives, and twisting dives. No participant described experiencing increased fear or uncertainty connected to front dives. Mike shared that "I'll have a group of-- like a diving group, like gainers or inwards, just a direction and I kind of have a mental block around that whole thing." Gainers, in particular, seemed to be a category in which participants experienced more fear. This was connected to the physical mechanics of executing the 
dive, as described by Mike: "From the get-go, gainers scared me. Just the fact that I'm jumping forward but spinning backwards and-- mind blown, that doesn't work." Some participants also noted fear of hitting their head or legs on the board when completing inwards, which led to them experiencing more fear when doing inward dives. However, some participants, like Anna, were unable to articulate why a specific dive group was scarier: "backs have always been my scariest group to learn. I don't know why, I've just been really terrified of them."

In general, a number of contextual factors related to the dive itself and to the environmental setting influenced divers' experiences of fear. Participants tended to experience more fear when diving from higher heights, performing dives with which they had negative experiences, competing in higher pressure situations, and attempting dives from specific categories or with which they have less historical repetitions. Another factor that emerged as significant in impacting participants' emotional experiences was that of the social influences around them. The manner in which fear was presented and discussed, or not discussed, among members of the athletes' social environment also played an important role. This factor is explored further in the following domain.

\section{Social Influences}

Athletes identified a number of different social influences that impacted their sense of fear either positively or negatively. Five categories were present within the data when identifying social influences on athletes' experiences including (a) vicarious experiences, (b) diving coach, (c) teammates, (d) team atmosphere, and (e) mental performance coach. 
Vicarious experiences. All participants in the sample described occasions where they experienced fear vicariously as a result of learning about others hurting themselves through personal observation, virtually via media sources, or through conversations with others. Participants described numerous examples of seeing someone else hurt themselves in person including hitting the springboard, hitting the tower, and smacking on the water. The level of fear that participants experienced or ways in which it impacted them varied, as some participants noted feeling more fear if observing someone hurt themselves on a dive that the participant also competed. For example, Adam described experiencing fear after watching someone hit their hands on a reverse dive in competition, which increased his sense of fear and led him to "play it safe" on his reverse dive. Also, two participants noted feeling more fear if the injury observed was one that they individually worried about such as hitting their feet on the tower when completing inward dives in a pike position.

While participants mainly described vicarious experiences as increasing sense of fear and as negative, two participants noted a positive experience of learning through others' experiences. For example, Megan shared that she often felt frozen when doing an inward dive on platform. She observed someone do a different kind of back press, and she decided to change her technique to help her leave the platform on the dive. Katie described feeling motivated when watching another diver, who she knew was terrified of diving from 10 meter, just step up to the platform and go. She shared that "we were learning dives kind of at the same time, and so it was like, she's doing it. I want to stick with her and follow on with her." Thus, the experience of observing another diver's fear did not increase her fear, but rather served as motivation since the teammate was willing 
to do dives in spite of her fear. In general, it was clear that numerous people could be sources of vicarious experiences that contributed to participants' sense of fear. In considering other specific social influences, the individual's diving coach was identified as a primary person who significantly impacted fear.

Diving coach. Participants' experiences with their coaches varied based on the coach's style of managing and discussing fear. Participants in this sample primarily discussed their current collegiate coach as a positive influence in managing and accepting fear, though noted mixed experiences when discussing previous club and high school diving coaches. Individual experiences with coaches varied based on previous experiences, thus results in this category are presented thematically.

In discussing their current collegiate coach [Coach], participants described his style in discussing fear as helpful and supportive. They discussed various elements in how [Coach] supported them including openly discussing fear, recognizing that fear would exist, encouraging divers to accept fear, and asking divers to focus on the sense of accomplishment they would have after doing a dive. There were also numerous behaviors participants identified that [Coach] did which indicated his willingness to work with participants to manage fear, including comfort in divers asking to do more lead-ups, having a structured program to build up dives, and willingness to engage in discussions with divers about fear to help them understand their source of fear and to overcome it. Several athletes described a general sense of comfort with [Coach], as he was viewed as willing to engage with each individual athlete in helping them learn how to best manage fear. 
Trust in [Coach]'s knowledge was also identified as important, as several participants noted that "sometimes you just have to trust your coach over your own instincts." Adam was another diver who spoke to this point, noting that "coach isn't going to put you up there if they know you're going to do bad. They don't want you to get hurt or anything." Thus, athletes also used the coach's expertise as a source of comfort to themselves that they were ready to execute a dive even when scared.

Related to experiences with previous coaches that were identified as positive or helpful, athletes described similar sentiments as with [Coach] including allowing athletes to build dives up correctly, taking time to learn dives, teaching coping strategies such as deep breathing, trusting in their coach, and encouragements to execute dives quickly rather than standing on the edge of the board..

Participants also identified coaching behaviors based on experiences with previous coaches that were viewed as increasing fear or not helpful in managing fear. Several participants described experiences where divers were asked to do dives before they were technically ready due to lack of practice structure, prioritizing learning "hard dives" over technique, or generally not trusting the coach's opinion. This often led to negative experiences when attempting the dive and increased fear. Nick's previous coach provided inauthentic advice, as the coach would discuss how "fear doesn't mean anything" and "pain is just weakness leaving the body." Nick disagreed with this, which made it challenging for him to connect with his coach's advice. Finally, several participants noted negative experiences connected to coaches who generally did not discuss or address fear. Katie described this, sharing that “everyone who's a coach, everyone knows there's fear in diving" but previous coaches would discuss fear by 
saying things like "I hear you're afraid, but everyone's afraid, so sucks. These are the people doing it, and they're afraid, so you've got to do it." Katie noted this was unhelpful because they focused on "pushing through it, instead of working through it." In sum, participants generally viewed coaching behaviors of talking about fear and working with divers individually to manage fear as positive. Coaching behaviors that were seen as unhelpful included not acknowledging fear, asking divers to execute dives before they were technically ready, or minimizing divers' experiences of fear.

Teammates. In addition to the coach, teammates were also described as having an influence over experiences of fear; however, the manner in which teammates were utilized in discussions around fear differed from that of the coach. Participants reported that, in general, they did not engage in deep discussions about fear with teammates. Anna preferred not to discuss fear in depth with teammates "because when we go into deep discussion about it, while it's good sometimes, it sometimes gets me thinking too much and I feel like if I think about it too much, I end up doing something weird or funky.” Instead, teammates were viewed as primarily providing emotional support to athletes when scared. Katie also spoke to how discussing fear with others made her feel less alone, as she realized that others have felt similarly to her. In total, four participants within this sample spoke to using teammates as sources of social support and, in what may be of note, all four of these participants identified as female. Nick spoke to teammates in connection with fear, and he discussed how "most of the guys, I want to say, are pretty good about hiding" signs of fear and that he could not often read his teammates well. No male-identified athlete spoke directly to using teammates as a source of emotional support when fearful within this sample. Within the athletes who spoke to 
using teammates for support, gender of the athletes from whom they sought support was not specifically identified. However, although male-identified athletes did not speak to the use of teammates for emotional support, several did discuss how the general team atmosphere could impact their own experience.

Team atmosphere. Beyond receiving specific support or instruction from teammates, some participants also identified how the general atmosphere of the team on a given day or time influenced their own sense of fear. Julie described how the "emotions in the people around me" influenced her own fear. She reported feeling more relaxed or happy if others around her were relaxed and more tense or nervous if, at a meet for example, “everyone's really intense and no one's talking to each other.” Three participants in total discussed the connection between how a positive social atmosphere increased their own excitement and decreased their sense of fear. In discussing the meet atmosphere, Adam shared how his experience was positive in a meet when teammates were "all jacked up and super supportive," as he was "super jacked up and all on adrenaline" and "it was just fun.” A positive environment could help Adam regain confidence after smacking in a meet as he can "get back up real fast." John discussed how this atmosphere could increase his and his teammates' motivation to try new dives in practice:

What I really liked about our team is we've got so many different personalities and everybody's weird in their own way, and we found a way to really get along and communicate well with each other. And when you can find that perfect niche. When everybody is like-- everybody is kind of giving each other the eye of like, "You're about to do some crazy shit?" "I'm in." And so suddenly, your team has 
become that crazy group on 10 meter. And that, at least for me, is when fear melts. And you start to notice that everybody's fear melts.

The social atmosphere of the group could play a role in positively impacting athlete's experience; however, other scenarios in which the team atmosphere could negatively influence athletes' individual experience were also discussed. For example, when asked to complete a new drill, Julie described how "if everyone's freaking out, like, 'Oh my gosh, I'm so afraid. I don't want to do this.' Again, the atmosphere is like everyone's going to get kind of afraid.” Megan went further to discuss how teammates not completing dives or standing on the ten-meter platform could create a team atmosphere of others not executing their dives or avoiding dives. Megan further elaborated on this, noting that on occasion it was better for some to "just go home" if there were days in which they were not attempting their dives "because then they're not hindering everyone else's practice." John also noted that "when one person shows up to practice with a shitty attitude, it ruins it for everybody, it really does." In general, the attitudes of teammates were seen to impact the participant's individual experience. John, in particular, spoke to intentionally trying to create a more beneficial team atmosphere as fear can "be a useful device for motivating teammates" in practice because "you've just created a standard for your teammates to follow" when they know you're afraid and execute a dive anyways. In sum, the emotional atmosphere created by teammates could serve to either benefit athletes in managing fear or increase a sense of fear within them.

Mental performance coach. In addition to their diving coach and teammates, five participants also spoke to the role that the mental performance coach had in influencing their experience of fear. Within this context, participants predominantly 
spoke to how the mental performance coach (MPC) had discussed fear with them and helped them develop skills for managing it. Adam noted how [Coach] would encourage people to meet with MPC if they were fearful, and that he "would rather go talk to her [MPC] if I have a fear of something" because "she specializes in that." Participants described working with MPC as a generally positive experience. In discussing what was helpful, participants described benefits of discussing what they were afraid of, creating game plans for managing fear, and revising approaches as needed. Megan appreciated how MPC acknowledged that "you have a fear and it's obviously going to be rational, maybe sometimes irrational, but she makes the point that we can do it things even if we are scared" which was a better approach "than just pretend [fear]'s not a thing." Katie, Anna, and Julie spoke to the process of evaluating what would work for them individually in managing fear and continuously revisiting this plan. Katie felt MPC was "empowering you to remember things that have helped. [...] So that you can game plan" because otherwise she would feel " $100 \%$ negative" and believe "I'm scared, I can't do it." Similar to the teammate category, four of five participants who spoke to this category were female-identified. In general, no participants spoke to negative experiences connected to working with the MPC.

Overall, the participants described numerous ways in which members of the participants' social environment affected fear. Fear increased through observing fearful events in others, through having a negative team atmosphere, or through coaching behaviors such as sending athletes up before they were technically ready to attempt a dive. On the other hand, social influences could also positively impact through individuals such as the coach, teammates, or MPC providing support. A positive team 
atmosphere helped by motivating others to try new things and generally leading to having more fun. To this point in analysis, the experience of fear has been explored including factors participants viewed as leading to fear or influencing their level of fear. At this point, ways in which fear was described as impacting the individual is discussed.

\section{Impact of Fear}

Beyond the level or quality of fear, participants also spoke to the psychological, emotional, and behavioral ways in which fear could impact them and their performance in diving. Four categories emerged through this analysis including, (a) cognitive, (b) benefits of fear, (c) maladaptive impact on performance, and (d) physiological symptoms. Results from the SAS-2 (see Table 4-1) are addressed within this section based on where the subscale fit best within the data. Thus, the somatic subscale was discussed within physiological symptoms. Worry and Concentration Disruption were addressed within the cognitive category. As a reminder, overall scores on the SAS-2 could range from 15-60, which higher scores being associated with higher levels of anxiety. Normative data for college-aged student athletes included an average score on the Somatic Anxiety subscale of $9.78(S D=3.61)$, on the Worry subscale of $12.12(S D=3.85)$, and on the Concentration Disruption subscale of $6.93(S D=2.37)$. Average total score for collegeaged athletes was $28.83(S D=8.05$; Smith et. al, 2006).

Cognitive. The primary way in which participants discussed cognitive impacts of fear was by experiencing worry. Participants described experiencing numerous "what if" type thoughts when experiencing fear, the topic of which varied by participant. Topics of worry discussed by participants included being on the wrong dive, balking on a dive, hitting the board, going short on dives, comparison to others in the competition, and 
general worry when diving from the tower. In considering the results of the SAS-2, worry was generally the highest subscale for participants with the exception of one diver who scored highest on physiological and one whose somatic score was tied with the worry score. This was consistent with normative data, which generally described worry as the highest scoring subscale. Kevin, whose scores were tied between worry and somatic symptoms, primarily described worry in the context of tower diving. However, he was no longer able to dive tower due to injury, and he described that "the fact that I don't have to worry about that is a huge relief off my shoulders."

These "what it" types of thoughts were also connected to a sense of distraction for some participants, as several participants discussed how their focus was not in the correct place when experiencing fear. For example, Adam discussed that he experienced vicarious fear after seeing another person hit the board, after which " $85 \%$ of my mind was thinking, "Let's not hit the board because that would not be fun."” Emily also discussed how fear can lead to her "thoughts racing," "overthinking" her dives, and thinking too far head in her dives. She described:

I failed a dive because I was kind of tripped up and I didn't really think about in the now. And I kind of was just focusing on the dive because I'm like, Oh, I failed this last time. I have to make it this time, so. I ended up thinking too far ahead, to where it would have helped.

Katie discussed how fear can make her lose focus on making a technical correction because 'I'm scared and my focus isn't on making that correction necessarily because I'm too scared to do it." In looking at the concentration disruption subscale of the SAS-2, 
Emily was tied for the highest score on this category among her teammates; however, Adam and Katie were among those tied for the lowest score on this subscale.

While worry and the potential resulting distraction was the primary cognitive impact noted among participants, other experiences were also described within the interviews. Several participants discussed how fear made them "not want to go" on dives. Adam expressed that "if the dive is scary enough, you're just like, 'I don't want to do this at all."” Megan noted how this can be brought up by other people as well, as seeing teammates stand on the tower all practice "makes people think more about doing that." Additionally, two participants discussed how fear leads them to believe they cannot do the dive on that day. Mike and Nick described mutual experiences in trying to learn new dives at the same time. Nick's level of fear led him to feel like he was not in the right "physical condition" or "not in the right mindset" to do the dive, which led him to think "I can't do it. I've got to step back. I can't do this dive today." Mike "grouped myself with [Nick] and was like, 'yeah, I can't do this' instead of just being like 'I got this. That was just one smack." This serves as a potential example of what Megan discussed in her quotation above, as one person's belief in their ability to do the dive was impacted by another's experience of fear.

Several participants described beneficial cognitive experiences that occurred, including Julie who described increased focus and motivation at times when scared and Emily who felt fear made her work "smarter" when executing dives. Further experiences of benefits of fear are discussed next.

Benefits of fear. Participants identified specific ways in which they found fear to benefit them either directly or indirectly. The predominant experience that participants 
spoke to as a benefit was not necessarily fear itself, but rather the mental and emotional reward experienced from overcoming fear. Five participants spoke to experiencing an increased sense of confidence or another positive emotional reward after they executed a dive when scared. John described that "conquering the fear, that's my high" and "there's an adrenaline rush like no other" after successfully completing a dive of which he was scared. He later stated that he gains "new found confidence from facing fear not from fear because that's what all of this comes from it-- facing fear." Anna reported a similar experience to John, as overcoming fear in diving "definitely gives me more confidence to know that I was terrified to learn all those 10-meter dives, but I was still able to.” For Katie, facing bigger fears increased her confidence in being able to complete other tasks when feeling scared:

It shrinks other ones, I guess, in comparison because it was like, 'That one was so big and I did it, and this one's so much smaller.' The size of the fear feels smaller, so if I did this one, I can do this one too.

Thus, although fear itself was not viewed as directly improving performance in this case, the ability to successfully dive with fear was seen by participants as increasing their confidence and capability with managing fear in the future.

Participants also described several ways in which fear could directly benefit the execution of the dive including increased focus, increased physical capability, more motivation to execute dives, and physical safety. Related to focus, three participants spoke to how fear increased their level of focus on executing technical components of the dive correctly. Adam described experiencing "laser beam focus" on getting the "perfect start and kick out" on one occasion, which led to good execution since "it's hard to mess 
up if you're so focused because you're so scared." Emily experienced increased focus on reverse dives in particular. Reverses were "actually one of my best dives, too, though. Probably because I try so hard to focus on it and try to make it as good as I can." Related to competition, Julie's nerves "allows me to be more focused and more zeroed in on what I need to do because I'm anxious or nervous, and it'll end up helping me dive better." Beyond increased focus, three participants also spoke to other physiological impacts of fear and how these could help in diving. Increased strength and physical ability due to biological fear responses could be harnessed if the participant was able to successfully channel the emotion into performance. John summarized this:

A lot of time the whole point of fear is that your mind is racing is like, "Oh, my God. All those things are gonna happen." But if you can use the fear in a way that you're up there, your body's on 500, level 500, you're like, [sound effect], but your breathing really fast, [breathing sound], and your mind slows. Suddenly you have a body that's operating at a higher capacity if you're doing things then it'll be in slow motion so if you can find a way to channel it.

Adrenaline could give Julie that "little kick, so like special superpowers" that could "make you jump higher, spin faster" than she would typically be able to without the fear.

Three participants also spoke to fear leading to a sense of motivation. Emily's fear "makes me want to do it to prove everything that was in my head wrong." Megan also described fear as a motivation to do a dive in practice because she did not "want to leave practices scared of dives." She "does not want to leave practice not doing" a dive “because you're like, if I do one then maybe I won't be scared next time." While those two participants spoke to a fear of the unknown or injury leading to motivation, Julie 
described how fear of falling behind her competition served as a motivation to learn new dives herself. This fear was "almost like a challenge that makes me want to train harder" so she can "be the best that I can be."

Finally, one diver spoke to safety as a benefit of fear. While other participants spoke to how changes to technical executive based on fear often negatively impacted the dive, which is discussed in the maladaptive impact on performance category below, it is of note that sometimes fear led to appropriate technical changes to maintain safety. Kevin was the only participant who mentioned in this context, noting that fear could be a motivation to change technique in order to make himself safe because "if I kept doing something wrong, it was going to hurt me." He believed there were occasions where fear was adaptive in motivating technique changes to ensure safety. However, other participants also noted that fear can also lead to inappropriate technical corrections when not needed. This phenomenon, among other impacts, is described in the following category.

Maladaptive impact on performance. When discussing how fear impacted performance, participants most often spoke to this as a negative impact. John believed "fear really doesn't do anything to help" in diving. In speaking to performance fear in competition specifically, Katie said that fear “doesn't help me in any way, shape, or form. Ever. That just hurts you." Participants reported a number of different ways in which fear could negatively impact their performance including technical execution of dives, not doing dives, not achieving potential, and generally leading them to perform negatively.

Nine participants spoke to fear leading them to execute technique in a different way that was needed for proper execution. Anna shared that, if she thought about fear too 
much, she "end[s] up doing something weird or funky that I wouldn't normally do." Participants described different ways in which fear negatively impacted technique including being cautious in the dive, jumping out further into the pool, not putting full effort into a hurdle, not spotting appropriately, and coming out of dives earlier than they should. Several participants spoke to pushing dives further than necessary into the pool as a common fear response, since they did not want to hit the board. After seeing someone hit their hands on a reverse dive in competition, Mike "definitely played it safe" on his reverse dive by “not putting all my effort into my hurdle so I didn't jump as high and I kind of jumped out further." Kevin also shared a similar experience: "when I first see something happen to someone else, I do what I know will avoid it happening to me." He reported that he would slowly correct his technique to bring himself closer to the board as he became more comfortable with the dive again.

Nine participants spoke to either personally or observing others not going on dives, delaying dives, or putting off dives completely due to fear. Mike observed this in a teammate, who he felt was ready to execute a new dive:

They'll also make up excuses not to do the dive. So I see that a lot, too, $[\ldots]$ he [his teammate] would just be like, "I'm not ready," and he'll step down, even though he's so ready for the dive, to do it, but he's so scared that, I don't know, I can see him doing it. I don't know if he can, but he'll just be like, "Not today." And he just won't do it and be done. So just getting out of practice and skipping that dive.

Adam described this in himself when growing up in diving, noting that if he "stood up there for longer than 30 seconds, [he] wouldn't go" due to starting to think "about all the 
fear of smacking or doing bad." Katie felt frozen on occasions, even if she knew she was going to be safe when trying a new ten-meter dive. She "could not get [her]self to go" and "it was this weird physical block." She noted that "as soon as my feet were on the edge, I was like 'I can't move. No, I'm not going to go. I can't do it.” Katie also shared that, even if it was a dive she had previously done, there were days where she did not feel as though she could execute it:

Yeah, that's stupid. I did this dive yesterday, I did like 20 of them and it was okay. But for some reason, today I just can't get it off and I don't know why, which is also a weird thing that I don't understand.

Megan also described difficulty going on dives on occasion. After smacking on an inward dive from tower, she was "scared of the dive for months" and could not bring herself to attempt the dive again for several months. She reported that this ultimately led her to not compete the dive that season, though she later did learn the dive again.

While most participants spoke to not going due to fear as a maladaptive performance impact, there also were times where participants felt that listening to that fear response by not going on the dive was needed to maintain safety. Anna described an experience of not going on one dive, but she expressed that this was likely a safe decision for her due to her level of fear in that moment:

Being terrified, I feel lightheaded, I feel like I'm-- tunnel vision shaking, terrified. I've only felt it-- I've only ever felt terrified on that one dive so far in my career. I think no matter what I would've done-- even if I would've done that dive right mechanically, I would've freaked out in the middle of it. I would've freaked out in the middle of it. I would've done something wrong even though I have all the 
mechanics to do it and I would've smacked. Being terrified is-- you don't really have a chance.

Thus, she felt as though there was no chance of successfully executing that dive on the given day. Therefore, she felt it was best to not attempt the dive.

Four participants spoke specifically to ways in which fear led them to not reach their potential as a diver or as negatively influencing their training progression. For example, Anna discussed how fear can lead her to "jump really far out" when executing inwards and reverses on tower, and so she was "slowly working on that" and "getting to where it looks good." This had "definitely set my training back from where it should be." Kevin's coaches saw a lot of potential in him as a platform diver; however, he "wasn't able to get over my fear to ever get a full 10-meter list" which "kind of hindered me in that I don't really know my full potential up there." His fear was so present on platform that he did not often want to dive from platform as a result, so he did not "really care about the fact that I don't know my full potential up there because I would rather focus on the things I like doing” [e.g., springboard diving]. Katie also spoke to not reaching her potential on platform, stating she "physically can't make myself do" dives at times and that "it's frustrating and so I feel like it holds me back." A part of her wondered "if I wasn't afraid, what could I have done?"

Finally, three participants discussed how they generally performed negatively at competitions as a result of fear. Anna expressed how performance fear and comparing herself to others led her to have "one of the worst tower meets of my life" because she "put way too much pressure on myself." Adam smacked hard in a meet on one occasion, which "shook [him]" and then he "dove really bad that meet" as a result. Overall, there 
were several ways in which fear was viewed to negatively impact performance in practice and in meets. This included not executing appropriate technique, avoiding or not going on dives, feelings of not reaching potential as divers, and generally believing they performed poorly as a result of fear. One aspect that also could influence dives negatively, such as technical execution of the dive, was the physiological symptoms that arose when experiencing fear.

Physiological symptoms. Six total participants spoke to the specific experience of physiological symptoms when experiencing fear. Five out of these six participants also had the highest scores among the participants on the Somatic subscale of the Sport Anxiety Scale - 2. Physical symptoms described by participants include lightheadedness, racing heartbeat, nausea, narrowed vision, and physical shaking. John, who scored highest of all participants on the SAS-2 (see Table 4-1), spoke to the experience of fear leading to physically shaking due to adrenaline "because your body has a natural reaction when you become afraid. It's jack up the heart rate, send adrenaline, you're going into battle." He later joked that this could impact his execution because "if you can't do the first thing right because your legs are shaking like a Polaroid picture [laughter], then you've got no chance.” Nick experienced several different types of physiological symptoms including "feeling a little heat" on his back in anticipation of a potential smack," his "stomach starts turning, and "lots of physical symptoms" in general. In trying to learn a new dive on tower, Nick described a high level of physiological symptoms that influenced his ability to try the dive:

I mean, I'm trying to learn a back $3 \frac{1}{2}$ right now on 10 meter. I stand up there, everything. I've got to have a great—a decent -- I can see everything, turn around, 
take a breath, step back to get ready and everything just kind of closes in. And a well probably this big where I can only see straight. Everything else is fuzzy, and I-- my heart starts beating real fast, and I can't do it. I guess it's more-- I get so just-- I don't know if it's jacked up ready to do it, or if it's like, "Man, I don't know what's going on." So it's just like I can't do this. I'm not in the right mindset. I'm not in the right physical condition to do this if that's what you call it, physical condition.

Physiological symptoms impacted Julie's diving in a more subtle way. She stated that her movements become "twitchier" and generally quicker when she has experienced fear, which negatively impacted her execution of the dive.

In sum, there were many ways in which fear was seen to impact divers. These were predominantly viewed by participants as negative impacts including worry, atypical technical execution, loss of potential, not going on dives, and strong physiological sensations. However, there were several benefits noted included increased focus, increased strength, motivation, and safety.

\section{Individual Coping Strategies}

Given the numerous ways in which fear was seen to impact the athlete, which was often perceived as a negative impact, researchers also sought to identify coping strategies that athletes used to manage their experience of fear. This domain was entitled Individual Coping Strategies to reflect the idea present within the data that successful coping strategies were unique to each individual. A general sense that emerged from speaking with participants was that there was not one specific or right way to cope. Coping was viewed as differing across divers based on individual needs. For example, in describing 
two different strategies she had observed people use, Katie noted that "I don't think one way is necessarily more constructive than the other way because everyone's different so different things work for different people." Anna also said, "everybody copes differently" as some people want to be "really hyped up" before doing feared dives and others "like to chill out and not really talk to anybody." Participants spoke to coping strategies that they utilized and also described strategies they had observed in others. Thus, specific coping methods discussed within this domain were not meant to be representative of the experience of all divers within the sample but rather to represent the range of coping strategies that could be utilized based on the specific experience and needs of an individual. Five categories emerged through analysis of the data within this domain: (a) acceptance and commitment, (b) use of psychological skills, (c) process orientation, (d) using social resources, and (e) avoidance.

Acceptance and commitment. All participants within the sample spoke to utilizing a process of accepting their fear and committing to the dive as a component of their coping process. This process was simplified for many to phrases within interview data such as needing to "just go for [the dive]" or "just do it" when scared. Kevin, who was coaching young divers as well, noted how it is challenging for him to coach kids to attempt dives when they are scared because "I don't know how else to say it other than you just have to do it. You just have to go." John agreed that you have to "just do it" when scared, as "it's something that you have to face. So, face the fear. Don't back down."

Anna spoke to willingness to try new or challenging dives as an important factor in performing well. In describing differences between her and another diver who were 
both executing a challenging leadup, she shared: "I think it's just your ability to try it or your willingness to try it because it makes me nervous, too. But I don't know. I think I was just very willing to go for it the first time around, just no matter what happened." This willingness separated her from the other diver, as the other balked or did not go as often on the dive. Megan described acknowledging fear and willingness to go as a positive coping strategy she had seen in other people:

Mainly just a lot of people will just come to you and be like, "I'm really scared of this dive but I'm just going to do it," and they'll do it, and I think that's the best way. I think that's the main people cope in a good way with fear.

John, in particular, spoke at length about the important aspects of accepting and committing to dives, as this was an integral part of his approach to coping. He described several different factors influencing this, including a sense of spirituality:

That sense of purpose, that sense of greater being, and I'd say absolutely that the people who have faith are usually, at least the Olympians I have seen, [Three Competitive Divers], they have great faith. And faith plays a role in it, whatever you believe. But believing in something greater-- some of the teammates that I've had who-- and this is club and college, who don't have something that they believe in beyond diving, they don't make it very long. They don't find it worth it. They're like, "I don't need to sacrifice my body for this. I can do something else." I don't know, but for me at least I believe it's absolutely worth it. So suddenly when the fear of death is gone there's no holding back. There's no point in dwelling on the fear but letting it pass because if I die, I die. 
He also spoke to the process of accepting pain after a smack, as he has learned to "just let it go" and "let it pass by." He reported that, after a smack, he thinks "I'm hurting. Okay, I put that over there. That's fine. You can be in pain. That's allowed. [...] All right; now what am I doing? That's just on the side. That [pain] doesn't have to be a part of your focus." He also discussed his process of accepting his body's own reactions to fear including increased heart and respiratory rate: "[Physiological arousal] can be there but your mind has to be like, I understand, this is where we're operating. Your heart rate is this fast, you're breathing needs to be that fast to keep up with your heart rate so that you can remain calm during the dive." Thus, the ability to accept one's experience of fear and to "just go for it" was seen as integral to the coping process by divers.

Use of psychological skills. The need to accept fear and to "just do" a dive was important; however, participants also spoke to specific psychological skills that they utilized to aid in coping with fear and ultimately execute the dive successfully. Psychological skills referenced by participants within the data included self-talk, mindfulness, energy management, cue words and phrases, mental and physical routines, and visualization. Two of the most common skills discussed by participants included some form of self-talk and deep breathing. Related to deep breathing, five participants directly mentioned utilizing deep breathing in some capacity to either directly control the fear response or as an integral aspect of their performance routine. Self-talk was also discussed in several different capacities. Most commonly, three participants discussed counting down in their head as a cue to leave the board or tower, which helped them commit to executing a dive. Kevin reported he told himself: "All right. One, two, three, go." Emily also used "Okay, One, two, three, go" as this "helps [her] to get things off." 
Megan reported feeling "frozen" when executing inwards from the ten-meter platform, since she could not complete a physical action prior to initiating the dive due to the technical requirements of the dive. To overcome this, she "started doing this thing where I just count myself down out loud. And sometimes I feel kind of weird because people around can hear me, but it's fine, I'm still doing my dive." Other ways in which participants discussed utilizing self-talk including reminding themselves that they will be ok if they smack, such as Emily who reminded herself "you're going to be fine. You've done other dives up here before, it's no farther than what you've fallen in the past." Finally, Adam also mentioned utilizing mental cues of "relax, breathe, and just do a simple hurdle" to manage fear related to balking in a meet.

A mental trick utilized by several athletes included comparing one dive to another or pretending that they are executing the dive in a different scenario. For example, Anna discussed trying to pretend she was just at practice rather than a competition to manage fear within competition:

I try not to overthink it and just kind of try and tell myself to "Do what you always do. It's just like it is in practice." I kind of try and get myself to think that it's not a competition I wish I'm not positive that that's how I should be doing it right now but that's where I'm at, at the moment. So just trying to get my mind away from the fact that I'm competing against a lot of really good people.

Kevin also used comparison strategies, but he described using these most often when learning a new dive or executing a dive with which he was uncomfortable. Kevin compared the dive he was currently doing to a similar dive that he executed on another board as a primary coping strategy to create a sense of familiarity with the dive. For 
example, when learning a front dive with three and one half flips from the ten meter platform, a dive he also competed on three meter springboard, he would remind himself "It's the exact same thing as 3-meter" to "tell myself that it's something I'm comfortable with doing to be able to do it." Overall, Kevin "compare[d] it to other things that I know that I like doing to make it more comfortable and be less afraid.” The comparison strategy could help him make technical corrections when he was uncomfortable executing certain techniques. He gave an example of comparing backs to gainers:

I'm doing a back, I try to compare it sometimes to a gainer. I'm not uncomfortable with either of them, but if I need to make my back come closer into the board I would tell myself "Make it feel like a gainer," so it does creep up in a little closer. This served to help bring his dive closer to the board, which was necessary for higher scores.

Other skills mentioned by participants included visualization, emotion regulation through taking breaks, and maintaining perspective. Two participants discussed incorporating visualization into their routine. Mike shared that he imagined "how would it feel if I did it right?” when trying to make a correction on a dive. Adam incorporated visualization into his meet routine, including "visualizing me doing the perfect hurdle, the perfect dive, and ripping it. [...] And kicking real nice and seeing my hands go through the water."

Related to emotion regulation, two participants described taking breaks as important when trying to complete a dive they are fearful of, particularly if they were having difficulty with the dive. For example, Mike would take a break and "got take a cold shower," which makes him feel "much better" and "be ready to go try it again." For 
Emily, going for a walk around the pool deck or to the locker room to "clear [her] head" helped when she was struggling with a dive in practice, and she then "walked back out, did a front $2 \frac{1}{2} 2$ lead up on one-meter, went up to three-meter, didn't use the bubbles, and just went" on the dive.

As mentioned, some participants also discussed maintaining perspective as helpful in reducing various types of fear. Anna described experiencing fear related to comparison to others in competition. She shared that this fear was reduced when she realized the "one of them was an Olympian and another one was an NCAA Champion, so I knew I couldn't compare myself to them because I'm just not as good as them." She shared that this "lowered [her] anxiety a little bit." Emily maintained perspective on the likelihood she would be hurt by reminding herself that "you've done other dives up here [e.g., platform] before, it's no farther than what you've fallen in the past." Finally, Julie said maintaining perspective on her reasons for engaging in sport also helps manage fear. She shared that, during meets:

I usually just try to remind myself-- I'm like, "It's all just for fun. Honestly, none of this really matters. You can get this place at this meet, but it doesn't matter really for anything." So, for myself it's just for fun, not paying attention at meets and then like I said, I'll take deep breaths before I go and stuff and just remember, one step at a time. Just like in practice. So trying to kind of counter those physical symptoms of the fear.

Maintaining perspective that diving was not "everything" to her helped her counter her fear. 
It is of note that participants did not often discuss utilizing a single discrete skill but rather connected multiple psychological skills into their overall management of fear. John described his overall process in refocusing when fearful thoughts arose which included components of mindfulness, deep breathing, self-talk, and cues:

We thought about it as a moving car. Are you going to stand in front of the moving car to try to stop it? Or are you just going to stay on the side of the road and let it pass by? The thoughts are going to happen; it's whether or not you dwell on them and try to be like, "No, I can't think about that." The thoughts come in, I just take a deep breath, and I'm like, "Okay," you just have to live with that, with that there. But as the car drives by, you're like, "Okay," I just take a second on the board, let the thought pass, and like, "Okay, let's get back to what I need to do. I just need to do one step in the middle, two, three, hold," and then you're just going. It's an easier process for me, and it's definitely a way that I've found success is not trying to stop the bad thoughts because that's inevitable, it's almost impossible, but letting them pass, not dwelling on them. And I just-- and just the imagery of it, of, Man, this thought is a moving car, I'm going let it keep driving. I'm just going to move out of its way, and it's gone.

Emily incorporated both deep breathing and counting self talk: "When I'm learning a new dive, I kind of just have to go. I count to myself and I stand there for a second, take a deep breath, and I go, Okay. One, two, three, go.” These skills could also be combined or utilized into general competition routines, which several participants spoke to as important for managing their fear within competition. 
Related to experiences of coping with fear in competition, Nick shared seeing "a lot of people listening to music" or doing other activities to distract themselves rather than actually watching the competition. Katie learned that not watching the competition was better for her performance:

When I'm in a meet, I don't watch anybody compete anymore. Even my teammates, I don't watch them compete. I'll cheer for them. I can hear that their names-- so they're dive and so I'm like, "Oh, yeah, go. Go [Julie]!" But I don't watch it.

Emily also did not watch the competition, so she did "not worry about others or what they are doing. Instead, she "kind of go[es] off by [her]self, put in headphones, turn away from everyone else so I don't see what they're doing" in order to "get in [her] zone." Thus, some participants discussed having specific places they go or ways of acting within competition to reduce fear. Kevin was an exception to this, as he did not want a specific routine. He did not "really have a pre-ritual routine" as this "covers the uncertainty because there's always the uncertainty that something could happen." He felt that this lack of routine helped him in "being flexible" to "take care of" the uncertainty in his sport.

Process orientation. Another way in which some participants coped with fear was by focusing on the process of diving rather than potential negative outcomes. In some cases, participants referenced focusing on specific technical aspects of the dive that would lead to appropriate and safe execution to manage fear. For example, three participants spoke to coping with fear after seeing another diver hit the board by noticing what the other person did technically wrong in order to put themselves in that situation 
and then reminding themselves of correct technique. Another way in which participants focused on the process of executing a new or feared dive was by building up dives in order to manage fear, including doing simpler dives at lower heights. Katie described creating a process for utilizing bubbles (a system that introduces a large bubble into the water, which breaks the surface tension of the water and decreases pain of smacking if a dive goes poorly) to reduce fear and successfully execute a feared dive. She noted that, in order to learn a new dive, she started using bubbles and then "weaned off of it." Starting, she "would do three [repetitions] in the bubbles," then "two in the bubbles, one without," then "one and two." Then, on the last day, she did all three repetitions into the pool without bubbles.

Another way in which two participants managed their competition process was by intentionally placing dives in a specific order on meet day to manage fear. Mike tended to put dives he was "fearful of kind of towards the beginning so I can get them over with" as he felt "way more relieved" once past those dives. Adam also spoke to putting his dives in a specific order, but he noted that his order changes based on a number of factors including the difficulty of the dive, how one dive may affect another, and how much experience he has with the dive. With a dive he did not know as well, he "put it either at the very front or very end" to either "go out with a bang" or to have it towards the front of his list in order to get past the dive. A feared dive would not be his very first dives, as he put "one of my easier ones that I know I can hit" first for a "confidence booster type thing." Thus, in general, participants focused specifically on aspects of their process such as dive order or technique in order to manage fear. Given the nature of technique or identifying specific processes that were going to be most beneficial for athletes, 
participants also spoke to using social resources in their environment to help with the process of managing fear or through receiving emotional support, which is explored further in the next category.

Using social resources. Participants intentionally sought out social resources in their life to help with management of fear. The specific social resource varied and could include teammates, coaches, or sport psychology personnel. The predominant resource discussed by three participants included meeting individually with the mental performance coach to discuss fear. More specific information regarding this relationship is discussed within the "Social Influences" domain above. Participants also noted that being able to speak with their diving coach in the moment could help manage fear. Nick described observing this in his teammates:

I've seen girls and guys try to do dives. Can't do it. Go down and talk to the coach and the coach sits them down. They have like a 5, 10-minute conversation just like-- trying to calm them down I think because at the end of the conversation they come out and feel like, well, less nervous, more balanced out. Not hyped up I guess. Hyped up on fear. They kind of seem like mellow out a little bit.

Nick noted that he had previous negative experiences with coaches, so he personally was less likely to use this resource in the moment. John agreed with the importance of having discussions with [Coach] to help manage fear, noting he will communicate to [Coach] when he was "not in the frame of mind" or "state of body" to execute certain dives, and [Coach] would work with him to put together a plan based on his needs that day. Emily noted how, in general, using social resources was a main strategy for her, as she was "the 
most non-independent" person and has often asked for others' input when having difficulties.

Avoidance. While the predominance of coping strategies thus far were viewed as adaptive for managing fear, participants also identified unproductive coping strategies. Avoidance was the primary strategy of this nature described, which was predominately discussed as not executing dives as a way of reducing fear in the moment. While other strategies have been seen as unique and varied in usefulness based on individual differences, no participants spoke to the strategy of avoidance as beneficial towards their overall experience of fear. For example, Mike noted that he "won't do dives" when scared and would "make up excuses," such as telling his coach that a previous dive hurt, to "skip the next dive and be done." He elaborated that he was aware of this tendency and it led to frustration with himself, though he still used those behaviors. Megan described another method of avoidance as intentionally "doing bad lead-ups so they never had to do the dive." Related to her own use of avoidance strategies, Megan would avoid doing dives by convincing herself she would execute the dive on the next occasion:

In the past when I wouldn't do dives because I was scared of them, I would just be like, "It's fine. I'll do it next time," and always just do that. Always be like, "Oh, no. It's fine. I'll just do it next time," but I would never do it. But I would make myself think it's okay because next time I knew I was going to do it.

Kevin also experienced avoiding doing a dive due to his level of fear. In attempting to learn a back dive with three and one half flips from the 10 meter platform, Kevin noted how he did not attempt the dive from 10 meter despite dryland training and lead-ups due to "the fact that I'd have to go up there every single time and be afraid of it again, and 
again, and again.” Kevin “didn't want to go through that, so I didn't do it.” Thus, while these avoidance behaviors served to reduce fear in the moment, it was not seen as overall productive in improving their experience of fear with specific dives.

\section{Summary}

Within their experience of fear early in the season, participants described several types of fear they experienced as part of their sport including fear of failure, fear of injury, and fear of the unknown. Numerous factors were identified that generally increased a sense of fear including previous negative experiences with a dive, diving from a higher apparatus, learning new dives, specific dive categories, seeing another diver hurt themselves or smack, having a coach who did not acknowledge fear or pushed divers to do dives before they were ready, and having a negative team atmosphere. Factors identified that were seen by participants as helping with their experience of fear included having a supportive coach, engaging in a positive team atmosphere, using a mental performance coach, and using various coping skills such as accepting fear, using psychological skills, focusing on the process, and using social support systems.

Avoidance was also identified as a coping strategy; however, this was not seen as a shortterm solution rather than positively impacting divers' experience of fear in the long term. Finally, participants described the ways in which fear was seen to negatively impact them including experiencing worry, distraction, poor technical execution, not reaching potential, and generally not executing dives. Participants also described some benefits of fear, including providing motivation, increasing focus, higher energy levels to bring to dives, and safety. 


\section{Time Point 2 Analysis}

Data analysis of time point two yielded six domains: (a) External Protective

Factors; (b) Risk Factors; (c) Differences within Competition Context; (d) Impact of

Fear; (e) Individual Attitude and Strategies Towards, and (f) Growth and Personal

Development, which included a total of 20 categories across the six domains. See Table

4-3 for a presentation of the data. Consistent with time point one, analysis of the results

of the Sport Anxiety Scale - 2 are included within the Impact of Fear domain.

\section{Table 4-3}

Time Point 2 Domains, Categories, and Frequencies

\begin{tabular}{|c|c|c|}
\hline Domain & Category & Frequency* \\
\hline \multirow{3}{*}{ External Protective Factors } & Coach Support & General (9) \\
\hline & Teammate Modeling & Typical (7) \\
\hline & Team Culture & Typical (7) \\
\hline \multirow{3}{*}{ Risk Factors } & Uncertainty Related to Dive & General (9) \\
\hline & \begin{tabular}{|l|} 
Dive-specific Context \\
\end{tabular} & Typical (7) \\
\hline & \begin{tabular}{|l} 
Vicarious Experiences \\
\end{tabular} & Typical (6) \\
\hline \multirow{4}{*}{$\begin{array}{l}\text { Differences within Competition } \\
\text { Context }\end{array}$} & Need to Execute on Demand & Typical (7) \\
\hline & \begin{tabular}{|l|} 
Heightened Social Awareness \\
\end{tabular} & Typical (6) \\
\hline & $\begin{array}{l}\text { Competition-Specific Coping } \\
\text { Strategies }\end{array}$ & Variant (5) \\
\hline & \begin{tabular}{|l} 
Fear versus Pressure \\
\end{tabular} & Variant (3) \\
\hline \multirow{4}{*}{ Impact of Fear } & Cognitive & General (10) \\
\hline & 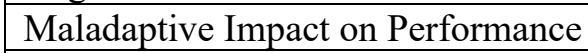 & General (10) \\
\hline & Benefits of Fear & General (9) \\
\hline & Physiological & Typical (6) \\
\hline \multirow{4}{*}{$\begin{array}{l}\text { Individual Attitude and Strategies } \\
\text { Towards Coping }\end{array}$} & Acceptance and Commitment & General (10) \\
\hline & \begin{tabular}{|l} 
Use of Psychological Skills \\
\end{tabular} & Typical (8) \\
\hline & \begin{tabular}{|l} 
Using Social Resources \\
\end{tabular} & Typical (6) \\
\hline & Avoidance & Typical (6) \\
\hline \multirow{2}{*}{ Growth and Personal Development } & Decreased Fear in Executing Dives & Typical (8) \\
\hline & \begin{tabular}{|l|} 
Coping Abilities \\
\end{tabular} & Typical (8) \\
\hline
\end{tabular}




\section{External Protective Factors}

The domain of external protective factors refers to environmental factors identified by participants that were viewed as beneficial in helping divers with their experience of fear. Three categories emerged within the external protective factors domain: (a) coach support, (b) teammate modeling, and (c) team culture.

Coach support. Participants described behavioral and relational experiences with their coach that assisted them in managing their experience of fear. Themes included providing support or affirmation to athletes about their abilities, directly addressing fear and ways to manage it with participants and adapting practice structures to divers' individualized needs. Related to providing support, two participants described positive interactions where [Coach] provided affirmation about their potential when they were experiencing fear. Anna described:

I feel like my Coach has said to me before how he thought I was a little bit of a badass because I've gotten up after all the times I've smacked this semester and done the dive again at practice. So, I think that was kind of motivating for me. Oh, he thinks this of me. I can actually get up and do it again whether I smacked or I'm able to this new dive. If he trusts me enough to send me up to do it then I can do it type of thing. So, I think that's been motivating.

Thus, acknowledging the participant's fear and recognizing the challenge of continuing to do dives after a smack led Anna to feel more motivated to continue the dive.

Approximately half of the participants spoke to ways in which [Coach] discussed fear with them and helped them work with it. Mike spoke to how [Coach] was trying to help him "take all the emotion out of diving" and "just let your body do the diving." 
Katie had also received a message from [Coach] about allowing her body to execute the dive:

But he is always just like just kind of do it autopilot, you know how to do it. You've done the dive so many times at this point. Just kind of stand there and just swing your arms and go and it'll be fine.

Nick spoke to how [Coach] helped him recognize that he would not always know how a dive would go, but that he could trust his body:

I think [Coach]'s kind of helped me a lot with this recently with -- In every situation in your life you're not going to have the answers $100 \%$ of the time. So your body's done flipping and diving for 10 years now, you've just to know-you've got to trust it's going to know what it's going to do. So, I think that message is just-- you can't have the answers $100 \%$ of the time. You've got to figure out the outcome anyway. That has definitely helped me get over some of my fears. With that big dive, I'm still afraid of it, but I know I can do it if I need to. So it's still scary, but I have an idea of what-- it's going to go, decent. It's just there's always a fear behind it.

Thus, participants found it beneficial for Coach to speak with them about fear and remind them that their body knew how to execute the dives even if they were scared. This also served to reduce fear in cases, as Katie spoke specifically to how her fear within competition was reduced by [Coach] reminding her that "when you're afraid, and being timid, and stuff, the only thing getting in the way of you diving well is yourself." This made her "have more fun" and "think differently," because worry about disappointing others was "only hurting me" and "not actually helping me dive." 
Another way in which participants felt supported by their [Coach] was through variations in practice structure. Participants shared different examples including instituting a "balk rule" to discourage divers from balking in practice, openness to divers' input on practice structure when feeling fearful, and structuring practices where they executed high repetitions of a feared dive. For example, Julie shared that "[Coach] normally is pretty supportive of it" when she asked for specific drills in practice. She reported that "every once in a while, he'll give me a workout or he's like, hey, we're going to do 10 of these because they're not great or you're afraid of them.'” She said this “definitely helps me at the time" even though "it's not necessarily what I want, but it overall helps a lot." Adam noted that, on occasion, [Coach] would also ask divers to leave practice if they had a poor attitude or were "freaking out and getting all pissed off" after smacks. The intention behind this was to keep the diver's attitude from impacting the rest of the team. While there was the potential for divers to negatively impact the team, as noted by Adam, there were also positive ways in which teammate modeling was a protective factor for participants.

Teammate modeling. Observing other teammates reactions to fear and ways of dealing with it served as a protective factor for some participants. The source of teammate modeling varied across participants, as two participants mentioned John as a model, one participant referenced the freshman on the team, and another person did not identify the specific teammate referenced. Related to John, Nick and Adam described how John was willing to do dives, did not show fear, and came up smiling after a smack. Nick shared that “whenever I get fearful [...] I look at him, I remember all the stuff he's done, like taken to just feel amazing." Adam also highlighted John as a positive 
influence, noting that John was the kind of person to "go straight at it" when scared of a dive, so he and John would do the dive that elicited fear first to "get it out of the way," and "then it just stopped being scary" after doing that over time. Related to being a model, John was intentional in trying to inspire others through his actions. He said, "you kind of become a beacon of hope and inspiration for others when you show conquering and using the fear is possible."

Another way in which participants saw teammates as positive models was when they knew the diver was scared but the individual chose to do the dive anyways. Emily described feeling inspired by watching a teammate who had just learned a new dive from the ten-meter platform, of which he was still very scared, successfully execute the dive in competition:

I was just, oh my gosh. You haven't been doing this dive for that long and you're scared of it to where the point you can't stand on the-- he can't stand on the platform that he's going to be going off of until they call his name. They call his name and then he runs up there, goes looks over, turns around and just goes. Because of how scared he is of it. [...] It kind of just makes me feel more positive, I guess, for tower. I could be so nervous, but I can still kill things just thinking and looking at what the does. And like, "Wow." He takes his nerves and his fearfulness of this dive and puts it into actually doing the dive really well. So it kind of motivates me to do that a little bit.

Katie also spoke to being inspired by others, particularly the freshman on the team since they were willing to try new dives and learned quickly. She shared that one of the freshmen "just does it and it's dives that I do, but I still will stand there forever and I'm 
like, shoot [laughter]. I can't let the freshman show me up.” Thus, the way in which teammates inspired each other varied and was not limited based on age or gender, as various participants found teammates from freshman to senior and male or female as potential models.

A final way in which modeling served as a protective factor was through observing the negative consequences of another teammate not doing dives. Thus, one participant learned from another modeling what would happen if one did not do a dive, which served as a motivation for other divers to act in a different way. For Julie, observing another diver put off a dive of which she was scared has:

made me realize if I'm afraid of a dive, it's better for me just to do it than to be afraid of it because it's almost-- it almost seems like it gets worse the longer you put it off, and becomes more irrational, and more frightening. Even though it is scary. [...] So I just would say if I was afraid of something, I would try to want to do it instead of avoid it, until I get over the fear, instead of just always have it kind of in the back of my mind.

Specific instances of observing teammates actions when scared could serve as a protective factor in participants' own experiences of fear. Another factor related to teammates was the general sense of team culture and attitudes towards fear.

Team culture. Team culture referred to how participants spoke about their teammates approach to discussing fear and managing fear amongst each other. Teammates described a culture of supporting one another through several different ways including teammates providing emotional support, sharing their coping strategies, creating an atmosphere of embracing challenges, or using humor. For example, Nick 
discussed that both men and women on the team support each other; however, their approaches to this may differ:

All around the guys' team $[\ldots]$ the message we have whenever we're trying to do something crazy or do something big for the first time, we'll scream send it. Just for some dumb reason. I don't enjoy the term, but when someone's going down, we just scream send it. And that kind of helped out, too because when you scream send it, you can't take it back. You just got to go for it, send it, and see what happens. So that's kind of back towards the, you don't know all the answers. [...] I think the guys are more-- they support others in a different way. Because the girls, if someone smacks, they'll go up to them, give them a hug, be like, "You got it next time." But the guys, if you smack and we know you're alright from it, we'll like, "Oh, it's on." Everyone just starts making jokes. The person that smacks comes up laughing. And just, when you smack, it kind of brightens the mood. You might have smacked, might have gotten your self-esteem down, but it definitely brightened the mood. And that's kind of the culture of the men's dive team has taken.

Thus, this participant discussed the culture of using humor after smacks and the guys challenging each other to "send it." Two other male participants also spoke this this culture in addition to one female diver. Emily shared how "people just being kind of goofy and just yelling like, send it!" when trying a dive that she normally fails in competition "just put a spark in my head. Like, oh my gosh. I have to do this."

Nick also mentioned how the women's team culture seemed focused on receiving positive support when scared. Three female participants spoke to using teammates for 
support in this manner. Megan, for example, thought "it really helps everyone when somebody tries to talk through [fear] with you," since "people sharing how they get through things sometimes helps other people." However, as mentioned above, this was not the only cultural aspect that female participants found beneficial as one diver mentioned responding well to "send it" and another, Anna, appreciated turning a dive into a competition with teammates:

turning a dive that both me and a teammate are struggling with or don't like to a competition that sometimes helps. Because they're challenging me to do well and to get it off the board if I may have been balking a lot.

Overall, fear was seen as a common aspect that was addressed in various ways throughout the team culture whether by turning dives into a competition, using humor to help each other, or providing positive support. Emily alluded to this idea, noting that fear brings our whole team together because sometimes we're all fearful together before our practice. And sometimes it's just individually, and when someone's fearful individually, especially like me or someone else, our whole team is cheering for them, and saying like, 'You got this. Come on. You know how to do this,' and stuff like that. And just having that support system of a team I guess kind of makes fear less of a thing, and more of nerves rather than fear. Teammate support and addressing fear within the culture served to reduce the experience of fear in Emily's eyes and was seen as bringing teammates together.

Overall, several external factors were seen as protective to the athlete's experience of fear including support from the coach and teammates. Additionally, the culture created by a team was important in helping participants manage fear in an 
adaptive fashion, including supporting each other and challenging each other to do dives when scared. In addition to discussing protective factors, participants also identified factors that were likely to negatively influence their sense of fear.

\section{Risk Factors}

Participants described a number of factors that served to increase their sense of fear, including contextual factors related to the dive itself, factors inherent to the nature of the sport and social influences such as coach corrections or vicarious fear. Three categories emerged as central to this domain: (a) uncertainty related to dive, (b) divespecific context, and (c) vicarious experiences.

Uncertainty related to dive. One factor that served to influence fear was a sense of general uncertainty related to the dive's outcome, which was viewed as inherent to the nature of the sport. Participants shared several experiences of uncertainty including worry that they would forget how to do a dive if they have not done one in a certain amount of time, fear over not knowing how they would execute a dive, a feeling of foreignness when changing technique or doing a new dive and general unpredictability of the dive itself.

Related to the unknown, four participants described fear connected to not knowing if they would be able to execute the dive correctly in competition. For example, Megan shared that "I think it's more fear of the unknown. So sometimes, being scared of not knowing how a dive is going to go, is what makes me miss the dive. It's not really that I'm scared of the dive, and I'm like, 'Oh. This dive's not that good. I'm scared it's not going to go well." Anna was "more comfortable" with her dives at this point in the season, so "the fear of-- I'm most often been confronted with is not knowing if it's going 
to be good or not" and "not knowing if I'm going to be able to do it right." Nick also expressed this, noting he:

narrowed [his understanding of his fear] down to I fear the unknown. I fear what I don't know what's going to happen because in a meet I'm kind of scared I don't know how I'm going to do. I don't know if I'm going to do good or bad. On dive, I don't know if I'm going to smack or be fine.

Lack of predictability of dives was also a factor that led to uncertainty. For example, John spoke to experiencing fear when changing technique or focusing on a correction from coach, because the dive now "feels foreign. The foreign feeling is what's most terrifying, I think, to a diver. You've done something a thousand times, you changed one little thing, suddenly you're like, what is this?" After this technique change, "things shouldn't change, but suddenly, they do. Suddenly, everything is different." Emily also spoke to unpredictability when learning a front dive with three- and one-half flips because she had difficulty spotting on that dive: "I know where I am in every single other dive but put me in that dive and I lose completely all my surroundings. I have no clue where I am, and I just get confused and scared." Anna described lack of predictability in learning a new twister dive from tower: "it was a little bit scarier to learn than some of my other dives because it was a twisting dive, and those scare me a little bit more because they're slightly a little more unpredictable." Thus, there were also certain dive factors that contributed to a sense of unpredictability. These contextual factors were explored in the following category.

Dive-specific context. Within this domain, participants described contextual factors that they related to the dive itself that increased their sense of fear including the 
specific apparatus that a diver was diving from, receiving technical corrections from the coach, learning new dives, or executing dives after taking time off. Related to apparatus, two participants discussed how they felt more fear on tower compared to springboard. Adam noted how he can "get a little nervous" before dives but that "there's never really the huge fear except when I'm on tower I start shaking and get real nervous." Megan also saw "more fear in people when it comes to tower than springboard because everyone's kind of used to springboard." She noted that several freshman had not competed tower before, so she noticed them "really worried it and stressing about things, kind of like scared to go or just don't want to do a new dive that day."

Four participants discussed experiencing more fear after taking time off from doing dives. Of a contextual note, divers typically had approximately one to two weeks of practice off around the Christmas holiday, and interviews occurred in late January. Thus, participants had recent experience of taking a brief time off of diving. Megan felt more nervous after taking a break from her platform dives:

I get nervous for my dives on tower, just like if I haven't done them. After Christmas break when I hadn't done them for a few weeks, it was kind of like nerve-wracking. But I always like to tell myself, "It's only been two weeks since I've done the last one." But whenever I learned it, I'd never done it before. So it's got to be at least as good as that one, right [laughter]? At least I like to believe that. It doesn't always end up like that.

Mike also experienced more fear after taking a break from tower, noting that "if I take a week off" he would "have fear when I get back up there to do the first one again. He descried feeling "a minute of kind of panic" where he wonders "what if I forget how to 
do this dive in the middle of it and there's nothing I can do once I jump off?” Katie echoed those thoughts, since "taking that much time off of doing my harder dives or my dives that are typically scarier" serves to "exponentially increases just the fear of, 'I'm going to mess up in the air,' or 'I'm going to smack,' or 'I'm going to hurt myself.'”. In addition to doing dive after a break, three participants reported learning new dives as a time in which they experienced more fear. Emily shared fear of learning a new twister dive, in particular, since she came out of the twist early. Although she did not smack, the fact that the technique was "just completely like a freak thing that I've never done before" led her to "freak myself out" and worry about coming out early each time she did the dive. Related to learning new dives, Kevin reported that he was rarely very scared in practice on a day to day basis, but rather more "casually afraid." However, “when I learn a new dive sometimes, I will be so afraid that I won't really be going on the dive. Versus, in a general practice and I'm casually afraid, I'll still do it. It's just a little bit scary."

Finally, three participants described how corrections from the coach could increase their sense of fear. Within this scenario, it seemed that all three participants were speaking about the same instance. Mike described an experience where coach told a story about how a diver had hit his head on the platform:

So it was the gainer on platform, and I did one and [Coach] comes and he's like, "Dude, if you keep doing it like that you're going to hit your head on the platform," and that just scared the crap out of me. He explained it in detail and he was like, "Yeah dude, he cracked his head on the platform and then there was blood everywhere, he sank to the bottom, blah blah blah." And then after he was 
talking about that he was like, "Okay, now go do one." [laughter] And I'm like, "You're shitting me."

Mike followed up by noting that [Coach] pushing him to do the dive, while increasing his sense of fear, was also a "good thing" in helping him push past his fear. Anna also appeared to speak to this experience and how she saw it impact her teammate, though noted it did not impact her personally due to not having that specific technical issue described by coach on the dive:

For instance, the other day he-- not to me but to a teammate-- gave a scenario in which he would hit the platform and I think that greatly increased his fear which the coach wasn't necessarily trying to do but it's kind of what it led to. [...] I wasn't doing the same dive he was doing and I don't have the issue that he was talking about with that other diver. So, I have if anything the exact opposite issue so I [inaudible] really scare me and that scenario but if I had some more issues on that dive that definitely would have scared me.

Katie described how [Coach] tried different coaching techniques to help divers work through fear, and that he realized the same technique would not work on everyone. Katie shared that she heard about [Coach] speaking to Mike and knew that [Coach] would not speak to her that way due to it increasing her fear:

If he were to sat me down and tell me a story about how someone almost died, that would not be helpful to me. But I don't know if he was like, "Maybe scaring him into doing it right might help." I don't know exactly what he was trying to do[...] And I know [Coach] does the whole thing where he tries different things out with you until he learns how to make it work. Yeah. Sometimes he's like, 
'Okay I'll give him the tough love.' And the tough love does not work, so he's like, 'Okay, I won't do that again.' So I don't know if that's kind of what he was doing with [Mike]. but I told [Mike], I was like, 'If that's freaking you out more you need to tell him. Be like, that's not going to help me.'

Thus, [Coach]'s corrections appeared to increase fear in this instance to protect the diver from hitting the tower. In this scenario, hearing about another diver hitting the tower was enough to elicit a fear response. This instance of vicarious fear is explored further in the following category.

Vicarious experiences. Six participants spoke to experiencing more fear themselves when they observe someone else smack, see someone hurt themselves or see another person be scared. For example, Nick reported that seeing a teammate smack badly on a dive "kind of affected me because that was right when I was first feeling somewhat comfortable with the dive." After seeing her smack, "every time I go up to do it I envision what she did, and it kind of plays in my head." Adam also spoke to seeing people smack from the tower, which "makes me not want to do it." Katie observed another teammate come close to the tower on a dive, which made her think "Oh, God. I wish I hadn't seen that." After that, she noticed herself "just close my eyes" when waiting for him to go because she did not want to watch him potentially hit the tower.

Another experience of vicarious fear that some spoke to was noticing that they became more nervous or fearful when other teammates were nervous or fearful. Two participants spoke to this idea, as John shared that "when somebody becomes so overly fearful about that skill, it has a negative impact on the team." Emily descrbied this as 
well, as she shared that observing "nervous ticks" in other teammates impacts her levels of fear or anxiety:

So it's like, Oh my gosh. Should I be nervous? Because tower usually does not get me freaked out or anything, because I like tower. For some reason, I feel more in control. But some people's nervous ticks kind of freak me out in a way because I'm like, Oh my gosh. Should I be scared?

Thus, even without a specific fearful event (e.g., someone hitting the tower or smacking), Emily felt more nervous after observing nerves in others. The specific setting in which vicarious experiences occurred was not noted, as it seemed these events could occur in either practice or competition.

\section{Differences within Competition Context}

Participants described unique factors that influenced their sense of fear within the competition setting compared to the practice setting. Four categories arose through analysis: (a) need to execute on demand, (b) heightened social awareness, (c) competition specific coping strategies, and (d) fear versus pressure.

Need to execute on demand. Within the competition setting, participants described fear specifically related to needing to execute the dive on that one occasion. In a meet, they did not have multiple tries or attempts to achieve a good score. Within competition, Anna found herself "getting scared because this one has to be the good one. I don't have multiple tries. It's everybody's watching on this one, you're being judged on this one. This one has to be good." Mike described pressure of needing to not only execute one dive but "six in row at the right moment is kind of challenging." Kevin experienced fear of making specific technical mistakes because he recognizes "the fact 
that I've made those mistakes before," such as making a mistake in his hurdle when executing a reverse dive. He worried about "what if it happens in a moment that it actually counts?"

Two participants expressed how the specific competition or set-up of competition could impact feelings of pressure. Katie described the NCAA qualification meet as one example, since "you have that one meet [to qualify for NCAAs] and so if you have a bad day, too bad, so sad." She reported "going into the meet is also really scary" because "you have to be on your A game on that one day," and "if I'm off today, its over. I don't get another chance." Megan also discussed this in the context of how doing well could also create pressure if one was in position to qualify for a final:

I think sometimes people get nervous whenever they know they're doing well. And they're like, Oh-- I even do this sometimes. I'll be like, This dive is it. It's either I make it or I don't. Make the final or I don't make the final. Or it's like, do well or I don't do well. And then it puts so much pressure of not knowing what's going to happen on that dive that sometimes that it just doesn't go as planned [...] It's more like an internal thing. Just because it's you personally wanting to do well. We just had a meet in [Diving Invitational] that was like a prelim-final. Everyone of course wanted to make a final. Of course, [Coach] wanted us to make a final and told us, 'All of you are capable of making a final.' But it was like when it came down to it everyone was like, oh, I'm going to make this final or I'm not going to make this final. And then some people blew it and some people didn't. So I think it's more of an internal thing. 
On a positive note, Megan shared how the setup of competition warm-up and competition itself had helped her become more comfortable with her dives:

In a meet warmup, you don't have a lot of time to warm up. You can't do 10 leadups before you take it up. You have to do one, maybe two, if you have time, and then go up. So I think that might be a little bit of it, because I had to get comfortable with only doing one of my lead-ups or I wasn't going to get through my whole list before I did the meet. [...] And when at Nationals, I had a little bit of a weird experience. The tower, my armstand [laughter], that I just explained before, that was a scary dive, did not go well in the warmup. And I ended up not being able to warm up all my dives. And I still did the dives. I still did it fine. It was a little scary, but I still did it them and I ended up okay. So I can do them in practice with lead-ups [laughter].

The pressure of needing to execute dives with less warm-up or without warm-up increased her sense of comfort with the dive in practice and competition afterwards.

Heightened social awareness. When discussing the competition setting, many participants referenced awareness of other people and concern around others' perceptions of them or of their performance. This theme was not present when examining data surrounding the practice setting. Within this category, participants spoke to two main areas of concern over evaluation including worry over letting others down and comparison to competitors. Related to letting others down, Mike spoke to how letting his parents down was a large concern for him:

I just feel like I don't want to disappoint people a lot that was a big one. Even though my parents were super supportive of me and they really don't care how I 
do they're proud of me no matter what which is nice but I just feel still like some things are just-- I don't know, I disappoint people because I don't do the right thing $[\ldots]$ at meets. I've worked so hard the last few months and then just let it go to shit. Because I just overthink about disappointing people it's a lot of things. Katie also described worry over letting others down related to the Conference Meet in particular, since only select team members were able to go:

But more leading into [Conference Meet], we have to leave people behind for [Conference Meet]. Not everyone can go and so then it sucks to show up to the meet and then not perform well and not bring points back for your team. And then it's like, well, I didn't score any points. Maybe that person that got left behind could have scored points and then I wasted that spot, kind of thing. So that's kind of the performance fear, I guess. It's I don't want to be the one to let the team down.

Emily described worry over letting others down, including her coach, herself, or other people such as her parents. She gave an example of texting her mother after a poor competition to apologize for her performance "because I thought I was going to let her down."

Four participants also spoke to awareness in the meet of either comparison to competitors or concern over how competitors were evaluating them. For example, Nick reported thinking his "biggest fear at meets" was "people just thinking why is he here? Why is he diving here?" He shared that he "was afraid of people not thinking I was good enough." Emily also described comparing herself to other divers in warm-up and "getting scared" because she wondered "Am I as good as them? Why am I here?" Anna noted that 
she "always get[s] a little bit intimidated by the competitors." Finally, Julie said that part of diving itself was stressful since, in competition, "you get on the board and kind of everyone's looking at you, and you're on stage."

Competition-specific coping strategies. Participants described their experiences of utilizing coping strategies within the competition setting, including differences in access to resources and specific strategies they utilize based on the competition. Nick shared how his teammates "are always right there with me" for support in practice when fearful; however, "they're always around other places" in competition and were "not really paying attention to you so they can't really help you." Emily described that part of her strategy during competition was intentionally being away from others, which would speak to Nick's comments about not being able to help others if they were fearful based on her competition routine. She noted that she "like[s] to be to myself, to focus on myself and [..] put on headphones and zone out" between dives. Megan liked to be on her own, as well, which helped her feel more in control over the information she was taking in during the competition:

I like to kind of do my own thing. And if people are talking about missing dives or being scared so that it would bother me. So, I just like to put on my headphones and kind of sit on my own or sit next to the other people that are doing the same thing. Not necessarily people that are talking about what's going on or what's happening [...] I kind of just like if I see the dive, I see the dive. If I don't, I'm not going to try to see someone's dive. I'm not going to try and see if someone scored and know whether I'm beating them or I'm not. [...] The only analogy I can come up with is if you were studying or something and you like some noise, but you 
like it to be the noise that you make. [...] I just kind of like to decide what I hear instead of hearing other people's thoughts. [...] Because it kind of helps me not to think about the meet. So I'll listen to my own music instead of hearing people that are like, 'Oh my gosh, so and so fail the dive' or whatever. I just like hearing my own music [...] it's just like I want to - I don't know - be in my own bubble.

Anna also described how the specific number of other divers in the competition and length of competition could impact coping needs from day to day:

At the bigger meets there can be like 40 people an event, but at dual meets there's like 10 so what you're doing then varies. I feel like it's easier to not have that fear in dual meets because you're moving so quickly, you don't have time to sit down and think. And it depends who you're drawing against of course. But at bigger meets, it depends on how someone's mood is that day. There's kind of a meet hangover that almost everybody gets. It's usually day two of the meet because the first day of competition, you're very amped up and very excited. But it's generally a very long day if it's a multiple day meet. Like in [Diving Invitational] there were 30 something people in our event so it takes like three hours. So, you're diving for three hours and staying focused for three hours which is a long time. And so you kind of get that second day meet hangover where you're a little bit more tired than you were the day before, maybe not necessarily wanting to get up and compete, but you got to do it anyway. So I feel like attitudes and ways you're dealing with it may shift from day one where you may be amped up and wanting to talk to people versus day two where you maybe just want to chill and be in your own space type of thing. 
Thus, Anna could experience more fatigue during the second day of competition and also when there was a large number of divers in the competition due to the length of the meet, which could impact competition strategy and coping.

Some participants reduced feelings of pressure in competition by imagining that they were in practice rather than competition. Megan noted that "with platform, I just need myself to realize that I'm fine. And I think that a way for me to do that is usually just getting going and just thinking of it more like a practice instead of a competition." Nick also spoke to this strategy:

Now, I tend to think of it as a practice. Practices, I'm always pretty jolly, like to have a good time. So, I like to think of it as a practice where-- just a training trip. We're going to a pool. We're going to see a bunch of friends there, and we're just going to all dive and have fun. So, I think, that and then the ability to alter my focus on something else really helped me now, because last time we talked about it I was-- that was right when I was starting to flip the switch in meets, okay? And that's really helped me to just-- now I can compete. Now I can dive because it's just a practice. There's no pressure in a practice. So, if I can flip my mind off and just be like, this is a practice. I'm just going right now just to show my coach what I can do. I think that's helped a lot.

Thus, focusing on viewing competition as a practiced helped Nick decrease pressure in competitions and improve his dive performance.

Fear versus pressure. Related to language usage, three participants denied experiencing fear in competitions but rather described experiencing "pressure," "nerves," or "anxiety" instead. Megan would not "categorize how I feel in a meet as necessarily 
fear." She described getting "a little anxious" but did not believe it was "because I'm scared of my dives." She shared that, it was "normally because of the pressure situation" when she experiences anxiety in competition, and she was "not necessarily scared of this dive." Kevin also described the difference between fear and nervousness in his perspective:

I think there's a little bit of a difference between nervousness and fear. Sometimes I can be a little nervous for a competition, but I'm not afraid of competition. [...] I've been doing it for so long at this point, I know what it is, I know how to do it. I know the schedule of what a competition is like, so I'm familiar with it. But I think the nervousness of it just comes to all the what ifs like what if I don't perform to the best that I can? What if this happens? What if that happens? But I'm not afraid of it because I know what it is.

While he did not experience fear in competition, he reported experiencing worry over what might happen. Emily expressed a similar sentiment, noting in competition there was "never any fear, just more nerves." She reported that she did "get a little fearful sometimes" related to worry about "what-ifs" rather than focusing on knowing how to do the dive, which was "the fearful aspect of it" for the her.

\section{Impact of Fear}

Participants also discussed the numerous ways in which fear could impact their performance on numerous levels. Four categories were identified: (a) cognitive, (b) maladaptive impact on performance, (c) benefits of fear, and (d) physiological symptoms. Results from the SAS-2 (see Table 4-1) are included in this domain based on the closest fit within the qualitative data. The Worry and Concentration Disruption subscales are 
discussed in conjunction with the cognitive category and the somatic subscales is discussed within physiological symptoms.

Cognitive. Participants identified a number of cognitive symptoms that they experienced as a result of or in conjunction with fear including worry, racing thoughts, distraction from task-relevant information, and mental or emotional fatigue. In general, five participants spoke to experiences of worry and their thoughts racing. Three participants spoke to worrying over disappointing people or letting others down within competition. For example, Mike shared that he "just overthink[s] about disappointing people." Of note, Mike had one of the highest scores on the Worry subscale on the SAS-2 (17/20). Emily also described this, noting that, when watching other divers, she would compare herself and doubt her abilities:

Wow! They're really good, then I start doubting my own abilities, like, what if I can't live up to what I think I can? Or what if I can't live up to what my coach thinks I can? I'll let him down. I'll let myself down. I'll let other people down. Emily also scored a 17/20 on the Worry subscale of the SAS-2.

Three participants highlighted experiencing worry over the outcome of the dive, including concern over physical safety. Adam worried over the general outcome of dives, noting that he will "go back and forth" between thinking "oh man, I'm going to crush this" and "what if this happens and then I just eat it real hard in front of everyone?" Katie experienced worry over safety:

So if I feel any fear kind of like that in a competition or I'm like, oh, I hit my feet on the board one time in this dive. I'm afraid, what if I do that in competition? It's not going to be good. 
Julie also discussed how having strong technical execution in the beginning of the dive could then lead to worry for her over kicking out too late:

If you're overthinking, you're like, oh wow, I'm spinning really fast, I should kick out early, and then it ends up being too early. So, if you over analyze it, it can be harmful. And I've done that sometimes. Just where I'm like, oh this is really good, kick out early, and it will end up short. So instead of just doing what I'm trained to do-- our coach always says sometimes, 'Oh it was good, but you had a thought in the air and I can see when you had the thought and then you did something that you normally don't do,' so. If you just let your body flow, I guess, then it's good, but as you have a thought sometimes, it can make things more difficult.

In general, seven of ten participants scored highest on the Worry subscale of the SAS-2 among the three subscales. Two participants had the Worry subscale tied for highest. Thus, only Adam, who scored highest on the Somatic scale, had a subscale with a score higher than their Worry score.

Three participants spoke to mental or physical fatigue that occurred as a result of experiencing this fear. For Emily, this fear could lead her to break down at practice and can lead her or teammates "to get really frustrated with ourselves" which "ruins our whole practice." Katie "dread[ed] going to practice" at the beginning of the year because “it's always hard physically but when it's hard physically and mentally it's just so much more draining, I guess, to even get through the practice." She shared that, "after tower days at the beginning of the year, I would just finish and I was like, I'm emotionally drained, because I had to put everything I had into that practice, not only physically, but just emotionally too." This improved over season, and she now thought "well, that was 
kind of fun" at times. Anna also described this, noting that "it's just a lot. And the dive is hard so it takes a lot of energy out of you" physically and "just mentally even because I was scared of the dive."

Five participants experienced distraction from the appropriate dive or its technical requirements as a result of fear. Megan reported that fear of one dive affected other dives in her list because she "would be anxious about this dive" and worry about how scary that dive would be. Adam expressed similar impacts, noting that fear of one dive would "just drag me down because the whole meet just be thinking about that one hard dive, that new dive I'm doing, and I'll mess up on everything else." Nick could be impacted by another person not going or doing poorly on the dive. He explained this process of how it typically occurred:

So I'll do a lead-up. I'll be all right. I'll go up to three-meter [springboard], get ready to do the dive, and right when I get up to three-meter, [image of diver smacking] just wipes across my vision. I'm like, okay. Got to get rid of that. And then I'll get on the board, and the first hurdle I'll do, I won't like it. So, I'll stop, turn around, do another hurdle. And once I do that, that's when I know it's-- that's when it starts to tumble. And then, I think, after four or five balks, I think I'll finally sit down in the hot tub and be like, we either got to do it or don't do it. Anna discussed how this distraction could impact her overall dive, as she thought about simply "getting the dive off" rather than "doing it right:"

I just want to kind of survive through the dive instead of do the dive well. And sort of the-- I mean when I'm just focusing on getting it off the board it's not-- I'm 
very rushed and I'm very anxious and not really focusing on what I need to be focusing on.

Julie also reported this phenomenon, noting that she would be "thinking about the dive, not about the hurdle" which "kind of gets me off balance so my arms will swing too fast." She felt like she was "ahead of my body-- instead of being in the present moment." Related to the SAS-2 scores, participants generally rated the Concentration Disruption subscale of the SAS-2 as having lower level of symptoms compared to other subscales of Somatic Anxiety or Worry. The highest score of all participants was Mike who scored a 10/20 on the subscale. All other participants' scores ranged from five (the lowest possible score) to nine.

Maladaptive impact on performance. Fear was seen to have various negative impacts on performance including impacting technical execution, balking or not going on dives, and general underperformance in competition. Related to technical execution of dives, five participants described not executing technique as needed due to fear. For example, Julie's worry over going over on dives could lead her to "kick out early, and it will end up short $[\ldots]$ instead of just doing what I'm trained to do.” Two participants spoke to how they tend to not put as much strength into their dives due to fear of making a mistake. Katie shared she does not "go as strong, and I know if I'm going to mess up a dive it's because I'm not being strong and confident." Julie also described this, noting she would "not be aggressive like I need to be" and "kind of tame things down." Anna also spoke to increased caution in dives in addition to other technical impacts. She shared that she does not "go for dives as hard if I'm scared." She "failed a couple dives before because I was scared and didn't go all out on the hurdle. And I kind of babied the hurdle. 
So, then my knees buckled, and I failed the dive." Other examples of technical impacts described by participants included not getting adequate height on the dive, not catching "the board quite right," having their head in the wrong position, and rushing rather than being patient on the board.

Five participants described balking or not going on dives as a specific negative impact. John described that the "start is tough when you're afraid because you're not focused on the fundamental thing that you know." He shared that, if "you're walking on the board and you're not sure whether or not you're going to go, if you're even thinking, you're going to balk. You're not going to go." Julie expressed experiencing this, noting "I think probably the thing that I would see the most for me fear wise is if I balk a lot because I'm like, oh, I don't like that hurdle if I take that hurdle it's going to be bad. It's like being afraid of a hurdle." Mike, Nick, and Kevin also spoke to not going or to balking on dives as a result of fear. Mike said this could be frustrating for him:

If you're scared to learn a new dive and you're trying to do it, but you keep balking or you just won't go, that fear will frustrate you. And then, now you're upset. And then, now your practice is ruined because it's hard to bounce back, for me at least.

Mike shared how this could occur on dives he has previously learned. Somedays, he "won't be able to do a dive or two" as "there's always one or two practices out of a month where I get up to do it and it's just like, 'can't do it."” He shared that "when I smack on a dive that I normally do pretty well on" it opens the door for him to doubt himself and his capability to execute that dive. 
Finally, six participants spoke to fear generally leading them to perform poorly in competition without providing specific information as to how or why within that portion of the interview. Adam shared that fear has "always just kind of hurt me during competition" and he would get "all in my head and just making myself blow the meet because I'm thinking about the one dive that's going to suck." Megan described how fear of how a dive would go in competition "is what makes me miss the dive" because "I'm like, oh, this dive's not that good. I'm scared it's not going to go well, and then it doesn't go well." Katie and Anna described how fear of not living up to expectations led them to underperform at an NCAA qualification meet. Anna shared:

I know I did a terrible job last year of dealing with my fear and ultimately it led me to dive really terrible. I probably could have made NCAAs but because of my fear I just dove the worst I ever had in a meet and didn't even come close.

For Emily, fear at a smaller meet led her to underperform, as she "just screwed up so much because I was scared of what other people were doing, rather than focusing on what I was doing in the moment."

Benefits of fear. Although participants predominantly described fear as negatively impacting their mindset or performance, they also identified several ways in which fear or overcoming fear had benefited them including increased confidence, improved focus, safety, and motivation to improve. Related to increased confidence, three participants spoke to how overcoming fearful situations increased their confidence in themselves and in their ability to be successful in future situations when fearful. Mike reported feeling "happy about myself and what I did at practice" when he does "the dives that I favor least." He noted that, "if I did that, no matter what I'll feel good about my 
day," and "facing those fears like a day to day basis is going to help me at a meet." Katie and Megan both spoke to how, as Megan said, "being able to get through [fear] helps you be able to get through things that aren't as extreme." Katie gave an example of doing an unusual drill from the ten-meter platform, of which she "was so scared." However, "after that, it was like, I can do anything." She noted that "it almost put your normal about of fear in perspective [...] When that was scary, it wasn't actually scary anymore."

Three participants described how fear could lead to increased focus on technical aspects of their dive, which improved performance. Adam noted that "if you're scared of something, you think you're going to eat it really hard like smack, you'll focus really hard on that dive, and make sure doing it right so you don't hurt yourself." Kevin and Emily both gave an example of how fear helped them on specific things they need to do in order to make their hurdle successful. For example, Emily could be "timid" in her diving when scared, which "sometimes helps me because I try to think about the simple things, and not try to fix my whole dive completely." With hurdles specifically, she tried "to focus mainly on my hurdle because if I think about more things then the fear aspect kind of overwhelms me, kind of makes me even more scared." Kevin reported knowing that "there are certain things I need to do to make my hurdle good" so fear "makes me focus on that."

Two participants addressed how fear could help keep them safe. As Kevin shared, fear "would help me kind of stay alive" because "if I wasn't afraid, I probably would get I guess dangerously close to the boards." Anna also shared how fear can lead to either stop when executing a bad hurdle or alter technique to stay safe: 
I guess if I'm getting a really bad hurdle and I would end up possibly hitting the board or hitting another board or whatever. Then I would stop and not take that hurdle so I guess fear would help in that aspect [...] Say you get a-- I don't even know. For instance, when I told you I smacked it was because my knees buckled. And I should have stopped [the hurdle] but I didn't. Whereas, I think I've seen it happen in other people where they've realized it fast enough that they stopped or they did a different dive or so that it was safer. Or I've seen a couple teammates almost hit the board but take measures so that they didn't, like straddling their legs so that they missed the board and things like that.

Finally, two participants spoke to how fear motivated them to improved dives in the future. Emily shared that she had seen teammates "absolutely bomb" a dive, and then "the fear of that dive kind of makes them hungry I guess to do it better and do more." Julie experienced this herself, since she knows "if I'm afraid of this in practice, I'm definitely going to be afraid of it in a meet" so "it motivates me to do whatever it is that I'm afraid of." She shared that "if I make it not scary now, it'll be better later."

Physiological. Participants described several physiological symptoms experienced as a result of fear. Mike, Adam, and Julie experienced stomachaches or butterflies in their stomachs when nervous or scared. Mike and Adam also reported physically shaking as a symptom. For example, Adam shared that, when on tower specifically, he "start[s] shaking" physically. Nick described fidgeting as a result of nerves: "I notice myself on seven meter kind of wiping myself dry-- dry as a bone with my shammy and [...] I shake my legs a lot.” John reported other physiological symptoms 
including racing heartbeat and noted that his mind goes "a thousand miles a minute" in those moments.

Julie identified how "that little extra adrenaline" she experienced could help her jump higher and spin faster, which could be a competitive edge "if you listen to your body and let it go [...] do what you're trained to do." She noted that "if you're overthinking, you're like, oh wow, I'm spinning really fast, I should kick out early, and then it ends up being too early." It was not the physiological symptoms itself that were the concern in this case, but rather her reaction to the extra adrenaline. Related to the SAS-2 results (see Table 4-1), four of the five participants who had the highest scores across the team on the somatic scale also referenced physiological symptoms within their interview data, including two participants who scored the highest on the team on the somatic scale at time point 2: Mike and Adam.

\section{Individual Attitudes and Strategies Towards Coping}

This domain captures the experiences described by participants of the manner in which they discussed coping with fear. Given that coping was discussed as unique to each individual, the term "individual" was used within the domain title to capture this sentiment from the data. Participants described a number of strategies and general attitudes of how they approached fear. Four categories emerged from analysis of this data within the domain: (a) acceptance and commitment, (b) use of psychological skills, (c) using social resources, and (d) avoidance.

Acceptance and commitment. Within this category, Participants described a process of coping by acknowledging fear, accepting that it would be present, and committing to executing their dive. Several participants spoke to their process of 
acknowledging and accepting that fear would be present within their sport. For example, Anna described an occasion where she smacked on a dive from the 10 -meter platform in warm-up for competition. Previously, she had not gotten back up to do the dive after. However, on this occasion, she "got back up and did another one in warm-up and then competed it." She shared that she still "get[s] scared and it still is a little bit of a mental block" but she does not "really let it affect me anymore." She elaborated that fear is "going to happen and am I going to let that ruin my meet or ruin my week or my season, or am I going to get back up and do it because I know I can?”

Several participants spoke to how acknowledging their fear or the physiological reactions they were experiencing was important to their process of coping. Kevin described how sometimes [Coach] would ask him "Are you scared of being close to the board, or do you just actually not know how to do this?" when Kevin struggled to make certain corrections that would bring him closer to the board on a dive. After this feedback, he would "get up the next round and try to do everything I can to make myself uncomfortable, I guess, on the start" because he knew that "to get the better points, I do kind of have to scare myself." He elaborated that "acknowledging the fact that I am going to be a little afraid makes it less scary." Furthermore, this process of acknowledging fear also helped him technically, as he realized 'I just don't know what he's talking about, and I don't know how to make the change physically" if he continued to make the same mistake after acknowledging fear. Related to corrections, John highlighted the importance of acknowledging that making corrections could be uncomfortable:

So let's say you want to do it right and you want to make the dive as best as you can, and to make that happen you're going to have to make corrections that are 
going to make you feel uncomfortable. And since we've last talked, I've recognized that and I'm learning to acknowledge that the uncomfortable feeling is normal because normal people don't do what we're doing.

John discussed how he accepts his body's physiological reactions when diving as normal: "I think I just get to the end [of the platform] and I'm like, Hmm. Well, if my heart's racing, good. It should be. Perfect. Glad you're here, [John]. Cool.” John summarized his strategy for acknowledging and accepting fear by referencing a popular movie:

It's just kind of like Ricky Bobby in the car with Karen the cougar. Just calm down and just recognize, yeah. I'm in the car with the cougar. I'm on 10 meter. The cougar's there, but the cougar doesn't have to attack me while I'm trying to do something.

Beyond acknowledging and accepting fear, participants also spoke to the need to commit to action with the dive. This was most often reference in a sentiment such as "just do it." For example, Mike reported he had to "just do the dives that scare the crap out of me." Megan said, "even though you're scared, it's better to just do it anyways, because then eventually, hopefully, you won't be scared of it. That's the only reason I've become comfortable with my dives because I was scared, and I did it anyways.”

For Mike, trusting that his body would know what to do in the air has helped:

When I'm doing gainer on platform, I think about just getting off the platform. Like, I've been trying, don't think about the dive at all and just stop thinking about it in general. You'll know what to do once you're in the air. It's just getting off the platform is the hard part, I think. 
Julie highlighted the importance of acceptance of fear and committing to action in the longer term, as she realized that if she "was afraid of something, I would try to want to do it instead of avoid it until I get over the fear" because otherwise she "always ha[d] it kind of in the back of my mind." She reported that, "in the past, too, whenever I've been afraid of something and not done it, I have experienced that it's gotten worse."

Use of psychological skills. Participants described a number of psychological skills utilized to aid them in the process of acknowledging fear, accepting it, and committing to action. Participants referenced focusing on the process of their dive, selftalk, deep breathing, mindfulness, routines, and also "tricking" themselves about what dive they were doing. Within the use of psychological skills category, several participants described their competition routines and strategies to stay focused within competition including specific preferences in how they spend their time between dives (e.g., around or not around other people, watching or not watching the competition, viewing competition as practice, etc.). These routines are described more fully in the Competition-Specific Coping category within the Differences Within Competition Context domain.

Related to focusing on their process, several divers described focusing on specific aspects of their dive as strategies to overcome fear. Mike reported thinking of "one thing," which for him was trying to "focus on my hands when I'm getting started." Focusing on his "hands and how tense they are, and my body is" tended to push fearful thoughts "to the side" because he was focused on his hands. For Emily, focusing on her hurdle was important because "if I think about more things, then the fear aspect kind of overwhelms me." 
Several participants incorporated mindfulness techniques into their process. For example, Mike reported that when "all of these thoughts are rambling around in my brain," he focused on "just going back to the hands" and "thinking about my body in relation to the board kind of." He also reported "trying to feel grounded for a second." Emily also described how work with the MPC and a sport psychologist on mindfulness had helped her:

MPC's actually really helped me with that, doing the centering activities, where you just close your eyes for five minutes. Also, [Sport Psychologist] has taught me about that, too, where you just need to close your eyes for like five minutes, and just refocus on where you are right now, bring yourself to the moment, think about your surroundings and what you're hearing, think about your breathing and stuff like that. And it kind of just will calm you down, kind of make you realize, Okay. I need to readjust my mindset [laughter], stop being so fearful, because I know what I'm doing.

Six participants described utilizing some form of self-talk within their coping process. The intent and purpose of this talk varied. Mike reminded himself that "you want to do this dive" and "tell yourself that you want to be there and you want to be doing this dive right now" to push past fear. Two participants convinced themselves that they were doing a different, less scary, dive that they were on. Nick, who experienced a higher level of fear on a full out (front dive with two and $1 / 2$ flips and one full twist), would tell himself “you're going to get a good hurdle. Everything's going to be fine. You're just doing front two and a half pike" and then "right when I get to the end of the board, I'm like, Sike! I'm doing full out." Julie used this strategy when she was balking on a dive. 
She told herself "ok, I'm just doing a front jump" and then "after I do the hurdle, I do the dive to make my brain not freak out too much."

Two participants reminded themselves of successful past executions to cope with fear. Kevin tried to ignore fearful thoughts and "go back to the fact that I've done things before many times successfully, so I should know that it's been successful before. It's going to continue to be successful." Megan reminded herself of this if there has been several weeks since her last attempted execution of that dive:

It's only been two weeks since I've done the last one. But whenever I learned it, I'd never done it before. So, it's got to be at least as good as that one, right [laughter]? At least I like to believe that. It doesn't always end up like that [...] And sometimes I feel like I forget that. The first time, you've never done it. You can do good the first time, though. You can do it good this time.

Katie also spoke to the use of self-talk in a meet setting, noting that she used "a lot of self-talk" and "told myself over and over again, I was like, this meet does not matter." She shared:

That's really the only way I know how to cope with, I guess, the performance fear in a meet is just to be like, it literally doesn't matter if I don't do well. I'm not going to die. It's not the end of the world. Life goes on. It's fine.

Five participants referenced the use of deep breathing as some aspect of their routine. Kevin tried to "slow down my breathing" because it "slows everything down and makes it seem like I'm focusing more." Katie and Julie used deep breathing to calm their physiological reactions. For example, Julie "always try to do deep breaths and things before I go just to lower my heart rate and be more relaxed, like a practice setting. So, I 
definitely feel like it can tighten me up a little bit, so I just need to stay loose and relaxed."

Finally, Nick described learning a unique routine, incorporating several different psychological techniques, to help him cope with a high level of fear when trying to learn a back dive with three- and one-half flips from the ten-meter platform:

For most of my dives, 10 is not an issue, but this one, I don't know. It's the biggest I have learned up there so far. So, I would go up there, stand, wait for [Coach] to call me or call 10, and that one never worked. So I was like, [Coach], what if we just start building up dives to where I stand literally at the end for two seconds, turn around and go? He was like, 'Yeah. Let's try it.' So we did that with my leadups and that went really well, and I was like, [Coach], I think one more thing I want to do is just stand on seven meter before I go. You're going to call me. I'm going to run up to 10 meter, run to the end. I throw my shammy down, look at the water, turn around and go. And that's how I learned it. So definitely affects the[...] I think I've just got to keep my mind busy at those points. That's why I kind of feel-- when I get feared I kind of start thinking more, not about diving but just thinking about anything that's popping in my head. And I move around and so I'm kind of like nothing's still. Everything's kind of still moving and I'm just kind of waiting for that scary moment to happen. It's in the back of my head, but I'm not there yet.

Nick learning this routine also impacted teammates, as two teammates described his learning of this process within their own interviews. Katie noted that Nick "does a really good job sometimes of coping with his fear" and described her perception of his routine: 
He does this really weird thing. And everyone thinks it's weird but it works for him where he'll -- he learned a new dive and it's really scary at the beginning of the year. And he learned it in the bubble machine. [...] So, he learned it in the bubbles and that was the only way he would go was if he had the bubbles. But [Coach]'s like, 'You can't have the bubble all the time. It just doesn't work that way. You can't do it. You have to compete it. You can't have a bubble.' So he'll wait on seven meter, because he gets freaked out if he stands on 10-meter for too long, and then [Coach] will be like, 'Okay, [Nick]. Your turn.' He'll run up to 10 meter, instantly stand on the end, look down at the water, and [Coach] will tell him like, 'Here comes your bubble,' even though it's not coming at all. And he'll look at the water and pretend he sees his bubble. And then immediately turn around and go before he misses his bubble [...] So he pretends. It's almost like he's visualizing seeing it and he's-[...] He's telling himself like, the bubble's there so I'm not going to get hurt. It's going to be okay. So I guess that's something I see [Nick] doing which is interesting because he found something that works for him. No one else does that. Everyone's like, 'What you doing? You know that bubble's actually not coming.' [...] But that's something that he does. [...]. And it looks weirder in a meet. He'll stand up there and he'll look at the water and then turn around and just go. And everyone's like, okay. Interesting. But he went. And it was a good dive. Julie also described the experience of watching Nick learn his strategy for coping with the fear from this dive: 
He was just afraid of learning it because it was scary. So, it took him a really long time to learn it. But when he did it, it was really good. And he's still scared of the dive, but he's found out the system. If he gets up, and turns around, and does his dive, he'll be fine. But if he stands up there for a really long time, waits around, it gets worse for him. So for him, even-- I don't know if I would necessarily apply this to me, but he'll stand on the 7-meter and won't even stand on 10-meter before his 10-meter dive because it's like if he's up there, he's thinking more about his fears versus if he just runs up there, does his dive.

Thus, the other participants identified a strategy that was unique to Nick in helping him cope with fear, which also allowed him to execute a dive that elicited a high level of fear.

Using social resources. Participants utilized others in their life to help manage their experience of fear. Specific resources identified included teammates, coaches, and sport psychology personnel. Related to [Coach], Katie noted how [Coach] would talk to her when she was scared and remind her that "you don't know what's going to happen when you're standing on the board $[\ldots]$ but once you leave, your body will know what it's doing." This reminder helped her to calm down. Julie spoke to how [Coach] had discussed focusing on enjoyment rather than outcomes, so she was less worried about pressure or if she had a poor meet.

Participants discussed using their teammates as models or as sources of support. Two participants spoke specifically to looking to John when they were fearful due to his approach in managing fear. Nick noted that John "does some crazy stuff" and "he'll just do anything that [Coach] tells him to do." So, "every time I'm down in the dumps like, oh, I don't know if this is going to happen, I'll give [John] a little look or I'll look at him 
and he's usually pretty good." He reported that John "knows when I give him that look, it's on. We're doing some big stuff today." Adam also mentioned that John had a positive impact on him, noting that "one of my coping methods is to get another person to do a new dive" with him, since "it really helps when someone's in the same boat as you." $\mathrm{He}$ identified John as a person who helps, and Adam described how this helped him reduce fear on a dive:

[John] is kind of that person. Whenever we're scared of something, or I guess just scared of a dive, we'll go straight at it. I used to be really scared of gainer $21 / 2$ pike, but every practice we had to do it, we would do that first and get it out of the way, and then we just kept doing it and doing it, and then it just stopped being scary. So it's like he helped.

Two participants turned dives into a competition with teammates in practice as a strategy for reducing fear. John reported:

I'll compete with a teammate. And you into a competition mindset and suddenly you're not thinking about how afraid you are but, I'm going to beat this person. Sure. And that's what this team is. Everybody is competitive. So when you can bring someone out of that fearful state to, I'm going to get a 10 because I'm going to beat you, the fear kind of melts away. So, if you're making light and you're going quickly in a competition mindset, I found that you can bypass fear if you don't know how to accept it as part of what you do.

Anna also reported that "turning a dive that both me and a teammate are struggling with or don't like to a competition that sometimes helps." In that case, "they're challenging me to do well and to get it off the board if I may have been balking a lot." 
Avoidance. Some participants discussed either personally experiencing or observing others avoid dives to reduce fear in the moment. Mike described himself as "a master of avoiders" as he "put off dives all the time," which was "a bad habit." He shared that he "will make up excuses not to do" the dive, though he was realizing that he needed to that he "accept it and kind of push past that." Four participants reported observing this behavior in practice in general. Julie noted that "every once in a while, people won't want to do dives, so they will either just avoid it or not do it." Adam also mentioned that people will "balk or just not do the dive" and "just let fear overcome them." John observed that people may sit in the hot tub by the pool for a long time as a strategy to avoid dives. Participants generally spoke about avoidance as a negative coping strategy, though they did not discuss specific impacts of avoidance strategies at this time.

\section{Growth and Personal Development}

Beyond specific strategies or impacts, participants also addressed how their experience with fear in general has changed over time. Participants discussed different themes of learning that had occurred including learning new coping skills, learning about dive execution, and learning more about their own experience of fear in general. Two categories emerged within this domain: (a) decreased fear in executing dives and (b) coping abilities.

Decreased fear in executing dives. Most participants spoke to how the level of fear that they experienced in executing dives over time had decreased both across the season but also generally over the course of their career. Katie spoke to this phenomenon: It's like the repetition that decreases the actual fear of doing the dive, or like the fear of injury and stuff. And then, so by the time I get to the end of the season, I'm 
like, I did 10 of these yesterday and I was perfectly fine. So I'm going to be perfectly fine today.

Specifically, she "used to be afraid of hitting my head on the tower;" however, at this point in season she has "done how many this season and I've never once been close to the tower." This helped her "realize that those fears are irrational and not really relevant."

Anna discussed how doing the dives more over the course of a season decreased fear over time. She had switched her reverse dive with two- and one-half flips from the tuck position to pike position. This was initially a scary switch, but she realized that she did not "absolutely hate doing this dive I practiced" anymore, though she still disliked doing the dive. Megan described this as representative of her team's experience in general: "We're at the point in the season where we have many of each dive underneath our belt. Our lists are set. We're getting pretty comfortable with it." For Adam this decreased fear in executing dives also occurred in meet settings, as "it's getting a little less fearful going into meets and stuff," but now "it's getting a lot less because [he is] just getting used to it."

While most participants spoke to a theme of experiencing decreasing fear over the course of the season, Anna spoke to how experiences of learning new dives has decreased her fear over the course of her career. She shared that, in learning a new dive from the ten-meter platform this season, her experience was "probably better because I've learned now several dives on 10-meter since I've just been at [Current Institution]." She elaborated that, while the twisting aspect of the time was a bit scarier than other dives, she "still had had the experiences of learning other dives on 10-meter, so the act of actually being on 10-meter was less scary.” In addition to generally experiencing less 
levels of fear over time, participants also spoke to how their abilities to cope with fear improved over time.

Coping abilities. Specific coping skills were addressed more thoroughly within the Individual Attitudes and Strategies towards Coping domain. Thus, this category addresses the theme discussed by participants of how they have learned and improved in their coping abilities over time.

Four participants discussed how their acceptance of their experience of fear had improved over time. John had learned to accept that "the uncomfortable feeling is normal because normal people don't do what we're doing." Acceptance of the uncomfortable feeling also helped him accept his body's reactions in the moment:

Once you kind of come to that acceptance, you can kind of move past the fear because, man, my heart's racing out of control. My body's shaking. And you just kind of say, yeah. Good. That's normal. That nobody does this, so of course my natural body's reaction is to be shaky and nervous and I am alert and $200 \%$ ready for what I'm about to do.

Nick reported that [Coach]'s has helped him realize that "you're not going to have the answers $100 \%$ of the time" so he has "got to trust [his body]'s going to know what it's going to do" and that he will "figure out the outcome anyway." Julie expressed the need to expect and be ready for fear:

In competition, I think I've just kind of learned to recognize that it's always going to be there. So instead of trying to get rid of it, try to expect it. So just get out there and know you're going to be afraid and know that you're going to do the 
dive anyway and everything's going to be fine. So just maybe try to calm it down the best you can, but it is going to be there. So just to be ready for that.

John also spoke to the idea of accepting that fear would always be present, noting that he was "mature enough in the sport to recognize that it's diving. That's part of diving. Being afraid is part of diving."

Several participants also spoke to specific aspects of their coping strategy that had improved over time. For example, John reported how he has learned to embrace the idea that he was not normal, take pride in this fact, and focus on how his actions impact others as a way to cope with his own fear:

I was talking to MPC about it, I think. And she was just like, 'Well, what you do isn't normal.' And then I was on a gainer, and so I was like, maybe I should think that right now. And I was on seven meter, and I was like, man. [Coach], I'm super nervous right now, and then the back of my head just thought about it, and it was like, good. I was like, what? [...] Why would I do this? Why would anybody do this dive?" [...] I was like, I'm crazy. Oh, okay. I'm crazy. Okay. Let's go. Let's do it. Just embracing the fact that you're not normal [...] But I've grown into the athlete where you take a hard smack and while you're underwater you just think, how I come out of the water is going to set the tone for everyone. And I'm aware that my reaction to that will either cause fear or inspire. So, I've done 10-meter optionals where I smack, and I think that I'm about to die. But I know I'm not. But I come out of the water and I just say something sarcastic and just kind of just silly. [...] And you grow into it, I guess, is what I'm saying. 
As mentioned in the use of psychological skills category, Nick reported that he had learned an entirely new coping routine to manage fear on a dive from the 10 -meter platform, during which he experienced a high level of fear. Nick also shared that, specific to competition, he now "tend[ed] to think of it as a practice," since he was "always pretty jolly" and liked to enjoy himself.

Several participants described learning about what they needed to do in order to be successful. These directions of focus were unique to each participant. For example, Anna expressed that focusing "on making a lot of the corrections that I've been practicing in practice" helped her not compare herself to others. Julie reported that she recognizes to herself that "if I get a bad hurdle, I can still put a dive in for a decent" score rather than feeling like she needed a perfect hurdle. Mike reported learning to go "back to [his] hands" and "thinking about my body in relation to the board." He reported this helps him "feel grounded for a second and just take a deep breath," "look off to the end of the board, and just be like, 'okay. You know what you're doing."' Katie shared that, rather than focusing on outcome, she has realized she needs to focus on having fun:

You can't really control the outcome of a meet, because you could still have the best meet of your life, but everyone else is still better and you don't qualify $[\ldots]$ so it's just a lot easier to make sure that I'm having fun than to make sure I get a certain outcome.

Related to focus, Emily reported that she has learned to focus on how to use fear to her advantage and "try to think about it as something else rather than fear itself." She reported finding it more helpful to think about fear "as an obstacle [to overcome] rather than a setback." 
Three participants spoke to improved abilities at focusing on themselves in competitions rather than others. Anna shared she has "gotten better throughout the season with dealing with my own fear in competition" and "focusing more on myself than other people." She has "learn[ed] to just focus on my diving and nobody else's" since "it doesn't matter what they're doing or where I end up compared to them. It matters how I did myself." Kevin learned to focus on himself and "realizing the fact that other peoples' actions don't really affect mine when it comes to diving" which he has tried "to keep that in the front of my mind" when in competition:

It's kind of hard to accept the fact that all my actions are on my own, because everyone wants to blame other things. [...] I can't do anything about [Competitive Diver] doing a 109 [front dive with four- and one-half flips] for 9's, so-- but I can do-- the fact that I can control whether I get like a two on a front $3 \frac{1}{2}$ versus a seven.

Nick also spoke to improving at focusing on himself, noting that "now, since I can shake that, I can kind of not hinder myself" because he was "afraid of doing the dives, and I was afraid of people not-- thinking I wasn't good enough" Since he improved at coping with that fear, he had "the opportunity to kill two birds with one stone and do good dives that I won't be afraid of" and "people will think, hey, this man's actually not he little kid he was."

Finally, two participants spoke to improved ability to recognize their experience of fear when it was occurring. Mike increased recognition of his tendencies to procrastinate when fearful: 
It'll make me not want to do a dive and it'll make me subconsciously put it off. Well, I don't know. I'll make up excuses not to do it. Yeah. I'll just make up really dumb excuses, like, hey, can I work on this instead of this because blah, blah. And I think that's the way it negatively affects me. But I'm kind of realizing that. I've realized it. I just got to accept it and kind of push past that that's when I do those things where today I want to challenge myself. I'll do the dives I don't want to do. Mike also spoke to increased recognition around what type of fear he was experiencing, which was in part spurred by the first interview in the beginning of the academic year: I think I'm a lot better at handling fear. I'm a lot better at being able to do shade away, or kind of just ignore it for a little bit. Because I'm going to be honest. After the last interview we had, I kind of thought about the questions you asked me because I kind of wanted to see if I could figure out how to best for myself. And the first question that you said was how would you describe fear, like what is the most fearful thing for you. I gave you tower diving or big dives on tower, but then I sat down a month after that, [Coach] was starting to talk to me about the art-- or not knowing. And I was like, dude, that's exactly what I'm afraid of. So, I kind of, since now-- or from then to now, I've kind of been figuring out myself how to put these questions, and put my answers, at rest, I guess. [...] because usually I never think about fear. It just kind of bridge when I get there. And now it's kind of a-- I can be proactive. I can figure out tactics on how to tackle it.

Thus, the ways in which coping abilities improved over time ranged from increased ability to recognize fear, improved routines or strategies in coping with fear, increased 
ability to accept fear, better ability to redirect focus to helpful aspects of performance, and a better overall understanding of their experience.

\section{Summary}

Within this time point, participants described factors that were seen as beneficial towards their experience of fear and factors that increased their sense of fear. Positive support from the coach, modeling of coping with fear by teammates, use of other social resources including sport psychology personnel, and a general team culture of support and encouragement of overcoming fear were seen as beneficial. Factors that increased fear including general uncertainty related to the dive outcome, specific contextual factors such as the apparatus or type of dive and observing events that provoked fear or anxiety in teammates or competitors. Participants described experiences unique to the competition context included increased pressure related to needing to execute the dive in the moment, increased awareness of competitors and the possibility of social evaluation, specific coping needs within the competition environment, and differences in the quality of fear experienced within the competition setting.

Participants identified several negative impacts of fear including distraction, worry, mental fatigue, atypical technical execution, balking, and general underperformance. They also described benefits of fear including increased confidence after overcoming fear, improved focus, safety, and motivation to overcome fear. Participants described how coping strategies were perceived as unique to the individual and could include acceptance and commitment, using various psychological skills such as self-talk or deep breathing, seeking support from others in their life, or avoidance.

Finally, participants spoke to how, since the first time point, they felt generally that their 
level of fear in executing dives had decreased and their abilities to cope with fear had improved. John summarized his experience of fear with this message he hoped to leave those in the future:

It would be that I would want to leave that you're supposed to be afraid. Good be afraid but that's part of it. Step back and look at this is the moment that I'm afraid [and] then, while you're stepped back removed from the moment, you can look forward to the point where you're not going to be afraid because that's what diving is. It's a journey. It's a long road and, man, this is dive is so hard right now. Oh right, that's the point in my diving career where that dive sucked but maybe over there it's awesome. Cool, that's the moment I'm in.

\section{Integration of Both Time Points}

Interview data. Overall, there were numerous similarities in themes across the two time points. Some domains and categories were largely similar across time including domains discussing coping strategies and the impact of fear. The Impact of Fear domain included the same categories cross time points, which could demonstrate consistency across time in how divers felt that fear could impact their performance such as distraction, worry, increased adrenaline, confidence after overcoming fear, or altered technical execution. The domain addressing coping strategies was also predominantly similar, though participants spoke more to using a process orientation in the first time point rather than the second time point. There were elements of a process orientation within the second time point; however, the data did not rise to the level of a category at that time. However, other categories of acceptance and commitment, use of psychological skills, using social resources, and avoidance were discussed within both time points. This 
is not to say that the specific coping strategies utilized by participants were the same at each time point, but rather the general categories of coping strategies identified by participants were consistent over time.

Although the previously discussed categories were predominantly similar across the time points, several other domains and categories showed similar themes over time but differed in the organization of the data based on the amount that participants discussed those elements. These domains included time point one domains of Uncertainty over Dive Outcome, Contextual Factors, and Social Influences and time point two domains of External Protective Factors, Risk Factors, and Differences within Competition Context. Participants spoke to experiencing uncertainty over the dive outcome at length, which emerged as a domain given its presence within the data at time point one. This theme was still of note to participants within time point two; however, it was placed at a category level due to seeing uncertainty discussed in a larger context of factors that negatively influenced divers' sense of fear (e.g., Risk Factors domain). This also occurred with regards to dive-specific contextual factors, which were discussed in more detail and at more length in the first time point in comparison to the second. However, similar themes were noted among the number of participants who did discuss dive specific factors within the second time point such as experiencing more fear on tower, increased challenge with specific dive types, or the challenge of learning new dives or executing them after a break. Though, the concern over executing a dive after a break was discussed more at the second time point while the first time point tended to have more data related to concern over learning new dives. This could be due to what primary concerns divers were experiencing at the different time points. At time point 1 , 
divers were often learning several new dives within their various dive lists. At the second time point, divers had already executed the new dives that they planned to for that season. However, they had recently taken a week's break from diving due to traveling for the holiday season.

Social influences on fear were also present within both time points. At time point one, this emerged at a domain level including elements such as vicarious experiences, coaching staff members, and teammates. At time point two, categories of social influences such as coach support, teammate modeling, and team culture fell within the external protective factors domain as participants largely spoke to how these factors were helpful in managing their fear.

Due to providing more background information within time point one interviews on previous coaches, participants presented more varied experiences of the impact of their coaches on fear in time point one compared to time point two. Participants spoke to ways in which previous coaches had not worked well with fear or had not addressed divers' fears within time point one. While there were some occasions participants noted when their current collegiate coach had unintentionally increased fear at time point two, [Coach] was generally viewed as supportive, helpful, and understanding in working with divers who experience fear across time points. Thus, when discussing themes of coaching in the second time point, divers generally viewed this as a protective factor in helping with their experience of fear given the positive working relationship with him and his understanding of fear.

Sport psychology personnel, such as the MPC, were discussed at both time points in varied ways. Within the first time point, MPC emerged as a category within the Social 
Influences domain. As the social influence domain was not present within the second time point, influences of MPC's work with divers at the second time point were discussed predominantly in relation to coping strategies or growth and personal development through either decreased fear or increased capability to cope with fear.

A new domain at the second time point that was present at the category level at the first time point was Differences within Competition Context. Within time point one, participants spoke to the impact of setting on their fear as a contextual factor. Divers provided more nuanced descriptions of the impact of competition on their experience of fear in the second time point including the impact of needing to execute, their unique coping needs such as not necessarily being able to rely on teammates, and increased social awareness. Fear of failure was also discussed within this category including worry over letting others down as an element of social awareness. This could also have been due to the time in season, as divers had already participated in a number of competitions and were approaching higher level competitions such as the conference meet. Thus, fears related to competition may have been more present within their mind at that time point compared to the first time point.

The Growth and Personal Development domain was the one domain that was completely unique to the second time point without overlap across domains or categories with the first time point. This was likely due to the timing and structure of the interview process, as participants were asked to speak to the ways in which their experience of fear at that time point compared to the first time point. Participants described ways in which they had grown and improved over time, though this was not necessarily limited to growth only since the second time point. 
SAS-2. In general, differences in scores between the two time points varied across participants. Two participants increased overall scores on the SAS-2 over time (See Table 4-1 for compiled results from two time points), six participants decreased overall scores on the SAS-2 from time point one to time point two, and two participants exhibited the same overall score from time point one to time point two. For several participants, changes over time were small. For example, Adam's score increased by one total point while Anna's score decreased by two total points. Other participants had larger changes in their anxiety score over time, including three participants whose overall SAS-2 score decreased by 7-9 points and one participant, Julie, whose score decreased by 15 points overall.

Participants also varied in which of their scores on subscales increased or decreased. For example, Mike increased scores in both somatic symptoms and worry. Adam increased only on the somatic subscale while other scales remained stable. Three participants had varied scores with slight increases on some subscales and decreases on others from the first to second time point. Four participants showed decreases on all three subscales including Nick, John, Emily, and Julie. Finally, Kevin reported the exact same scores on each subscale from the first to second timepoint. He also had the lowest overall SAS-2 score of all participants at both time points. 


\section{CHAPTER FIVE}

\section{DISCUSSION}

This study examined factors that influenced divers' experiences of fear within their sport and the ways in which this impacted performance. Using CQR methodology, the research team interviewed ten current collegiate divers at two time points in their competitive season, August and January, to examine the experience of fear at different periods within the season and capture potential changes in the experience over time. The research team consisting of three primary data analysts and one external auditor analyzed the interview data to find emergent domains and categories.

At the first time point, which occurred in late August to early September, participants discussed reasons they may experience fear including fear of injury, fear of failure, and generally never being able to count on knowing how a dive would be executed. Even for previously well-learned dives, participants described feelings of uncertainty that could continue to arise with the dive. Participants also described specific contextual factors that influenced their level or expression of fear including specific dive factors such as apparatus or dive type, with more fear generally being associated with platform dives than springboard dives. Social influences were also identified, as participants noted the challenge of vicariously experiencing fear from others, the importance of the role of the coach in addressing fear, and the impact of teammates and other support staff such as a mental performance coach. Divers described ways in which they coped with fear, which was seen as unique to the individual. Strategies included general importance of accepting fear and committing to executing the dive, use of specific psychological skills such as routines or imagery, and focusing on the process of 
the dive. Divers also described using avoidance to cope with fear, which was not viewed as a positive or adaptive strategy. Finally, divers identified ways in which fear impacted performance including negative cognitive impacts such as worry or distraction, negative impacts on performance through atypical technical execution or general underperformance, and physiological symptoms. Participants also described potential benefits of fear including increased focus, increased confidence when they are able to overcome fear, and maintaining safety.

Participants expressed some similar experiences at the second time point, particularly in how fear impacted their performance in addition to general categories of coping strategies they utilized to manage fear. Participants spoke to several protective factors that positively impacted their experience of fear including support from the coach through different mechanisms including emotional support, engaging in discussions around fear, or structuring practices to help athletes overcome fear. Factors that were found to increase fear included vicarious experiences through observing teammates or competitors, specific dive factors such as the apparatus, and a general sense of uncertainty over the outcome of their dive. Participants also discussed how their experience of fear differed within the competition context compared to the practice setting, including increased awareness of social evaluation from others, needing unique coping strategies in competition compared to practice, and pressure related to the challenge of executing dives on demand. Finally, participants also spoke to how their experience of fear had grown and changed over time. They described a general sense of decreased fear in executing dives over time and improved skills to cope with fear at the second time point. 


\section{Conclusions}

A number of conclusions can be drawn from the data across time points. Foremost, the interviews suggest the importance of acceptance that fear is an inherent part of the sport of diving. This understanding moves beyond a passive acceptance, but rather speaks to the need to actively acknowledge fear, recognize its potential impacts, and commit to executing dives. Participants described previous negative experiences of coaches who minimized fear, as one coach told a participant that "fear doesn't mean anything." This advice was inauthentic to the participant's own experience in that fear was a challenge and a barrier in their diving. All participants identified fear as a part of their experience of diving in numerous ways, and to try to ignore that aspect or pretend it was not present did not allow participants space to work with or past their fear.

Many participants spoke to either engaging in avoidance behaviors or seeing others avoid dives due to fear, which was not seen as a beneficial coping strategy overall. While several participants often simplified this concept into needing to "just do it," it was clear that a number of factors were necessary in being able to "just do" the dive when fearful. The focus on the importance of acceptance and committed action is consistent with mindfulness and acceptance-based models and theories that have been adapted from the field of psychology and emerged within the sport psychology realm (e.g., Gardner \& Moore, 2004; 2007; Hayes, Strosahl, \& Wilson, 2012).

Beyond the need for acceptance of fear, the results of this study also illuminate the types of fear that a diver may experience. Divers within this sample identified experiencing both fear of failure and fear of injury (Conroy \& Elliot, 2004; Duda, 1995; Duda \& Gano-Overway, 1996; Klint \& Weiss, 1986; Kori, Miller, \& Todd, 1990; Sagar 
\& Lavallee, 2010). However, the source of fear that seemed to underlie fear of failure and fear of injury was more nuanced: the unknown. Certainly, divers experienced fear based on previous personal fearful experiences in diving; however, many participants also spoke to times where there was no specific source of their fear. Rather, they experienced fear because they could not count on the outcome of a dive at any point. Pattinson and Cotterill (2017) also briefly noted this phenomenon, though described this more in the context of learning new or unfamiliar dives. Within this sample, it was clear that even with well-learned dives, there was always a chance that the dive could go wrong due to the precise nature of execution within their sport. The presence of the unknown was seen both related to fear of injury, particularly when executing newer dives or when changing technique on existing dives, and also fear of failure in competition due to some participants having lower confidence in their ability to successfully execute the dive on demand in competition. This uncertainty and possibility that they could become injured was also a factor divers needed to accept within their sport in order to successfully execute dives.

Clearly, fear is a complex emotion in the sport of diving. This lends to the importance of working to understand the experience of fear within its full personal, social, and environmental context. Fear was not seen just in response to the height from which they were executing the dive, though that was certainly a factor. Rather, numerous variables influenced their fear including vicarious experiences, dive type, previous experiences on the dive, coaching style, team atmosphere, type of setting in which they were executing, and time since they last executed that dive. Several of these factors were previously identified as contributing to anxiety or fear within the literature (McGregor \& 
Abrahamson, 2000; Pattinson \& Cotterill, 2017; Post et al., 2014), though this study provides a more nuanced and complete understanding of these factors in combination with one another.

There were also numerous social influences on the experience of fear, consistent with Social Learning Theory (Bandura 1963; 1977). There was support for vicarious learning of fear through observation of others at both time points. Two primary social influences that emerged included the coach and teammates, which is understandable given the amount of time that collegiate athletes spend with their coach and with their teammates. As seen in Pattinson and Cotterill (2017), factors of trust in the coach's expertise and support from the coach were seen as facilitators of working with fear. Additionally, similar negative coaching behaviors across studies included lack of diving knowledge, rushing the diver to do dives before technically ready, or not providing emotional support to the athletes. Within the current study, the participants generally trusted their coach and found him to be supportive in their experience of fear, though some divers noted experiences of previous coaches who had differing approaches. Related to teammate influence, teammates could serve as either positive models of coping with fear or negative models as what occurs if one is unable to adaptively cope with fear. Additionally, the general atmosphere and culture among teammates in coping with fear served to impact the individual as divers learned expectations for how fear was handled among the team from each other (Bandura, 1977).

Of note, parents were not often discussed in the context of social influences on fear in divers' day to day experiences. However, several participants discussed parents more specifically when discussing fear of failure or letting others down in their life. For 
example, Emily mentioned texting her mother after a poor competition to apologize for letting her down. This could be due to the level of involvement of parents at the collegiate level, as parents are not often involved or present at day to day practices; however, they may be more involved in attending to or watching larger competitions. Additionally, the competition context brought up a general heightened sense of social awareness, which seemed to include parents. The impact of parents on fear could be explore more in depth in further studies, as the reason for which parents were discussed in this manner was not further explored.

Another general conclusion based on the data was that participants generally viewed fear as primarily hurting their performance in diving. Similar to Post et al. (2014), many participants described ways in which fear kept them from practicing specific dives such as balking or engaging in avoidance behaviors. While not addressed with this language, participants also spoke to some themes consistent with literature on Lost Movement Syndrome (LMS) or mental blocks (Bennett, Hays, Lindsay, Olusoga, \& Maynard, 2015; Bennett, Rotherham, Hays, Olusoga, \& Maynard, 2016, Collins, Morriss, \& Trower, 1999; Day, Thatcher, Greenlees, \& Woods, 2006; Pattinson \& Cotterill, 2017). Participants described experiencing loss of awareness in dive, having days where they are unable to go on previously learned dives, and differences in technical execution of dives. Additionally, there were numerous similarities in this data compared to Pattinson and Cotterill (2017)'s analysis of mental blocks with divers including worry, physiological sensations, concern over smacking, and the concept of the unknown. Additionally, similar beneficial aspects were seen across the data including positive 
coach support, positive team atmosphere, use of psychological skills, and adapting their training environment to their needs.

While some atypical execution could be potentially contributed to an experience like LMS, divers also noted engaging in these behaviors for potential safety. The protective function of fear was noted within the impact of fear category at both time points (Ekman, 1992; Olsson \& Phelps, 2007), as fear could lead to atypical technical execution in order to protect from a real or imagined threat. Divers acknowledged that, at times, this safety function was needed as divers were in real danger of hitting the board or tower. However, participants also recognized that there were numerous instances where technical changes due to fear were not truly needed to maintain safety but rather were a response to feelings of discomfort or cognitive worry. Impacts on attention also varied, consistent with previous literature. For example, some participants described benefits of fear including increased focus on their dive, which has been seen to be of benefit in some performance contexts (Buckley, 2016); however, at other times fear led participants to direct attention towards threat-related stimuli like the outcome of their dive and lose focus on the task related stimuli such as their hurdle (Eysenck, Derakshan, Santos, \& Calvo, 2007).

Given the numerous ways in which fear was experienced and also the unique ways in which fear impacted individual divers' performance, it is also understandable that divers would have unique and individualized coping needs. Consistent across time points was the theme that coping was unique to each individual and that there was no one right way to cope. Multiple coping strategies were discussed including acceptance, commitment to executing the dive, various psychological skills, using social support, and 
avoidance. Previous literature has focused on specific psychological skills such as selftalk, rationalizations, and imagery (Highlen \& Bennett, 1983; Post et al., 2014), which were also supported as coping skills within the current study. However, the current study expands beyond the psychological skills training model to include support for other potential strategies including acceptance and commitment-based approaches (as seen with Schwanhausser, 2009) and intentional use of social resources such as the coach, teammates, or other athletic personnel like sport psychology practitioners.

This study lends to the idea of being creative in considering ways in which divers could cope with fear and encourages mutual input and discussion among team members to consider new ways of coping. Nick was a primary example of this, as he identified a strategy that could work for him, asked for what he needed from the coach, and also had support from his coach in helping to create a specific routine for coping with a high level of fear on a new dive. This creativity led him to find a routine that worked for him and also inspired other members of the team who observed Nick's level of fear and also his ability to do the dive with that fear. This approach may take more time and effort from both the diver and other members of the staff, as it could require discussion of what exactly the diver is fearful of, their mentality towards diving, and experimentation with specific strategies. However, the end result would be a routine specific to that divers' individualized needs.

A final conclusion is that divers' experiences of fear does appear to change over time. One way in which fear seemed to change over time was the type of fear experienced. Divers spoke more strongly to fear related to specific dive elements or of learning new dives at the first time point. However, at the second time point, divers spoke 
more to fear of failure and differences within the competition context specifically. This is not to say that divers did not experience both fear of injury and fear of failure at both time points; however, the source fear that was most pressing at that time appeared to shift across the course of the season.

Consistent with Social Learning Theory (Bandura 1963; 1977), divers’ experiences of fear also changed over time as a result of new learning experiences. At the second time point, this was predominantly viewed as growth and positive development over time as divers generally had decreased fear over time in executing dives and increased ability to cope. The decreased fear overall was consistent with have increased learning experiences, as divers had more opportunity to have positive experiences of successfully doing the dive without injury. This could increase self-efficacy in one's dive performance. Additionally, divers had more opportunity to learn what worked for them personally when it came to coping with fear. These experiences led to an improvement in experience of fear over time.

However, there were certain exceptions where fear increased on specific dives since the last time point. For example, Megan described increased fear on a previously learned dive after she unexpectedly hit her feet on the tower between the first and second interview time point. Thus, she had the opposite learning of introducing fear back into her experience based on a negative technical execution. However, this fear also decreased as she was able to have increased opportunities to have positive or neutral experiences with the dive later on. In sum, it is clear that divers need the opportunity to have positive learning experiences with a dive in order to overcome fear. This learning can come from 
their personal experiences or with influence from others; however, the importance is in accepting that fear exists and doing the dive with fear.

\section{Limitations and Future Directions}

A main limitation of this study is that generalizations of this data to other divers cannot be made. Participants within this study were all members of the same team at the same institution. They had all pursued diving with the capability of diving at a high level in college, which also means that they may have had inherent characteristics or experiences that enabled them to work with fear in continuing to pursue diving as a sport. There may be others who dropped out of sport as a result of inherent risk or fear; however, this type of population was not captured within the sample. Additionally, participants within this sample had been exposed to sport psychology principles at a minimum of engaging in weekly group sessions over the course of one season and, for some, had been engaging in group sessions for approximately $2 \frac{1}{2} 2$ years and also working one-on-one with the mental performance coach (MPC). Thus, ways in which these divers experienced or described fear could have been biased based on work with this MPC. Future studies with other samples of divers, including those who do not have prior experience with sport and performance psychology principles, is recommended. Additionally, this study highlights the various coping strategies and approaches that divers may use to influence their experience of fear. Given that results from this study indicate that fear changes over time, quantitative studies of fear and also intervention studies are recommended to more clearly understand performance enhancement approaches that are effective with this population. Given the success of the Schwanhausser (2009) case study and the importance of acceptance and commitment as 
discussed within this study, intervention studies from acceptance and commitment-based approaches in addition to the more standard psychological skills training approaches are recommended.

Potential impact of biases. One limitation is that of the potential impact of researcher biases on the data. As discussed in the methodology, several strategies were utilized to minimize the impact of researcher bias on the data including reaching consensus among the data analysis team and member checking procedures. However, it is possible the impacts remain. One of the main potential biases, as noted within Chapter Three, was the impact of time point one analysis on expectations for time point two. As discussed in Chapters Four and Five, there were noticeable similarities among domains and categories across the two time points, particularly in the impact of fear and coping strategies domains. Additionally, several themes that were prominent in the first time point also emerged at the category level within analysis of the second time point.

Researchers also discussed a bias that fear of injury would be more present at time point one while competition fears would be more present within the second time point. This bias may have impacted analysis as, at the first time point, more specific contextual factors related to the dive itself emerged as a larger domain while the impact of setting (e.g., competition vs. practice) emerged at the category level. The opposite occurred at the second time point, with differences in competition context emerging at the domain level and dive-specific factors at a category level.

Finally, the primary investigator operated from an acceptance-based approach and used psychological skills in working with the team on experiences of fear in addition to other topics. Thus, the research team could have been biased to see these themes within 
the analysis of coping strategies. Additionally, the sample itself could be biased towards these approaches based on their work with the primary investigator in a mental performance coaching setting.

Overall, researchers were aware of these biases throughout the data analysis process and believe the data analysis was as accurate a representation as possible of the participants' experiences. However, interpretations of the results should be made with these researcher biases in mind.

\section{Implications}

The current study expands on the literature with divers and adds an increase in depth and nuance to the understanding of experience of fear within springboard and platform divers specifically. There are a number of practical applications that have emerged as a result of this study for coaches, athletes, and sport psychology practitioners seeking to work with this population.

Time point 1 implications. Results from the first time point suggest the importance of attending to the numerous contextual factors that a diver may be experiencing when working with fear including their history with the dive, specific dive factors, and social environment. Ignoring or minimizing fear was not considered beneficial, particularly given the level of fear divers experience regarding learning new dives early in the season. Rather, coaches, athletes, and sport psychology practitioners should acknowledge that fear is an inherent part of the sport of diving and actively seek ways to cope with it including acceptance, psychological skills training, focusing on the process, and providing social support. These coping skills could minimize the harmful impacts of fear on performance including worry, distraction, atypical technical execution, 
underperformance, and overall loss of potential. Additionally, using coping strategies such as acceptance of the fear response could also help divers capture the benefits of fear including increased physiological arousal, confidence, and focus.

Time point 2 implications. Time point 2 suggests that the experience of fear grows and changes over time, which can be important to communicate to athletes. Creating positive habits of facing fear rather than avoiding it can serve to increase confidence in coping and decrease the overall experience of fear over time whether related to fear of injury or fear of failure. Additionally, it is recommended to look beyond the individual level and consider the general team culture and atmosphere in how the group responds to fear. The team culture and modeling set expectations for others in the social environment in responding to fear, so intentional creation of a culture of approaching rather than avoiding fear among the team would be of benefit to the whole system. However, attention to how one creates the culture of approaching fear is also important. Beyond the moniker of "just do it," discussions with the coach or other personnel about the steps of how to "just do it" is important, as pushing a diver to do a dive without adequate support can serve to increase the experience of fear.

General implications. Overall, this study underscores the importance of acknowledging fear directly within the sport environment. Seeking to avoid fear or pretend that it is not there was not seen as beneficial. Rather, finding ways to engage in discussions or self-reflection about fear was important in understanding the unique ways in which it could impact each individual athlete. Additionally, minimizing that fear has an impact could invalidate participants' experiences of fear. Once fear is acknowledged, it is also important to accept it as a part of the sport environment and sport experience. It 
may not be an enjoyable part, as the numerous negative impacts within this study could attest. However, one could be scared and do the dive anyways. Having adequate coping methods in place could also mitigate this impact and increase one's ability to continue to execute when experiencing fear. When considering specific ways of coping, it is clear that there was no one right way to do so. Rather, finding creative ways to work with fear could not only help the individual athlete but also inspire others on the team, as one teammate's attitude towards approaching fear could influence other teammates.

Additionally, more than one strategy may be needed as fear was seen to change over time and vary based on the time of the season. Thus, what one needed to do to manage fear related to learning a new dive could be different from what one needed to do in order to manage competition related stress. Overall, as John said, diving with fear is like being in the car with a cougar: "Just calm down and just recognize, Yeah. I'm in the car with the cougar. I'm on 10 meter. The cougar's there, but the cougar doesn't have to attack me while I'm trying to do something." 


\section{REFERENCES}

Aoyagi, M. W., \& Poczwardowski, A. (Eds.). (2012). Expert approaches to sport psychology: applied theories of performance excellence. Morgantown, WV: Fitness Information Technology.

Ardern, C. L., Taylor, N. F., Feller, J. A., \& Webster, K. E. (2012). Fear of re-injury in people who have returned to sport following anterior cruciate ligament reconstruction surgery. Journal of Science and Medicine in Sport, 15, 488-495. doi:10.1016/j.jsams.2012.03.015

Bandura, A. (1963). Social learning and personality development. New York, NY: Reinhart and Winston.

Bandura, A. (1977). Social learning theory. Oxford, England: Prentice-Hall.

Barlow, M., Woodman, T., Chapman, C., Milton, M., Stone, D., Dodds, T., \& Allen, B. (2015). Who takes risks in high-risk sport?: The role of alexithymia. Journal of Sport \& Exercise Psychology, 37(1), 83. doi:10.1123/jsep.2014-0130

Barlow, M., Woodman, T., \& Hardy, L. (2013). Great expectations: Different high-risk activities satisfy different motives. Journal of Personality and Social Psychology, 105(3), 458-475. doi:10.1037/a0033542

Bawden, M., \& Maynard, I. (2001). Towards an understanding of the personal experience of the 'yips' in cricketers. Journal of Sports Sciences, 19(12), 937-953. doi:10.1080/026404101317108444

Beck, A. T., Epstein, N., Brown, G., \& Steer, R. A. (1988). An inventory for measuring clinical anxiety: Psychometric properties. Journal of Consulting and Clinical Psychology, 56, 893-894. doi:10.1037/0022-006X.56.6.893 
Beck, A. T., \& Steer, R. A. (1991). Relationship between the Beck anxiety inventory and the Hamilton anxiety rating scale with anxious outpatients. Journal of Anxiety Disorders, 5(3), 213-223. doi:10.1016/0887-6185(91)90002-B

Bennett, J., Hays, K., Lindsay, P., Olusoga, P., \& Maynard, I. W. (2015). Yips and lost move syndrome: exploring psychological symptoms, similarities, and implications for treatment. International Journal of Sport Psychology, 46(1), 6182.

Bennett, J., Rotherham, M., Hays, K., Olusoga, P., \& Maynard, I. (2016). Yips and Lost Move Syndrome: Assessing impact and exploring levels of perfectionism, rumination, and reinvestment. Sport and Exercise Psychology Review, 12(1), 1424.

Birrer, D., \& Morgan, G. (2010). Psychological skills training as a way to enhance an athlete's performance in high-intensity sports. Scandinavian Journal of Medicine and Science in Sports, 20(s2), 78-87. doi:10.1111/j.1600-0838.2010.01188.x

Breivik, G. (1995). Personality, sensation seeking and arousal in high risk sports. Oslo, Norway: Norwegian University of Sport and Physical Education.

Brewer, B. W. (1994). Review and critique of models of psychological adjustment to athletic injury. Journal of Applied Sport Psychology, 6, 87-100. doi:10.1080/10413209408406467

Brewer, B. W., Van Raalte, J. L., \& Linder, D. E. (1993). Athletic identity: Hercules' muscles or Achilles heel? International Journal of Sport Psychology, 24, 237254. 
Buckley, R. C. (2016). Qualitative analysis of emotions: fear and thrill. Frontiers in Psychology, 7, 1-13. doi:10.3380/fpsyg.2016.01187

Castanier, C., Scanff, C. L., \& Woodman, T. (2010). Who takes risks in high-risk sports? A typological personality approach. Research Quarterly for Exercise and Sport, $81(4), 478-484$.

Chase, M. A., Magyar, T. M., \& Drake, B. M. (2005). Fear of injury in gymnastics: Selfefficacy and psychological strategies to keep on tumbling. Journal of Sports Sciences, 23(5), 465-475. doi:10.1080/02640410400021427

Creswell, J. W. (2014). Research design: Qualitative, quantitative, and mixed methods approaches, $4^{\text {th }}$ ed. Thousand Oaks, CA: Sage Publications.

Crotty, M. (1988). The foundations of social research: Meaning and perspective in the research process. Thousand Oaks, CA: Sage Publications.

Collins, D., Morriss, C., \& Trower, J. (1999). Getting it back: A case study of skill recovery in an elite athlete. The Sport Psychologist, 13(3), 288-298. doi:10.1123/tsp.13.3.288

Conroy, D. E. (2001) Progress in the development of a multidimensional measure of fear of failure: The Performance Failure Appraisal Inventory (PFAI). Anxiety, Stress, and Coping, 14, 431-452. doi:10.1080/10615800108248365

Conroy, D. E., Willow, J. P., \& Metzler, J. N. (2002). Multidimensional measurement of fear of failure: The Performance Failure Appraisal Inventory. Journal of Applied Sport Psychology, 14, 76-90. doi:10.1080/10413200252907752

Cox, R. H. (2012). Sport psychology: Concepts and applications, $7^{\text {th }}$ ed. New York, NY: McGraw-Hill. 
Datalys Center. (2014). Football injuries: Data from the 2004/05-2008/09 season.

Retrieved from http://www.datalyscenter.org/a647b9718d_sites/datalyscenter.org/ files/NCAA_Football_Injury_WEB_1_.pdf

Datalys Center. (2014). Men's soccer injuries: Data from the 2004/05-2008/09 seasons. Retrieved from http://www.datalyscenter.org/a647b9718d_sites/datalyscenter.org/ files/NCAA_W_Soccer_Injuries_HiRes.pdf

Datalys Center. (2014). Women's volleyball injuries: Data from the 2004/05-2008/09 season. Retrieved from http://www.datalyscenter.org/a647b9718d_sites/ datalyscenter.org/files/NCAA_W_Volleyball_Injuries_HiRes.pdf

Day, C., Stolz, U., Mehan, T. J., Smith, G. A., \& McKenzie, L. B. (2008). Diving-related injuries in children $<20$ years old treated in emergency departments in the United States: 1990-2006. Pediatrics, 122(2), e388-e394.

Day, M. C., Thatcher, J., Greenlees, I., \& Woods, B. (2006). The causes of and psychological responses to lost move syndrome in national level trampolinists. Journal of Applied Sport Psychology, 18(2), 151-166. doi:10.1080/10413200600653782

Duda, J. L. (1995). Level of competitive trait anxiety and sources of stress among members of the 1993 TOP team. Technique, 16, 10-13.

Duda, J. L., \& Gano-Overway, L. (1996). Anxiety in elite young gymnasts: Part II. Sources of stress. Technique, 16, 4-5.

Ekman, P. (1992). An argument for basic emotions. Cognition \& Emotion, 6(3-4), 169200. doi:10.1080/02699939208411068

Ericsson, K. A., Krampe, R. T., \& Tesch-Römer, C. (1993). The role of deliberate 
practice in the acquisition of expert performance. Psychological Review, 100(3), 363-406.

Evans, L., Hardy, L., \& Fleming, S. (2000). Intervention strategies with injured athletes: An action research study. The Sport Psychologist, 14, 188-206. doi:10.1123/tsp.14.2.188

Eysenck, M. W., Derakshan, N., Santos, R., \& Calvo, M. G. (2007). Anxiety and cognitive performance: attentional control theory. Emotion, 7(2), 336-353. doi:10.1037/1528-3542.7.2.336

Feltz, D. L., Landers, D. M., \& Raeder, U. (1979). Enhancing self-efficacy in highavoidance motor tasks: A comparison of modeling techniques. Journal of Sport Psychology, 1(2), 112-122. doi:10.1123/jsp.1.2.112

Foss, J. M., Minaker, E., Doerr, C., \& Aoyagi, M. W. (2017). Developing a theoretical orientation to performance excellence. In M. W. Aoyagi, A. Poczwardowski \& J. Shapiro (Eds.), The peer guide to applied sport psychology for consultants in training (pp 1-17). New York, NY: Routledge.

Gardner, F. L., \& Moore, Z. E. (2004). A mindfulness-acceptance-commitment-based approach to athletic performance enhancement: Theoretical considerations. Behavior Therapy, 35(4), 707-723. doi:10.1016/S0005-7894(04)80016-9

Gardner, F. L., \& Moore, Z. E. (2007). The psychology of enhancing human performance: The mindfulness-acceptance-commitment (MAC) approach. New York, NY: Springer Publishing Company. 
Grange, P., \& Kerr, J. H. (2010). Physical aggression in Australian football: A qualitative study of elite athletes. Psychology of Sport and Exercise, 11(1), 36-43. doi:10.1016/j.psychsport.2009.04.006

Grouios, G. (1992). The effect of mental practice on diving performance. International Journal of Sport Psychology, 23, 60-69.

Hanin, Y. L. (2000). Individual Zones of Optimal Functioning (IZOF) Model: Emotionperformance relationships in sport. In Y. Hanin (Ed.), Emotions in sport (pp.6590). Champaign, IL: Human Kinetics.

Hayes, S. C., Strosahl, K. D., \& Wilson, K. G. (2012). Acceptance and commitment therapy: The process and practice of mindful change. New York, NY: Guilford Press.

Highlen, P. S., \& Bennett, B. B. (1983). Elite divers and wrestlers: A comparison between open- and closed-skill athletes. Journal of Sport Psychology, 5, 390-409. doi:10.1123/jsp.5.4.390

Hill, C. E. (2012). Consensual qualitative research: A practical resource for investigating social science phenomena. Washington, DC: American Psychological Association.

Hill, C. E., Know, S., Thompson, B. J., Williams, E. N., Hess, S. A., \& Ladany, N. (2005). Consensual qualitative research: An update. Journal of Counseling Psychology, 52(2), 196-205. doi:10.1037/0022-0167.52.2.196

Hill, C. E., Thompson, B. J., \& Williams, E. N. (1997). A guide to conducting consensual qualitative research. The Counseling Psychologist, 25, 517-572. doi:10.117/0011000097254001 
Hinton-Bayre, A. D., \& Hanrahan, S. J. (1999). Sensation seeking, physical self-concept and attentional style in elite springboard and platform divers. Journal of Human Movement Studies, 37(4), 183-203.

Huber, J. (2016). Springboard and platform diving. Champaign, IL: Human Kinetics.

Kerr, Z. Y., Baugh, C. M., Hibberd, E. E., Snook, E. M., Hayden, R., \& Dompier, T. P. (2015). Epidemiology of National Collegiate Athletic Association men's and women's swimming and diving injuries from 2009/2010 to 2013/2014. British Journal of Sports Medicine, 49(7), 465-471. doi:10.1136/bjsports-2014-094423

Klint, K. A., \& Weiss, M. R. (1986). Dropping in and dropping out: Participation motives of current and former youth gymnasts. Canadian Journal of Applied Sport Sciences, 11, 106-114.

Kori, S. H., Miller, R. P., \& Todd, D. D. (1990). Kinesiophobia: A new view of chronic pain behavior. Pain Management, 3, 35-43.

Lazarus, R. S. (2000). How emotions influence performance in competitive sports. The Sport Psychologist, 14, 229-252. doi:10.1123/tsp.14.3.229

Leddy, M. H., Lambert, M. J., \& Ogles, B. M. (1994). Psychological consequences of athletic injury among high-level competitors. Research Quarterly for Exercise and Sport, 65(4), 347-354. doi:10.1080/02701367.1994.10607639

Llewellyn, D. J., \& Sanchez, X. (2008). Individual differences and risk taking in rock climbing. Psychology of Sport and Exercise, 9, 413-426. doi:10.1016/j.psychsport.2007.07.003 
McGregor, H., \& Abrahamson, E. (2000). The psychological effects of pre-competitive stress on elite divers - a review. South African Journal of Psychology, 30(3), 3844. doi:10.1177/008124630003000306

NCAA (2015). Swimming and diving: 2015-16 and 2016-17 rules and interpretations. Retrieved from http://www.ncaapublications.com/p-4403-ncaa-mens-andwomens-swimming-and-diving-rules-2015-2016-and-2016-2017.aspx

Ohman, A. (2000). Fear and anxiety: Evolutionary, cognitive, and clinical perspectives. In M. Lewis \& J. M. Haviland-Jones (Eds.). Handbook of Emotions (pp. 573593). New York, NY: The Guilford Press.

Olsson, A., \& Phelps, E. A. (2007). Social learning of fear. Nature Neuroscience, 10(9), 1094-1102. doi:10.1038/nn1968

Pain, M.T.G., \& Pain, M.A. (2005). Essay: Risk taking in sport. Lancet, 366(Suppl. 1), S33-S34. doi:10.1016/S0140-6736(05)67838-5

Pattinson, E.M. and Cotterill, S.T. (2017) Barriers and facilitators to overcoming mental block in springboard and highboard diving. Journal of Qualitative Research in Sports Studies, 11(1), 1-14.

Patton, M.Q. (2002). Qualitative evaluation and research methods (3rd ed.). Newbury Park, CA: Sage.

Podlog, L., Dimmock, J., \& Miller, J. (2011). A review of return to sport concerns following injury rehabilitation: Practitioner strategies for enhancing recovery outcomes. Physical Therapy in Sport, 12, 36-42. doi:10.1016/j.ptsp.2010.07.005

Post, P. G., Simpson, D., Young, G., \& Parker, J. F. (2014). A phenomenological 
investigation of divers' lived experience of imagery. Journal of Imagery Research in Sport and Physical Activity, 9(1), 67-82. doi:10.1515/jirspa-2014-0005

Sagar, S. S., \& Lavallee, D. (2010). The developmental origins of fear of failure in adolescent athletes: Examining parental practices. Psychology of Sport and Exercise, 11(3), 177-187. doi:10.1016/j.psychsport.2010.01.004

Sheldon, J. P., \& Aimor, C. M. (2001). The role aggression plays in successful and unsuccessful ice hockey behavior. Research Quarterly for Exercise and Sport, 72, 304-309. doi:10.1080/02701367.2001.10608965

Silva III, J. M. (1994). Sport performance phobias. International Journal of Sport Psychology, 25(1), 100-118.

Slanger, E., \& Rudestam, K. E. (1997). Motivation and disinhibition in high risk sports: Sensation seeking and self-efficacy. Journal of Research in Personality, 31, 355374. doi:10.1006/jrpe.1997.2193

Schwanhausser, L. (2009). Application of the mindfulness-acceptance-commitment (MAC) protocol with an adolescent springboard diver. Journal of Clinical Sport Psychology, 3(4), 377-395. doi:10.1123/jcsp.3.4.377

Sheard, M., \& Golby, J. (2006). Effect of a psychological skills training program on swimming performance and positive psychological development. International Journal of Sport and Exercise Psychology, 4(2), 149-169. doi:10.1080/1612197X.2006.9671790

Smith, R. E. (2010). A positive approach to coaching effectiveness and performance enhancement. In Williams, J. M. (Ed.), Applied sport psychology: personal growth to peak performance, $6^{\text {th }}$ ed. (pp. 42-58). New York, NY: McGraw-Hill. 
Smith, R. E., Smoll, F. L., Cumming, S. P., \& Grossbard, J. R. (2006). Measurement of multidimensional sport performance anxiety in children and adults: The sport anxiety scale-2. Journal of Sport and Exercise Psychology, 28(4), 479-501. doi:10.1123/jsep.28.4.479

Smith, R. E., Smoll, F. L., \& Schutz, R. W. (1990). Measurement and correlates of sportspecific cognitive and somatic trait anxiety: The sport anxiety scale. Anxiety Research, 2(4), 263-280. doi:10.1080/08917779008248733

Thelwell, R. C., Greenlees, I. A., \& Weston, N. J. (2006). Using psychological skills training to develop soccer performance. Journal of Applied Sport Psychology, 18(3), 254-270. doi:10.1080/10413200600830323

Tod, D., Andersen, M. B., \& Marchant, D. B. (2009). A longitudinal examination of neophyte applied sport psychologists' development. Journal of Applied Sport Psychology, 21(S1), S1-S16. doi:10.1080/10413200802593604

Tracey, J. (2003). The emotional response to the injury and rehabilitation process. Journal of Applied Sport Psychology, 15(4), 279-293. doi:10.1080/714044197

Tripp, D. A., Stanish, W., Ebel-Lam, A., Brewer, B. W., \& Birchard, J. (2007). Fear of reinjury, negative affect, and catastrophizing predicting return to sport in recreational athletes with anterior cruciate ligament injuries at 1 year postsurgery. Rehabilitation Psychology, 52(1), 74-81. doi:10.1037/0090-5550.52.1.74

Tucker, L. W., \& Parks, J. B. (2001). Effects of gender and sport type on intercollegiate athletes' perceptions of legitimacy of aggressive behavior in sport. Sociology of Sport Journal, 18, 403-413. doi:10.1123/ssj.18.4.403

Turner, C., McClure, R., \& Pirozzo, S. (2004). Injury and risk- taking behavior-A 
systematic review. Accident Analysis and Prevention, 36, 93-101.

doi:10.1016/S0001-4575(02)00131-8

Vealey, R. S. (1988). Future directions in psychological skills training. The Sport Psychologist, 2(4), 318-336. doi:10.1123/tsp.2.4.318

Wadey, R., Podlog, L., Hall, M., Hamson-Utley, J., Hicks-Little, C., \& Hammer, C. (2014). Reinjury anxiety, coping, and return-to-sport outcomes: A multiple mediation analysis. Rehabilitation Psychology, 59(3), 256. doi:10.1037/a0037032

Weinberg, R. S., \& Gould, D. (2007). Foundations of sport and exercise psychology (4 ${ }^{\text {th }}$ ed). Champaign, IL: Human Kinetics.

Weinstein, M. D., Smith, M. D., \& Wiesenthal, D. L. (1995). Masculinity and hockey violence. Sex Roles, 33, 831-847.

Woodman, T., Barlow, M., Bandura, C., Hill, M., Kupciw, D., \& Gregor, A. M. (2013). Not all risks are equal: The risk taking inventory for high-risk sports. Journal of Sport \& Exercise Psychology, 35, 479-492. doi:10.1123/jsep.35.5.479

Zillmer, E. A. (2003). The neuropsychology of repeated 1-and 3-meter springboard diving among college athletes. Applied Neuropsychology, 10(1), 23-30. doi:10.1207/S5324826AN1001_4 


\section{APPENDIX}

Demographic Questionnaire

Age:

Years of diving experience:

Race/Ethnicity:

High school and Collegiate Diving accomplishments (list):

\begin{tabular}{|c|c|}
\hline 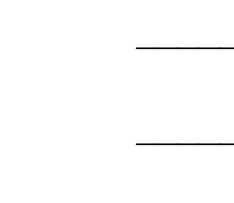 & $\begin{array}{l}\text { African-American/Black } \\
\text { American Indian/Alaskan } \\
\text { Native }\end{array}$ \\
\hline & Asian American/Asian \\
\hline & Hispanic/Latino/a \\
\hline & Hawaiian/Pacific Islander \\
\hline & Multi-Racial \\
\hline & White \\
\hline & Self-identify (specify): \\
\hline Religious or & Spiritual Preference: \\
\hline & Agnostic \\
\hline & Atheist \\
\hline & Buddhist \\
\hline & Catholic \\
\hline & Christian \\
\hline & Hindu \\
\hline & Jewish \\
\hline & Muslim \\
\hline & No preference \\
\hline & Other (please specify): \\
\hline
\end{tabular}

Gender Identity:

W_ Moman
Man
Transgender
Self-identify (specify):

Religious or Spiritual Preference:

Sport and performance psychology experience (briefly explain):

Sexual Orientation:

Heterosexual/Straight
Lesbian
Gay
Bisexual
Questioning
Self-identify (specify):

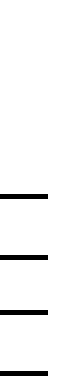




\section{Semi-Structured Interview Guide: Time Point 1}

The purpose of this study is to gain a better understanding of the experience of fear in the sport of diving. I am going to ask you a number of questions about your thoughts on fear in diving and experiences you have had related to the sport of diving. When I talk about fear, what I am referring to is concern related to a known or specific threat to us in some way. For example, you would experience fear if someone attempted to rob you while walking down a dark alley. You may also experience fear when speaking in front of a large audience or prior to taking a test. There is a clear and definite object to be feared in each situation. Do you have any questions about that distinction? (Answer questions). I know it may be difficult for some to speak about these emotions, so please know that you can choose not to answer any question if you do not wish to do so.

1). Please describe how you began the sport of diving and your history with it.

- What attracted you to the sport of diving?

- Tell me about your coaches that you've had throughout your career.

- Tell me about your parents influence when beginning and continuing in the sport of diving.

2). Please explain your thoughts on how, if at all, the emotion of fear is present within the sport of diving.

3). How do your coaches talk about the emotion of fear in diving, if at all?

- Teammates/friends?

- Parents?

4). Have you personally experienced fear in diving?

- If yes: What experiences, if any, have you observed in others that have influenced your emotions of fear?

○ Have you seen others hit the board/platform or pool deck?

- What was your reaction to these events?

- If no: Tell me more about what emotions you experience in the course of diving?

5). (If yes to 4): Please describe your own experiences in the sport of diving, if any, that have led to feelings of fear or anxiety.

- If no to 4: use participant's language about what emotions they have experienced rather than fear or anxiety.

6). (If yes to 4): In what ways, if any, has fear helped you during practices in diving?

- In competition?

- If no to 4: use participant's language about what emotions they have experienced rather than fear or anxiety.

7). (If yes to 4): In what ways, if any, has fear hindered your practices in diving?

- In competition? 
If none: tell me more about how you prevent fear from negatively impacting your performance?

- If no to 4: use participant's language about what emotions they have experienced rather than fear or anxiety.

8). (If yes to 4): How do you cope with feelings of fear, if present, in your sport at this point in time?

- If no to 4: use participant's language about what emotions they have experienced rather than fear or anxiety.

9). How do you see others cope with feelings of fear in your sport at this point in time?

- If no to 4: use participant's language about what emotions they have experienced rather than fear or anxiety.

10). Do you have any other thoughts you could add that would help me better understand anything we have discussed so far? 


\section{Semi-Structured Interview Guide: Time Point 2}

The purpose of this study is to gain a better understanding of the experience of fear in the sport of diving. I am going to ask you a number of questions about your thoughts on fear in diving and experiences you have had related to the sport of diving. When I talk about fear, what I am referring to is concern related to a known or specific threat to us in some way. For example, you would experience fear if someone attempted to rob you while walking down a dark alley. You may also experience fear when speaking in front of a large audience or prior to taking a test. There is a clear and definite object to be feared in each situation. Do you have any questions about that distinction? (Answer questions). I know it may be difficult for some to speak about these emotions, so please know that you can choose not to answer any question if you do not wish to do so.

1. Have you experienced fear in the sport of diving since the last interview time point?

a. If yes: Tell me more about what you have experienced

b. If no: What emotions have you experienced during diving?

2. If yes to 1: What experiences, if any, have you observed in others since the last interview that have influenced your emotions of fear?

a. If no to 1: use participant's language about what emotions they have experienced rather than fear or anxiety

3. If yes to 1: What messages have you received from others that have influenced your experience of fear since the last time point?

a. If no to 1: use participant's language about what emotions they have experienced rather than fear or anxiety

4. If yes to 1: In what ways, if any, has fear helped you during practices in diving?

In competition?

- If no to 1: use participant's language about what emotions they have experienced rather than fear or anxiety.

5. (If yes to 4): In what ways, if any, has fear hindered your practices in diving?

In competition?

- If none: tell me more about how you prevent fear from negatively impacting your performance?

- If no to 1: use participant's language about what emotions they have experienced rather than fear or anxiety.

6. (If yes to 1): How do you cope with feelings of fear, if present, in your sport at this point in time?

- If no to 1: use participant's language about what emotions they have experienced rather than fear or anxiety.

7. How do you see others cope with feelings of fear in your sport at this point in time?

- If no to 1: use participant's language about what emotions they have experienced rather than fear or anxiety. 
8. Overall, how does your experience now compare to your experience earlier in the season?

a. If no to 1: use participant's language about what emotions they have experienced rather than fear of anxiety.

9. Do you have any other thoughts you could add that would help me better understand anything we have discussed so far? 


\section{VITA}

Joanna Foss is doctoral student in Counseling Psychology at the University of Missouri, where she has engaged in an emphasis area within sport psychology throughout her doctoral career. Joanna was a collegiate volleyball player at Marist College in Poughkeepsie, NY. Shortly after her junior season at Marist, she injured her shoulder which started a 14-month injury recovery process. Through her experience, she became motivated to understand how athletes cope with difficult life events and inspired to help others through the process of whatever challenges they were experiencing. Luckily, Marist College had an internship relationship with the Center for Enhanced Performance at the United States Military Academy. Through this experience, Joanna not only found tools to help with her own return to sport but also discovered her passion for the field of sport psychology. Joanna received her M.A. in Sport and Performance Psychology from the University of Denver in 2014. Knowing she ultimately wanted to pursue licensure as a psychologist, Joanna then pursued her PhD at the University of Missouri. During her career at Mizzou, Joanna served as a mental performance coach in the athletic department for four years and engaged in numerous clinical placements including the Westminster College Counseling Center, University of Missouri Counseling Center, and Thompson Center for Autism and Neurodevelopmental Disorders. She then matched for internship at the University of North Carolina-Chapel Hill, where she is engaging in a sport psychology emphasis area within UNC Athletics. Upon graduation, she hopes to continue working in collegiate sport. 